Florida International University FIU Digital Commons

FIU Electronic Theses and Dissertations

University Graduate School

6-6-2018

\title{
Three Essays in Health, Welfare, and International Economics
}

Amin Shoja

ashoj003@fiu.edu

DOI: $10.25148 /$ etd.FIDC006879

Follow this and additional works at: https://digitalcommons.fiu.edu/etd

Part of the Economics Commons

\section{Recommended Citation}

Shoja, Amin, "Three Essays in Health, Welfare, and International Economics" (2018). FIU Electronic Theses and Dissertations. 3757. https://digitalcommons.fiu.edu/etd/3757

This work is brought to you for free and open access by the University Graduate School at FIU Digital Commons. It has been accepted for inclusion in FIU Electronic Theses and Dissertations by an authorized administrator of FIU Digital Commons. For more information, please contact dcc@fiu.edu. 


\title{
FLORIDA INTERNATIONAL UNIVERSITY
}

Miami, Florida

THREE ESSAYS IN HEALTH, WELFARE, AND INTERNATIONAL ECONOMICS

\author{
A dissertation submitted in partial fulfillment of \\ the requirements for the degree of \\ DOCTOR OF PHILOSOPHY \\ in \\ ECONOMICS \\ by \\ Amin Shoja
}

2018 
To: Dean John F. Stack, Jr.

Green School of International and Public Affairs

This dissertation, written by Amin Shoja, and entitled Three Essays in Health, Welfare, and International Economics, having been approved in respect to style and intellectual content, is referred to you for judgment.

We have read this dissertation and recommend that it be approved.

$\begin{array}{r}\text { Sheng Guo } \\ \hline \text { Ronald Mesia } \\ \hline \text { Tobias Pfutze } \\ \hline \text { Hakan Yilmazkuday, Major Professor }\end{array}$

Date of Defense: June 6, 2018

The dissertation of Amin Shoja is approved.

Dean John F. Stack, Jr. Green School of International and Public Affairs

Andrés G. Gil Vice President for Research and Economic Development and Dean of the University Graduate School

Florida International University, 2018 
(C) Copyright 2018 by Amin Shoja All rights reserved. 


\section{DEDICATION}

For my wonderful parents, Shirin and Mohammad, and my lovely sister, Nazanin, who always instilled in me a feeling that learning was the most amazing thing that could happen to you, and it never ends. If I succeed, it is because of your sacrifices, understanding, and unwavering loving support; I found all the strength to carry on with my graduate studies, all the way to the Ph.D. degree. 


\section{ACKNOWLEDGMENTS}

First and foremost, I would like to express my deepest gratitude to my major professor, Dr. Hakan Yilmazkuday, for his excellent guidance, patience, and invaluable insights throughout all the stages of researching and writing this dissertation. His passion and dedication are incomparable and always inspire me.

Next, I wish to express my great appreciation to Yasemin Shirazi and Ehsan Asghari Ghara, for all the friendship, support, care, and their guidance over the years. Thank you for always having my back. I cannot imagine a better group of people like them to accompany me through this journey.

Furthermore, I am grateful to my committee members, Dr. Sheng Guo, Dr. Ronald Mesia, and Dr. Tobias Pfutze, for sharing their knowledge, their valuable discussions, and for improving the quality of this dissertation. I am also grateful to my coauthors for their contribution and support; Ehsan Asghari Ghara, Dr. Syed A. Uddin, and Renzo M. Alvarez.

I would like to acknowledge the support provided from the Department of Economics at Florida International University. I am also thankful for all the years of help from Mayte Rodriguez, Mariela Delgado, Lorette Garcia, and Dr. Mihaela Pintea. 


\section{ABSTRACT OF THE DISSERTATION \\ THREE ESSAYS IN HEALTH, WELFARE, AND INTERNATIONAL ECONOMICS by}

Amin Shoja

Florida International University, 2018

Miami, Florida

Professor Hakan Yilmazkuday, Major Professor

Both economists and policy makers are interested in understanding the welfare effect of economic policies, especially in small open economies such as Turkey and Iran. This knowledge is crucial for priority setting in any informed policy discussion. This dissertation aims to study the impoverishing effect of high levels of out-of-pocket (OOP) payments in the health sector, referred to as catastrophic health expenditure (CHE), and investigates the impact of exchange rate passthrough (ERPT) on both the microeconomic and macroeconomic indicators of a country. For millions of people worldwide, health payments present a huge financial risk. A high rate of OOP health care payments can lead to CHE, which can force households to cut down their consumption, minimize access to their needs, or face poverty. This makes the design of financial risk protection necessary for governments in order to secure people against the financial hardship at the time of incurring CHE. This thesis comprises three essays. The first investigates financial risk protection indicators related to OOP health care payments through CHE mean positive overshoot and incidence and depth of impoverishment. This research observes that in the absence of universal health care insurance in Iran, together with a high share of OOP spending for health care (more than 52\%), the Iranian households facing CHE will eventually face poverty. In the second essay, using a difference-in-differences propensity score matching approach, I seek to analyze the degree to which Iranian universal health care insurance protects households from high rates of OOP health 
expenditure. In this study, I evaluate the effect of the universal health insurance program on Iranian CHE. The results show that the program was successful in decreasing the rate of OOP health expenditures and CHE in Iran during the sample period. The third essay estimates the ERPT using product-level daily data on wholesale prices of imported agricultural products, where the identification is possible by using daily data on the domestic inflation rate. The results of standard empirical analyses are in line with existing studies that employ lower frequencies of data by showing evidence for incomplete daily ERPT of about 5 percent. 


\section{TABLE OF CONTENTS}

CHAPTER

PAGE

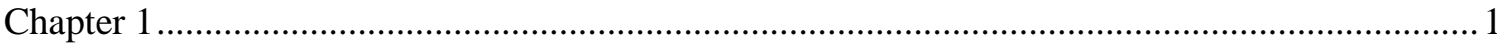

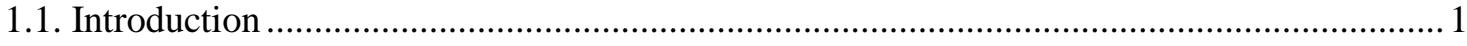

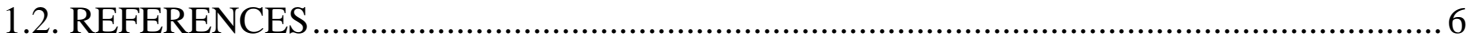

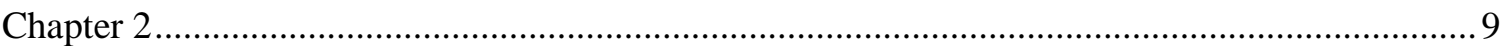

CATASTROPHIC AND IMPOVERISHING EFFECTS OF OUT-OF-POCKET PAYMENTS FOR HEALTH CARE IN IRAN: EVIDENCE FROM IRAN HOUSEHOLD INCOME

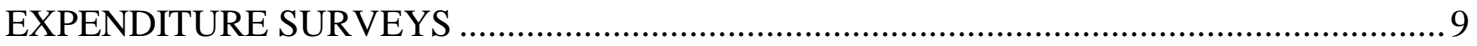

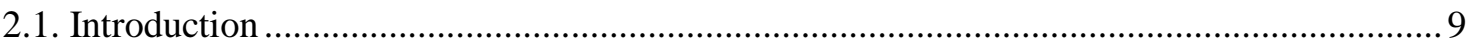

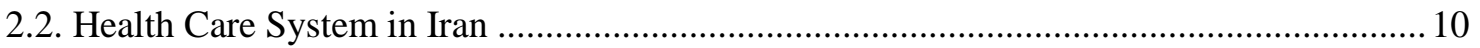

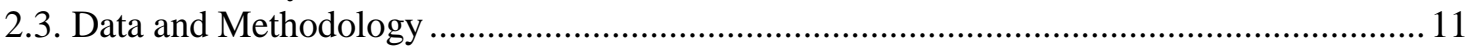

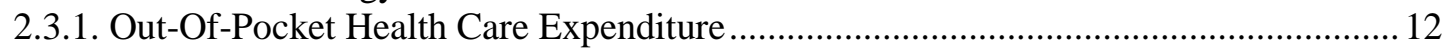

2.3.2. Measuring incidence and intensity of catastrophic health care expenditure.................. 14

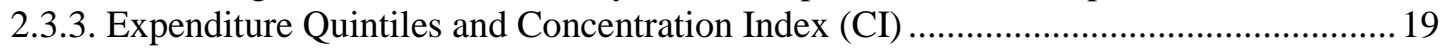

2.3.4. Impoverishment Impact of OOP Health Payments..................................................... 20

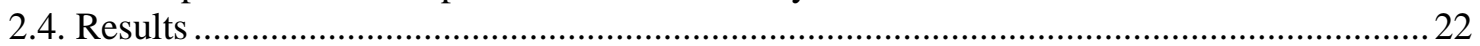

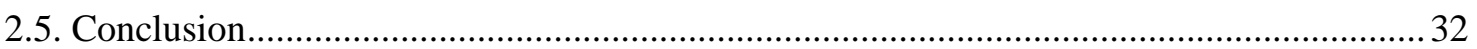

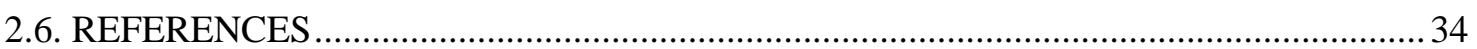

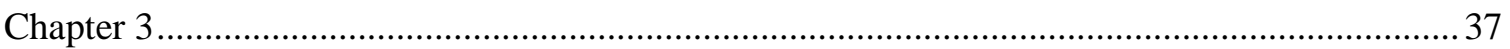

CATASTROPHIC HEALTH CARE EXPENDITURE AND THE HEALTH REFORM IN

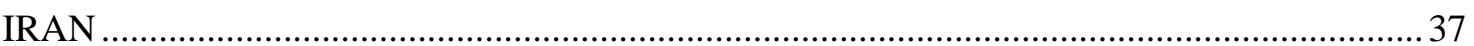

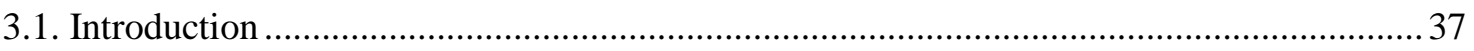

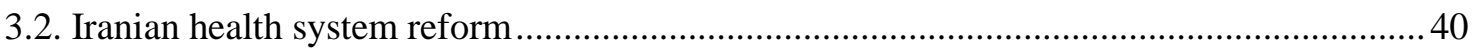

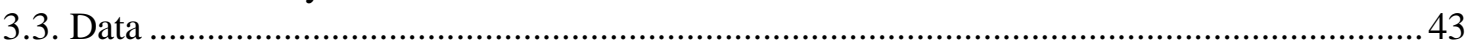

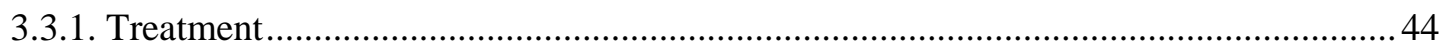

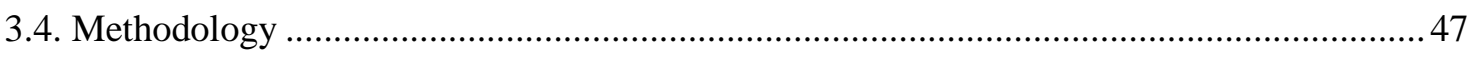

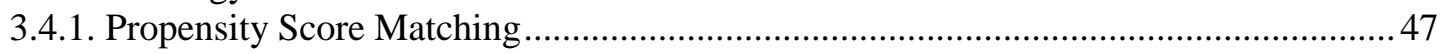

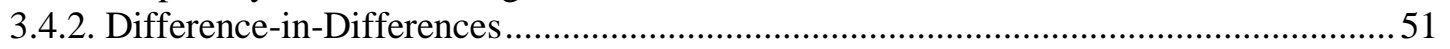

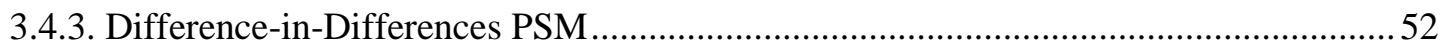

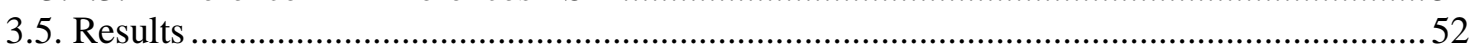

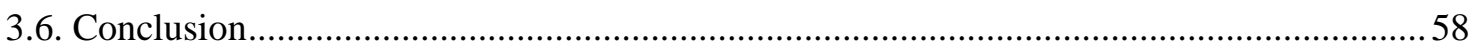

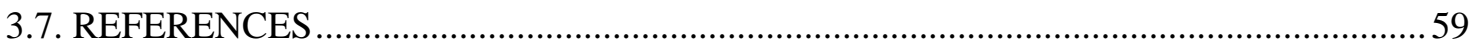

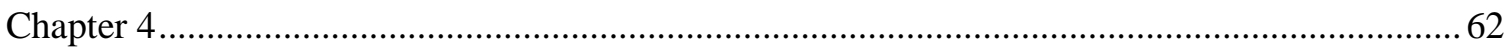

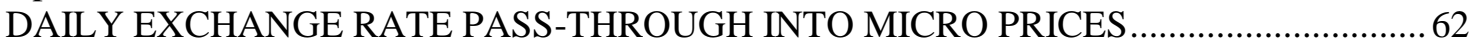

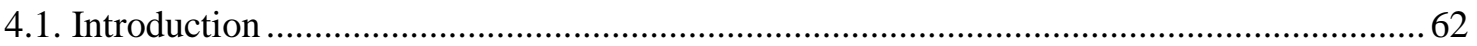

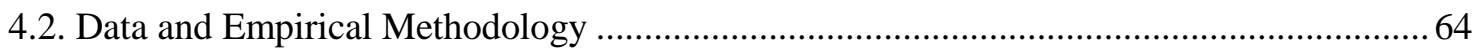

4.2.1. Nominal Exchange Rate between the Turkish Lira and the U.S. dollar .......................65

4.2.2. Local Macroeconomic Developments; Daily Domestic Inflation Rate ...........................67

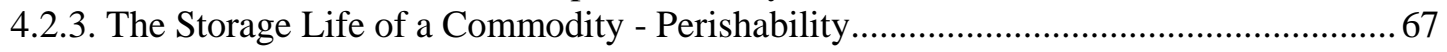

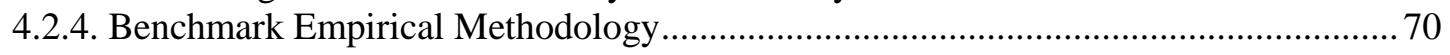

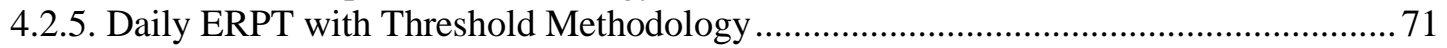

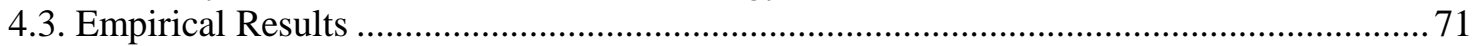

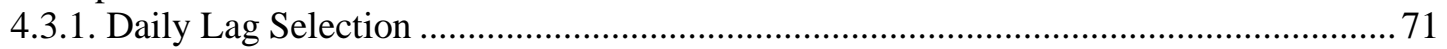

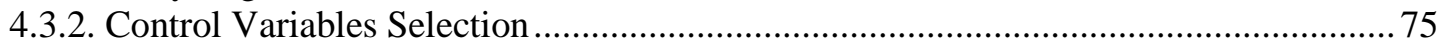

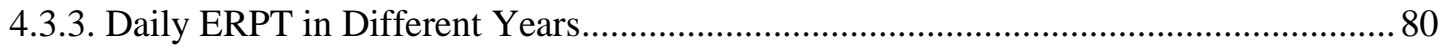

4.3.4. Daily ERPT by Positive/ Negative Exchange rate Changes ......................................... 83 


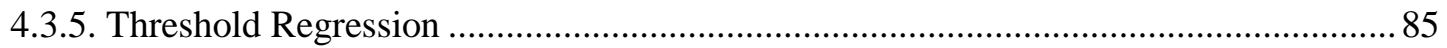

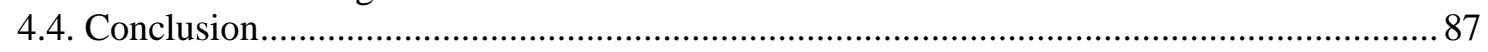

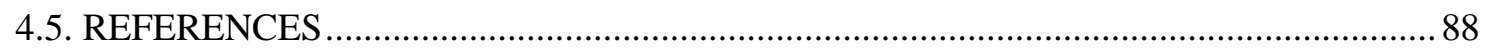

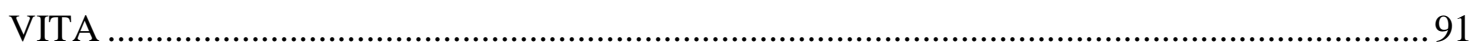


Table 2-1 The Average Out-of-Pocket Payments in IRR (Standard Error) Per Household across Expenditure Quintiles and Rural Urban Areas, 2013.

Table 2-2 The Incidence of Household CHE across Expenditure Quintiles of Urban and Rural Areas, CHE Headcount.. .25

Table 2-3 The Intensity of Household CHE across Expenditure Quintiles of Urban and Rural

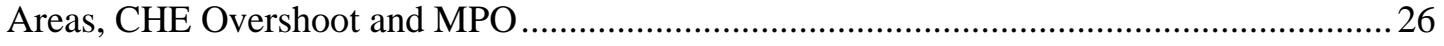

Table 2-4 The Mean Positive Overshoot in urban and Rural Areas ........................................... 27

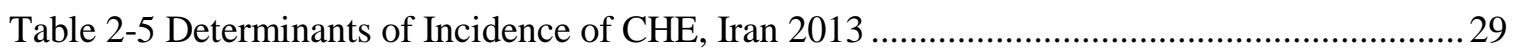

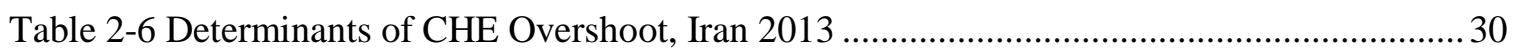

Table 2-7 Impact of Out-Of-Pocket Payments on Incidence and Intensity of Poverty.................. 31

Table 3-1 Rate of out-of-pocket health expenditure - Country Ranking (2013)........................... 40

Table 3-2 Annual percentage change of average out-of-pocket health care expenditure ............. 42

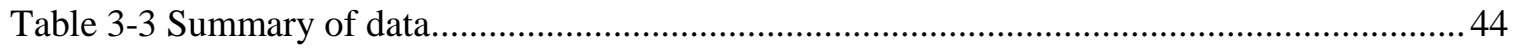

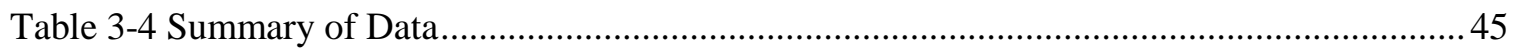

Table 3-5 Proportion of households observing CHE on health at different threshold level across

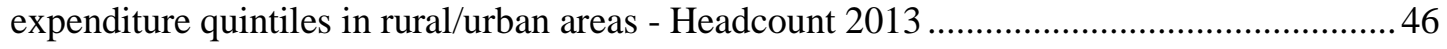

Table 3-6 Average Treatment Effect on different thresholds of CHE (PSM) ..............................50

Table 3-7 DID estimate of out-of-pocket health expenditure ratio............................................55

Table 3-8 DID estimate of ATE on CHE for different quintiles (15\% Threshold) ......................56

Table 3-9 DID estimate of ATE on CHE for different thresholds .............................................57

Table 3-10 DID PSM estimate of ATE on CHE for different thresholds .....................................58

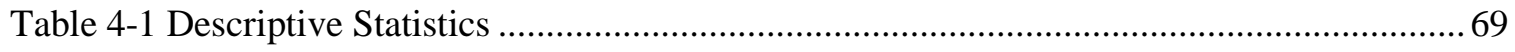

Table 4-2 Daily ERPT with Alternative Lags, All Price Changes.............................................. 73

Table 4-3 Daily ERPT with Alternative Lags, Non-zero Price Changes...................................... 74

Table 4-4 Daily ERPT with Alternative Lags and Inflation Control Variable, All Price Changes 76

Table 4-5 Daily ERPT with Alternative Lags and Inflation Control Variable, Non-zero Price

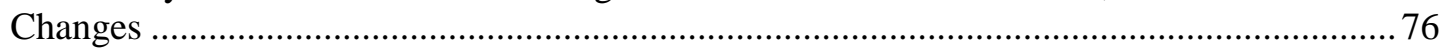


Table 4-6 Daily ERPT with Alternative Lags and Control (Perishability, Seasonality, and Goods Fixed Effects), All Price Changes

Table 4-7 Daily ERPT with Alternative Lags and Control (Perishability, Seasonality, and Goods Fixed Effects), Non-zero Price Changes

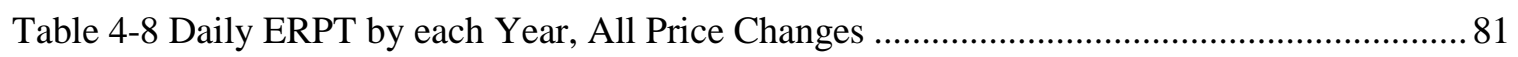

Table 4-9 Daily ERPT by each Year, Non-zero Price Changes ................................................ 82

Table 4-10 ERPT by Positive/ Negative Exchange Rate Changes, All Price Changes ................. 84

Table 4-11 ERPT by Positive/ Negative Exchange Rate Changes, Non-zero Price Changes ....... 84

Table 4-12 Daily ERPT with Threshold and Non-zero Price Changes ........................................ 86 


\section{LIST OF FIGURES}

FIGURE

PAGE

Figure 2-1 Out-of-Pocket Health Expenditure - Iran

Figure 2-2 Out-of-Pocket Payment as Percentage of Total Household Expenditure, Average by Household Expenditure Quintile, 2013

Figure 2-3 Health Payment Budget Share against Cumulative Proportion of Population Ranked by Decreasing Health OOP Share......

Figure 2-4 Poverty Impact on Pen's Parade of Total Expenditure before and after Subtracting

Health Per-Capita Expenditure using the National Poverty Line 32

Figure 3-1 Out-of-Pocket Health Expenditure - 2013 39

Figure 3-2 Health Care Expenditure Composition ................................................................. 42

Figure 3-3 Moving Average of Out-of-pocket ratio for treatment and comparison groups .......... 47

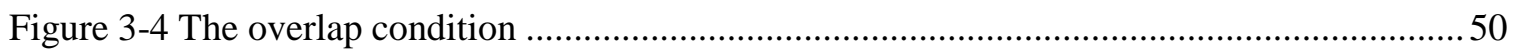

Figure 4-1 (a-b). Price of domestic bananas and price of imported bananas from January 2005

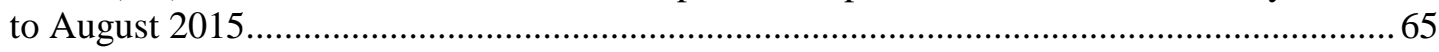

Figure 4-2 Daily nominal exchange rate between Turkish Lira and U.S. dollar .66

Figure 4-3 (a-b). Average daily log changes in price and NER from January 2005 to August 2015 


\section{ABBREVIATIONS AND ACRONYMS}

OOP

CHE

ERPT

HIES

NER

CI

SCI

MPO

WHO
Out-of-pocket

Catastrophic health expenditure

Exchange rate pass-through

Household Income Expenditure Survey

Nominal exchange rate

Concentration index

Statistical Center of Iran

Mean positive overshoot

World Health Organization 


\section{Chapter 1}

\subsection{Introduction}

Historically, understanding welfare impacts of economic policy setting have received considerable attention from both policy makers and economists, especially in small, open economies such as Iran and Turkey. This dissertation attempts to study the importance of catastrophic and impoverishing effects of out-of-pocket (OOP) payments for health care, as well as the significant impacts of exchange rate pass-through (ERPT) on both the microeconomic and macroeconomic indicators of a country; since, such knowledge is crucial for priority setting in any informed policy discussion. It is important to discuss the financial risk protection that helps secure people against the financial hardships associated with paying for health care services. For millions of people worldwide, health payments present a huge financial risk. A high rate of OOP health care payments can lead to catastrophic health care expenditure (CHE), forcing households to cut down their consumption, minimize access to their needs, or face poverty. These facts make financial protection against high levels of OOP health expenditure and its consequences an important goal for any health care system adopted by governments.

This thesis comprises three essays. Chapter 2 investigates the catastrophic and impoverishing effects of OOP payments for health care: evidence from Iran Household Income Expenditure Surveys (HIES). Chapter 3 evaluates the health care reform (universal health coverage) in Iran and its effects on catastrophic health care expenditure. Finally, Chapter 4 measures the daily exchange rate pass-through into micro prices of agricultural products imported by Turkey. Through these chapters, this study seeks to provide new insight into the literature on economic policy making and its welfare impacts.

In Chapter 2, I focus on the impact of high levels of OOP health care expenditure in Iran. Studies such as Kochar (1995) and Gertler and Gruber (2002) find that the poor segment of the 
population in low-income countries mainly finance their health care expenses with OOP payments, which can severely affect their consumption of basic needs and lead to extreme financial hardship. Such high levels of OOP health care expenditure can push households below or further below the poverty line and disrupt a household's ability to maintain living standards to the extent that the household members must forgo consumption of necessary goods and services. This study investigates financial risk protection indicators related to OOP health care expenditure through incidence and intensity of CHE as well as CHE mean positive overshoot and incidence and depth of poverty.

The source of the data used in the study is the Iran Household Income Expenditure Survey (HIES) for 2013. I measure headcount catastrophic payments using different thresholds and the decomposition of indicators by expenditure quintiles across urban and rural areas to better understand their effects.

Moreover, this study investigates the impoverishment effects of OOP health care expenditure through setting a poverty line that is not sensitive to highly variable health care needs. Therefore, this study measures both poverty headcount using total household expenditure and such expenditure without OOP payments for health care separately. Comparing differences between these two average levels of poverty headcounts captures the impoverishment impact of OOP payments. I also use the poverty gap to measure intensity of poverty by calculating the amount by which poor households fall short of minimum expenditure as the poverty line.

Generally, most societies give higher priority to the status of the poorest quintile rather than that of the richest when incurring the catastrophic OOP payments and, hence, care about how different the level of such payments are between these two groups. To estimate this, I have calculated the concentration index (CI). This study observes that, in both urban and rural areas, the households belong to the highest expenditure quintile, the richest, had a higher budget share on OOP payments for health care. Although, this study shows that in the absence of comprehensive 
health plans, such as universal health insurance in Iran, along with a high rate of OOP expenditures on health care, the Iranian households facing CHE will eventually face poverty. That motivates my investigation into the health care reform (universal health care coverage) carried out by the Iranian government in 2014 and evaluate its effects on CHE in this thesis.

Chapter 3 studies CHE and health care reform in Iran. Generally, the literature notes that a good health care system must protect households against the unexpectedly high levels of OOP health care expenditure ( $\mathrm{Su}$, Kouyaté, \& Flessa, 2006; Xu et al., 2003). OOP health care expenditure is that part of a household's health care expenditure that it pays directly out of its own pocket. It is important to understand the possible risk factors that households with high OOP health care expenditures face. This study seeks to provide new insight into the literature on CHE and its welfare impacts.

The literature presents several definitions of CHE. Russell (2004, p. 147), the term catastrophic implies that such expenditure levels are "likely to force household members to cut their consumption of other minimum needs, trigger productive asset sales or high levels of debt, and lead to impoverishment." Yet in general, the definition of CHE is "an excess out-of-pocket payment for health care at the various thresholds for household total expenditure (Dorjdagva, Batbaatar, Svensson, Bayarsaikhan, \& Kauhanen, 2016, p. 105). There are two main approaches to determine whether catastrophic health care expenditure occurred or not. The first is to set a threshold for catastrophic health care expenditure as a percentage of total household income (e.g., Pradhan \& Prescott, 2002) and the second is to set it as a percentage of disposable household income, which is defined as household income remaining after the deduction of monies spent for food (Xu K. , et al., 2003). However, as Wyszewianski (1986) argues, a specific threshold could be catastrophic for a poor household while not imposing any financial burden for a wealthier household and, hence, there are various thresholds in existing literature. 
Moreover, the existing literature shows that CHE has a negative impact on a household's welfare (Chuma, Gilson, \& Molyneux, 2007; Chuma \& Maina, 2012; Wagstaff \& van Doorslaer, 2003; Xu, Evans, Carrin, Musgrove, \& Evans, 2007). According to the World Health Organization (2017), on average, around 100 million individuals are impoverished and an additional 150 million incur CHE during any given year because of direct health care expenditures. Therefore, in order to observe sensitivity, I use thresholds of $5 \%$ with incremental progress of $5 \%$ up to $40 \%$ to shed light on CHE and its risk factors among Iranian households.

Since May 2014, the Iranian government has enforced its health care reform program that aims at providing universal health care insurance, decreasing OOP health expenditure, and decreasing the rate of CHE. In this chapter, I analyze the degree to which Iranian universal health insurance protects households from high rates of OOP health care expenditure and evaluate the effect of the universal health insurance program on Iranian CHE. To that aim, I draw on rotating panel data of Iranian household budgets for 2013-2014 and the use of difference-in-differences propensity score matching approach to compare the households that received the benefit from the universal health insurance program with the households that were not part of the program. Our results show that the program was successful in decreasing the rate of out-of-pocket health expenditures and CHE in Iran during the sample period. I also use difference-in-differences strategy to estimate the average effect of the health care reform on CHE and find that the program significantly decreased the CHE for eligible households. The program only offers basic health insurance and has not been able to reach all targeted groups. The results show that the program significantly decreased the OOP health expenditure ratio by about $17.3 \%$ for the treatment group at the national level. This is in line with other studies (e.g., Piroozi, Moradi, Nouri, Bolbanabad, \& Safari, 2016) that investigated this program at the province level.

Finally, Chapter 4 investigates the exchange rate pass-through (ERPT), which is the percentage change in local currency import prices resulting from a one percentage change in the 
nominal exchange rate (NER) between the exporting and importing countries, (Goldberg \& Knetter, 1997). Long a subject of interest in international economics, ERPT has a significant impact on both a country's microeconomic and macroeconomic indicators. Thus, it is important to understand the way changes in exchange rates affect import prices (pass-through). It is important for central bankers and monetary policy makers to know how nominal exchange rate changes would affect domestic prices; therefore, the interest to monetary policy and trade policy makers in studying ERPT has increased, especially for small, open economies such as Turkey.

Literature has evidenced over several dimensions of ERPT and found that it varies considerably across sectors and products and across countries (Campa \& Goldberg, 2005; Menon, 1995). Most of the studies before the late 1990s have used aggregated- and disaggregated- level data to investigate ERPT and found that ERPT is higher based on aggregate-level data sets and provide evidence of incomplete pass-through (Campa \& Goldberg, 2005; Goldberg \& Knetter, 1997; Menon, 1995). Literature shows that the degree of ERPT is lower for consumer prices compared with import prices and most of the time it is incomplete even in the long run (McCarthy, 2007). Studies such as Aron, Farrell, Muellbauer, and Sinclair (2014), and Lott and Einav (2013) explore ERPT to consumer prices using sets of highly disaggregated data at the product-level and based on micro prices, which are the closest to this study. These researchers have found that ERPT is dramatically varying across products, and is incomplete in the short-run, which is consistent with my results.

I use micro-price daily data for 52 agricultural products imported by Turkey from January 2005 to August 2015. ${ }^{1}$ Having such high-frequency data (daily prices) and the ability to distinguish between imported products and products domestically produced in Turkey, makes this data set one of the few rich data sets on micro prices and a perfect fit for daily ERPT investigation. I also employ

\footnotetext{
${ }^{1}$ The web page of Istanbul Metropolitan Municipality is www.ibb.gov.tr
} 
the corresponding data on NER (between the Turkish Lira and the U.S. dollar) by daily frequencies. $^{2}$

Within that context, I investigate ERPT at the product-level by estimating the role of NER changes on wholesale prices of imported agricultural goods in Turkey. I have achieved an identification methodology by using daily data on the domestic inflation rate and controlling for seasonality (such as weekday, month, and month of Ramadan) and goods fixed effects. Moreover, this study examines the degree of ERPT with respect to the perishability of agricultural goods to find out whether or not products with different degrees of storage life have different pass-through rates. The results of the benchmark empirical analysis are in line with the body of the literature, showing evidence for incomplete ERPT of about 5\%. Further, this study contributes to the body of the literature with a novel methodology—considering nonlinearities in ERPT-where ERPT doubles to about $10 \%$ when daily NER changes are above $0.55 \%$, daily frequencies of price change are above $3.12 \%$, and storage life of a product is over 10 weeks.

Next, I introduce these essays with all of their details and specifications.

\subsection{REFERENCES}

Aron, J., Farrell, G., Muellbauer, J., \& Sinclair, P. (2014). Exchange rate pass- through to import prices, and monetary policy in South Africa. Journal of Development Studies, 50(1), 144164.

Campa, J. M., \& Goldberg, L. S. (2005). Exchange rate pass-through into import prices. Review of Economics and Statistics, 87(4), 679-690.

Chuma, J., Gilson, L., \& Molyneux, C. (2007). Treatment-seeking behaviour, cost burdens and coping strategies among rural and urban households in Coastal Kenya: An equity analysis. Tropical Medicine \& International Health, 12(5), 673-686.

Chuma, J., \& Maina, T. (2012). Catastrophic health care spending and impoverishment in Kenya. BMC Health Services Research, 12(413), 413-422.

\footnotetext{
${ }^{2}$ The web page of The Central Bank of the Republic of Turkey is www.tcmb.gov.tr
} 
Dorjdagva, J., Batbaatar, E., Svensson, M., Dorjsuren, B., \& Kauhanen, J. (2016). Catastrophic health expenditure and impoverishment in Mongolia. International Journal for Equity in Health, 15(1), 105-113.

Gertler, P., \& Gruber, J. (2002). Insuring consumption against illness. American Economic Review, 92(1), 51-70.

Goldberg, P. K., \& Knetter, M.M. (1997). Goods prices and exchange rates: what have we learned? Journal of Economic Literature, 35, 1243-1272.

Kochar, A. (1995). Explaining household vulnerability to idiosyncratic income shocks. The American Economic Review, 85(2), 159-164.

Lott, Z., \& Einav, L. (2013). Exchange Rate Pass-Through on EBay. Stanford University, mimeo.

McCarthy, J. (2007). Pass-through of exchange rates and import prices to domestic inflation in some industrialized economies. Eastern Economic Journal, 33(4), 511-537.

Menon, J. (1995). Exchange rate pass-through. Journal of Economic Survey, 9(2), 197-231.

Pradhan, M., \& Prescott, N. (2002). Social risk management options for medical care in Indonesia. Health Economics, 11(5), 431-446.

Piroozi, B., Moradi, G., Nouri, B., Bolbanabad, A. M., \& Safari, H. (2016). Catastrophic health expenditure after the implementation of health sector evolution plan: A case study in the west of Iran. International Journal of Health Policy and Management, 5(7), 417-423. doi: 10.15171/ijhpm.2016.31.

Russell, S. (2004). The economic burden of illness for households in developing countries: A review of studies focusing on malaria, tuberculosis, and human immunodeficiency virus/acquired immunodeficiency syndrome. American Journal of Tropical Medicine and Hygiene, 71(2 suppl), 147-155.

Su, T. T., Kouyaté, B., \& Flessa, S. (2006). Catastrophic household expenditure for healthcare in a low-income society: A study from Nouna District, Burkina Faso. Bulletin of the World Health Organization, 84(1): 21-27.

Wagstaff, A., \& Doorslaer, E. V. (2003). Catastrophe and impoverishment in paying for health care: With applications to Vietnam 1993-1998. Journal of Health Economics, 12(11), 921-934.

World Health Organization. (2017, December 31). Universal health coverage . Retrieved from World Health Organization: http://www.who.int/en/news-room/factsheets/detail/universal-health-coverage-(uhc)

Wyszewianski, L. (1986). Financially catastrophic and high-cost cases: Definitions, distinctions, and their implications for policy formulation. Inquiry, 23(4), 382-394. 
Xu, K., Evans, D. B., Carrin, G. A.-R., Musgrove, P., \& Evans, T. (2007). Protecting households from catastrophic health spending. Journal of Health Affairs, 26(4), 972-983.

Xu, K., Evans, D. B., Kawabata, K., Zeramdini, R., Klavus, J., \& Murray, C. J. L. (2003). Household catastrophic health expenditure: A multicountry analysis. The Lancet, 362(9378), 111-117. 


\section{Chapter 2}

\section{CATASTROPHIC AND IMPOVERISHING EFFECTS OF OUT-OF-POCKET PAYMENTS FOR HEALTH CARE IN IRAN: EVIDENCE FROM IRAN HOUSEHOLD INCOME EXPENDITURE SURVEYS}

\subsection{Introduction}

For millions of people worldwide, health payments present a huge financial risk. Financial risk protection helps secure people against the financial hardships associated with paying for health services (World Health Organization, 2010). The absence of health insurance, or a poorly functioning risk protection mechanism and high levels of OOP health care expenditure, expose households to financial risks associated with major illnesses (World Health Organization, 2005). A high rate of OOP can lead to $\mathrm{CHE}$, forcing households to cut down their consumption, minimize access to their needs, or face poverty. These facts make financial protection against high levels of OOP health expenditure and its consequences an important goal for any health care system adopted by governments, including the government of Iran. Poor populations in low-income countries mainly finance health care from OOP payments that severely affect their consumption during periods of major illness, or force them to forego treatment, which raises the chance of long-term deterioration of health and earning capacity (Kochar, 1995; Gertler \& Gruber, 2002).

As stated by Saksena, Hsu, and Evans (2014: 2): “...two commonly applied concepts capture the lack of financial risk protection. The first, catastrophic health expenditure, occurs when a household's out-of-pocket (OOP) payments are so high relative to its available resources that the household foregoes the consumption of other necessary goods and services. The second concept, impoverishment, occurs when OOP payments push households below or further below the poverty line, a threshold under which even the most basic standard of living is not ensured." This study investigates financial risk protection indicators related to OOP health care payments through $\mathrm{CHE}$ mean positive overshoot (MPO), and incidence and depth of impoverishment. 
More than 35,000 households participated in the Iranian Household Income and Expenditure Survey (HIES) in 2013, which provides a detailed analysis of key issues related to OOP spending on health care and financial difficulties resulting from these expenditures in Iran. This paper also uses a nationally representative survey to calculate the mean CHE headcount and its concentration indices as well as CHE MPO. Utilizing demographic and socioeconomic characteristics, this study predicts the tendency of households to face CHE. Further, it estimates poverty headcount using total household consumption expenditure and such expenditure without OOP payments for health care in comparison with the absolute poverty line. Moreover, analyzing the average household OOP spending on health care and the financial consequences of such expenditures is crucial for priority setting in any informed policy discussion. Therefore, presenting the background of the health care system in Iran provides a detailed analysis and sheds light on financial risks associated with a high rate of OOP spending on health care.

\subsection{Health Care System in Iran}

Comprising the health care system in Iran are three sectors of provision: public, private, and not-for-profit. Over the last two decades, the Iranian government has kept its focus on making the main provider of health care services the public sector (Mehrdad, 2009). The private sector generally provides secondary and tertiary health care in urban areas, whereas the public sector plays a critical role within all three sectors. Non-governmental organizations (NGOs) are active in providing health care services for chronic illnesses (e.g., diabetes) and the severely ill, such as cancer patients (Hajizadeh \& Nghiem, 2011; Mehrdad, 2009). Health insurers also comprise institutional bodies in Iran's health care system based on employment status. Insurance is employer based and individuals are covered by different insurance carriers provided by their employer (Hajizadeh \& Nghiem, 2011; Mehrdad, 2009). Citizens who are either not employed or selfemployed have the option to purchase health insurance or receive government-funded health insurance coverage either through the Public Medical Service Insurance Coverage Act or through 
the Urban Inpatient Insurance Scheme. According to Mehrdad (2009), there are five main health insurers in Iran.

1. Covering the formal sector of employees and their dependents is the Social Security Organization. It also owns health care facilities such as clinics and hospitals within all provinces in Iran and those covered by the Social Security Organization receive free health services or at a greatly reduced cost.

2. The Medical Service Insurance Organization covers government employees, rural dwellers, self-employed individuals, and students. In some cases, a patient may need to make a copayment.

3. The military personnel insurance, Armed Forces Medical Service Organization, covers members of the military and their dependents.

4. The Imam Khomeini Relief Foundation focuses on providing coverage for the uninsured poor.

5. Special organizations such as the Ministry of Welfare and Social Security, oil companies, radio and television broadcasters, banks, NGOs, and others provide health insurance for their employees and their dependents.

Despite the existence of these health insurers, the health care system in Iran suffers from a high rate of health care OOP payment, which is the major payment strategy (more than $50 \%$ of total health financing) in Iran that can expose households to substantial financial risks and, in the most extreme cases, can result in households left in poverty.

\subsection{Data and Methodology}

This paper assesses OOP expenditures for health care in Iran using the Iranian Household Income Expenditure Survey (HIES) data for 2013. The HIES has been collected every year by the Statistical Center of Iran (SCI) and geographically covers national areas without exclusion. The HIES uses a three-staged cluster sampling approach with strata in the survey: Stage One, census 
areas are classified; Stage Two, city blocks in urban areas and villages in rural areas are sampled in each province; and Stage Three, the optimized number of households are randomly selected within the selected villages and city blocks. The survey is therefore representative of all areas. HIES's main purpose is to estimate household income and expenditures for national accounts at provincial and country levels for both urban and rural households. Sample sizes vary from year to year in order to better represent demographic and population changes. The total sample size of the Iran HIES was 35,372 in 2013 and included information on household demographics, education, labor, income, health status, health care payments, and various categories of household expenditures.

\subsubsection{Out-Of-Pocket Health Care Expenditure}

It is important to analyze the extent to which OOP payments for health care are voluntary. One can determine if the health care expenses are large relative to the resources available to the household and whether disruptions to the standard of living are catastrophic (World Health Organization, 2018). Thus, we are concerned with the payments households make during or after the time of health care delivery and include spending at the point of care that is not covered by insurance companies, government agencies, or are non-reimbursable costs, such as health insurance copayments or payments devoted to deductibles as well as those paid indirectly through insurance premiums and social insurance contributions.

As is common for developing countries (O’Donnell, van Doorslaer, Wagstaff, \& Lindelow, 2008), OOP payments comprise the greatest share of health care expenditures, $52 \%$ in this case. As outlined in Figure 2-1, in Iran the percentage of OOP health care expenditures fluctuated between $50 \%$ and $57 \%$ during the period of 1995 to 2013 , where the average was $52.64 \%$ with a standard deviation of 1.80 . It was $52.11 \%$ in 2013 . Its highest value during this period was $56.16 \%$ in 2000 and its lowest value was $49.67 \%$ in 1997. 
Figure 2-1 Out-of-Pocket Health Expenditure - Iran

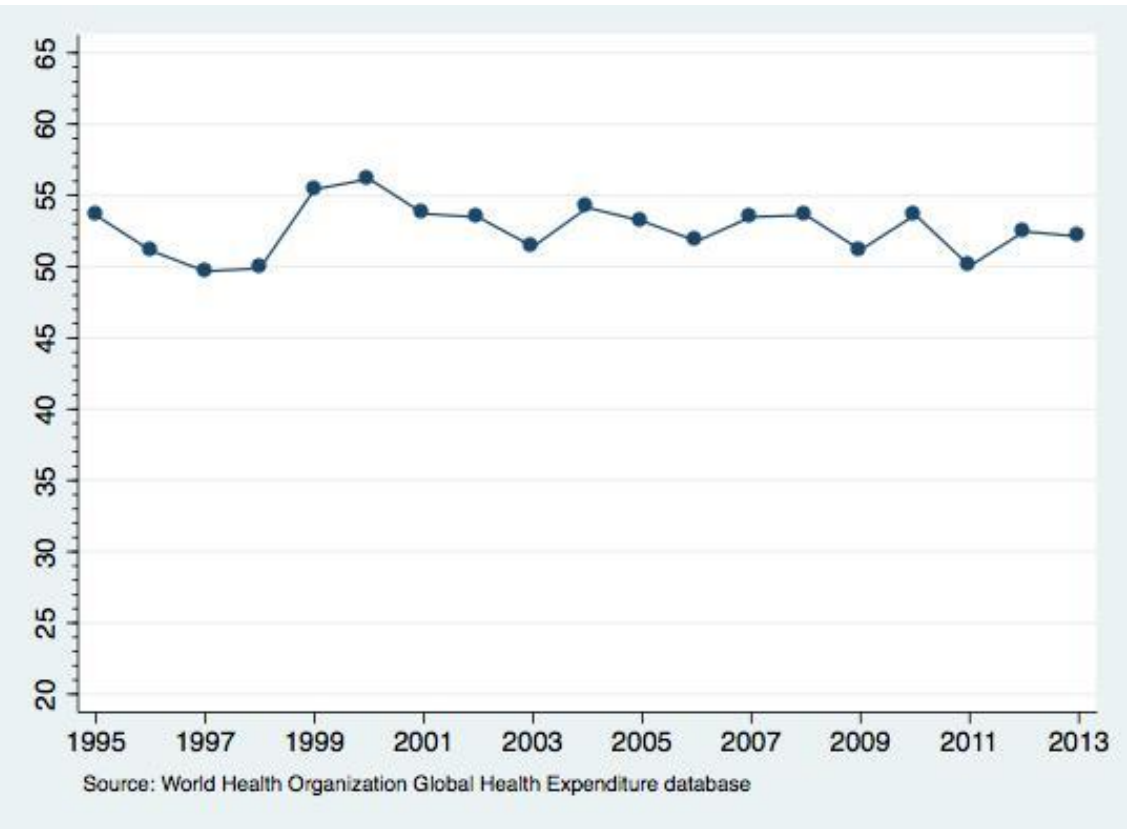

According to Figure 2-2, OOP payments for health care as a percentage of total household expenditure vary for different expenditure quintile groups. On average, OOP payments claim about $6 \%$ of household expenditures and there is a tendency for this share to rise with total expenditure, in this case $8.2 \%$ for the better-off section of the population compared with $6.2 \%$ for the poor. Large and unexpected health care spending could cause households to face financial risk. Therefore, one of the most important issues related to high OOP expenditures on health care would be to protect households against financial risks such as CHE and impoverishment. 
Figure 2-2 Out-of-Pocket Payment as Percentage of Total Household Expenditure, Average by Household Expenditure Quintile, 2013

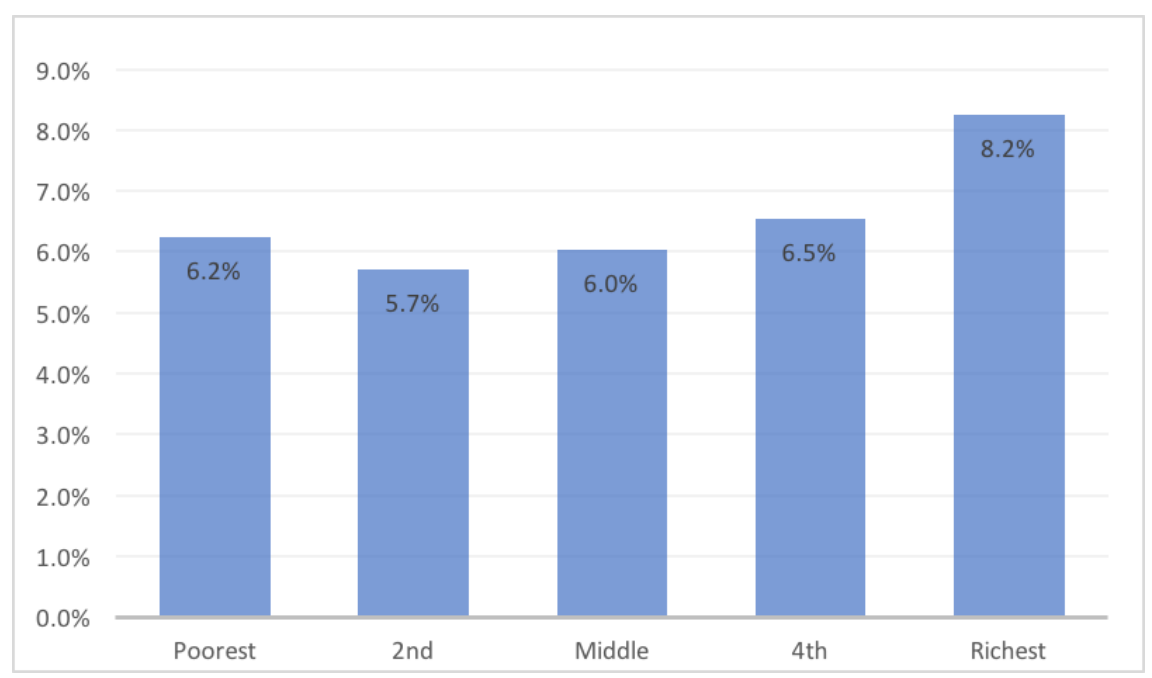

\subsubsection{Measuring incidence and intensity of catastrophic health care expenditure}

Several definitions of CHE exist in literature. Russell (2004, p. 147) states: "The term catastrophic implies that such expenditure levels are likely to force household members to cut their consumption of minimum needs, trigger productive asset sales or high levels of debt and lead to impoverishment." A popular approach has been to define medical spending as "catastrophic" if it exceeds some fraction of household income or total expenditure in a given period, usually one year (Berki, 1986; Russell, 2004; Wagstaff \& Doorslaer, 2003; Wyszewianski 1986; Xu, Evans, Kawabata, Zeramdini, Klavus, \& Murray, 2003). It is important to know how the household would finance such a high expenditure level on health care. In the short term, it could be the cutting of other goods and services; or, in the long term, the high expenditure could push households to use their savings, sell their productive assets, or even secure credit. To measure CHE, we need access to total household expenditure for health and to a measure of household available resources such as total income, expenditure, or consumption to use for the latter. By employing HIES, we have access to both household total expenditure and total household OOP payments for health.

According to O'Donnell et al. (2008), households with the same level of income and OOP health expenditure may be in a different situation if they have savings or access to credit and are 
able to finance their OOP health payments compared with households that have no savings and pay for their OOP health expenditure by cutting other expenses. The ratio of health payments to income remains the same for both households. Therefore, it does not reflect the difference of the ratio. However, the ratio of health payments in comparison with the total household expenditure will show a significant increase for the household without savings. If we assume the opportunity cost of current consumption is, in fact, higher for the household, then the catastrophic impact would be more significant for the household with no savings. Thus, in this study we use the household total expenditure as the denominator in the definition of CHE (O'Donnell et al., 2008). Yet, in general, $\mathrm{CHE}$ is an excess OOP payment for health care at the various thresholds for household total expenditure (Dorjdagva, Batbaatar, Svensson, Dorjsuren, \& Kauhanen, 2016). Households make OOP payments during or after the time of health care delivery and include expenditure at the point of service not covered by insurance companies, government agencies or is non-reimbursable (health insurance copayments or payments devoted to deductibles).

There are two main approaches to indicate whether CHE occurred or not. The first approach is to set a threshold for CHE as a percentage of total household expenditure (e.g., Pradhan \& Prescott, 2002), and the second approach sets it as a percentage of disposable household expenditure defined as household expenditure remaining after the deduction of food expenditure (Xu et al., 2003). However, as Wyszewianski (1986) argues, a specific threshold might be catastrophic for a poor household while it does not impose any financial burden for a wealthier household. Therefore, there are various thresholds in existing literature; the most commonly used are between " $10-25$ percent of total consumption expenditure and 25-40 percent of nonfood expenditure" (Smith \& Nguyen, 2013, 116). Moreover, the existing literature has shown that CHE has a negative impact on households' welfare (Wagstaff \& Doorslaer, 2003; Chuma, Gilson, \& Molyneux, 2007; Chuma \& Maina, 2012; Xu, Evans, Carrin, Musgrove, \& Evans, 2007). 
As a result, we present the occurrence of CHE from the fraction of OOP payments for health care costs in comparison to households' total expenditure for various thresholds in this study. The value of threshold represents the point at which a high level of OOP payments for health care imposes severe disruption to a household's standard of living. Most will consider this a matter of judgment, and it should be noted that researchers should not impose their own opinion but instead should present results for a range of values of thresholds and allow the reader to make observations as necessary (O’Donnell et al., 2008). Therefore, in order to observe sensitivity, we use thresholds of $5 \%$ with incremental progress of $5 \%$ to $40 \%$ to shed light on CHE and its risk factors among Iranian households.

We can estimate the incidence of CHE for any household with OOP health care expenditures as a share of a household's total expenditure exceeding the chosen threshold. This study defines an indicator $E_{i}$, which equals 1 if OOP health care costs as a share of household's total expenditure exceed the threshold and 0 otherwise. The summary measure of the extent of the exposure to $\mathrm{CHE}$ (defined along these lines) of a given sample of households would be the fraction of households whose OOP health care costs as a share of household total expenditure exceeded the threshold. Below is an equation that shows the estimate of the headcount, where $\mathrm{N}$ is the sample size (O’Donnell et al., 2008).

$$
H=\frac{1}{N} \sum_{i=1}^{N} E_{i}
$$

One criticism of the aspects of the headcount index is that it does not incorporate a measure by which households exceed the threshold level (Wagstaff \& Doorslaer, 2003). This is instead given by the 'catastrophic payment overshoot.' The overshoot represents the average extent by which health care expenditure (as a proportion of total expenditure) exceeds the respective threshold. In other words, it measures the intensity of catastrophic OOP payments. Therefore, the overshoot complements the headcount measure of catastrophic payments. 
The CHE incidence measure and CHE headcount do not reflect the amount by which households exceed the threshold. We estimate the catastrophic payment overshoot, indicated by what percentage the households incur CHE and exceed the threshold. The overshoot represents the average extent by which OOP health care expenditure (as a proportion of total expenditure) exceeds the respective threshold. We can define the household overshoot as $O_{i}$ equal to the difference by which households' OOP health care costs as a share of household total expenditure exceeded the threshold when $E_{i}$ equals 1 otherwise $O_{i}$ would be 0 . The CHE overshoot measures the degree by which a share of OOP health expenditure exceeds the threshold in a given sample of households (O'Donnell et al., 2008). Then the overshoot is simply the average:

$$
O=\frac{1}{N} \sum_{i=1}^{N} O_{i}
$$

Hence, it measures the intensity of catastrophic OPP. In this respect, the overshoot complements the headcount measure of catastrophic payments. The mean positive overshoot, on the other hand, gives an idea of the average spending out-of-pocket for all those exceeding the threshold. It reflects both incidence and intensity of CHE.

$$
M P O=\frac{O}{H}
$$

This implies that the catastrophic overshoot equals the fraction of catastrophic payments times the mean positive overshoot, the incidence times the intensity. MPO displayed in Table 2-4 can estimate the average spending of OPP for all those exceeding the threshold in urban and rural areas.

Moreover, this study estimates the extent that different explanatory variables, containing information about demographic and expenditure quintile, influenced the probability of incidence and intensity of households facing CHE and CHE overshoot. The regression model used to evaluate the factors affecting the chance of occurrence of CHE is as follows, for different threshold levels: 


$$
\begin{aligned}
& E(\text { threshold })=\beta_{1}+\beta_{2} \text { i.quintile }++\beta_{3} \text { urban }+\beta_{4} \text { age }+\beta_{5} \text { female }+ \\
& \beta_{6} \text { i.education }+\beta_{7} \text { nliterate }+\beta_{8} \text { i.activity }+\beta_{9} n_{-} \text {employed }+ \\
& \beta_{10} \text { child } 1+\beta_{11} \text { child } 2+\beta_{12} \text { elderly }+\beta_{13} \text { surgery }_{l y}+\beta_{14} \text { i.size }+ \\
& \beta_{15} \text { i.province }+\beta_{16} \text { internet }+\beta_{17} \text { tv }+\epsilon
\end{aligned}
$$

Dummy variable $E$ is the dependent variable, with a value of 1 when the household faces CHE for the specified threshold level. As the dependent variable is a dummy, this study has the advantage of using a Logit model to evaluate how independent variables affect the chance of incidence of CHE. Quintile is a vector of dummy variables presenting the expenditure quintile. Urban is a dummy variable with the value of 1 when the household is located in urban areas. Age is a continuous variable reflecting the age of the head of household. Female is a dummy variable with a value of 1 when the head of the household is female. Education is also a vector of two dummies for three categories of "elementary and lower education," "secondary education," and "higher education." Further, "n-literate" indicates the number of literate individuals in the household. Activity is a vector of two dummy variables for the three categories "unemployed," "employed," and "retired and others." Moreover, "n-employed" indicates the number of employed individuals in the household. Child1 is the number of children at the age of pre-school ( 0 to 5 years old) and child 2 is the number of children at school age (6 to 18 years old). Elderly shows the number of elderly people — above the age of 65 years old — residing in the household. Province is a vector of dummy variables showing to which province each household belongs. The model includes dummy variables for availability of Internet and television access, as these resources can provide information to help prevent unhealthy behaviors.

Additionally, using the same set of demographic and expenditure quintile variables, this study estimates the intensity of such an influence on households facing CHE overshoot. The regression model used to evaluate factors affecting the chance of occurrence of CHE is the 
following: while the dependent variable is a continuous variable representing CHE overshoot, this study employs the OLS model for the following equation, which we can specify for different threshold levels:

$$
\begin{aligned}
& O(\text { threshold })=\beta_{1}+\beta_{2} \text { i.quintile }++\beta_{3} \text { urban }+\beta_{4} \text { age }+\beta_{5} \text { female }+ \\
& \beta_{6} \text { i.education }+\beta_{7} \text { nliterate }+\beta_{8} \text { i.activity }+\beta_{9} n_{-} \text {employed }+ \\
& \beta_{10} \text { child } 1+\beta_{11} \text { child } 2+\beta_{12} \text { elderly }+\beta_{13} \text { surgery }_{l y}+\beta_{14} \text { i.size }+ \\
& \beta_{15} \text { i.province }+\beta_{16} \text { internet }+\beta_{17} \text { tv }+\epsilon
\end{aligned}
$$

\subsubsection{Expenditure Quintiles and Concentration Index (CI)}

The headcount and overshoot indexes well represent the aspects of catastrophic payments in the total population. Yet, they explain little about who is more likely to suffer such catastrophic payments and are blind as to whether it is poor or better-off households who exceed the threshold. It seems as if society will sympathize more with those households in the lowest quintile whose spending (as a share of its expenditure) exceeds the threshold compared with a household in the top quintile. To have a better understanding of this, we need to see how the proportions of those exceeding the threshold vary across the income distribution. To calculate the proportion of those exceeding the threshold, a concentration index for, $E_{i}$, which we define as CI (Wagstaff \& Doorslaer, 2002), can be used. If those who exceed the threshold tend to be poor, the concentration index CI will be negative, and the catastrophic payment problem is worse than it appears simply by looking at the fraction of the population exceeding the threshold, since it ignores the fact that it tends to be the poor who exceed the threshold. By contrast, if better-off households tend to exceed the threshold, CI will be positive, and CHE headcount will overstate the problem of the catastrophic payment problem and show that better-off households have a greater tendency to fall into catastrophic payments (Wagstaff \& Doorslaer, 2002). The concentration index (CI) displayed in Table 2-1, Table 2-2, and Table 2-3 can estimate such effect. 


\subsubsection{Impoverishment Impact of OOP Health Payments}

The previous section measured incidence and intensity of CHE that occurs when a household's OOP health care payments are extremely high in comparison with its total expenditure, in a way that is disruptive for maintaining household living standards to the extent that the household foregoes consumption of other necessary goods and services. The methods used to measure poverty do not take into account factors such as OOP payments on health. For example, when measuring poverty, we need to follow two steps. The first is to set a threshold for household income or expenditure and then set a poverty line that is not sensitive to highly variable health care needs. It is essential to focus on two types of households, a household that is facing high OOP payments in which household members, out of necessity, must cut their consumption of minimum needs, to an extent that the amount of their available spending for basic necessities falls below the poverty line but does not meet the definition of "poor." Those households who borrow in order to make OOP payments do not meet the definition of poor as the total expenditure goes above the poverty line (O’Donnell et al., 2008).

A 2006 study conducted by Doorslaer, Masseria, and Koolman found that $2.7 \%$ of the population under review — equal to additional 78 million people in Asia—do not fit the description of "poor" even though they spend less than one dollar per day after netting out OOP health spending. In this section, we describe measures and methods to estimate the impoverishment impact of OOP payments and state adjusting measures of poverty to be accountable for spending on health care. The measurement of poverty is required for comparison with the difference average levels of poverty with and without OOP payments. This comparison involves household expenditure net of OOP payments for health care as well as an extreme poverty measurement such as food poverty line $^{3}$ (Karakurum-Ozdemir et al., 2016).

\footnotetext{
${ }^{3}$ In this study, we use a poverty rate of $\$ 5.50$ per person per day purchasing power parity (PPP) for the poverty line.
} 
Therefore, this study measures both poverty headcount using total household expenditure, and such expenditure without OOP payments for health, separately. Comparing differences between these two average levels of poverty headcounts captures the impoverishment impact of OOP payments on levels of poverty. Thus, we estimate the pre-payment poverty headcount, which compares per capita household expenditure to the poverty line, as follows. We define an indicator, $P_{i}^{\text {Pre-Payment }}$, equal to 1 if per capita total expenditure (including OOP payments) of household i is less than the extreme poverty line and 0 otherwise. The pre-payment poverty headcount is $H^{\text {Pre-Payment }}$ gives the fraction of households living in poverty, which represents the extent to which a given sample of households has fallen below the poverty line. Next, an estimate of the headcount is given by the equation below, where $\mathrm{N}$ is the sample size (O'Donnell et al., 2008).

$$
H^{\text {Pre-Payment }}=\frac{1}{N} \sum_{i=1}^{N} P_{i}^{\text {Pre-payment }}
$$

Similarly, we can estimate the post-payment poverty headcount $H^{\text {Post-Payment }}$ using an indicator such as $P_{i}^{\text {Post-Payment }}$, which equals 1 if per capita total expenditure minus OOP payments of household $\mathrm{i}$, is less than the extreme poverty line and 0 otherwise. The post-payment poverty headcount, $H^{\text {Post-Payment }}$ represents the fraction of households that fall under the poverty line. Next, we give an estimate of the headcount using the equation below, where $\mathrm{N}$ is the sample size. So, $H^{\text {Post-Payment }}-H^{\text {Pre-Payment }}$, is the fraction of the population that is not considered poor based on measures of poverty that are not accountable for spending on health care. Thus, after reducing OOP spending on health care, their resources fall below the poverty line.

$$
H^{\text {Post-Payment }}=\frac{1}{N} \sum_{i=1}^{N} P_{i}^{\text {Post-payment }}
$$

Measures such as pre-payment poverty headcount and post-payment poverty headcount represent the rate of households below the poverty line and do not measure the intensity of poverty; we use the poverty gap that measures the amount by which the poor households fall short of 
minimum expenditures as the poverty line. Similarly, the pre-payment and post-payment poverty gap is defined, respectively, where PL representing the poverty line, $O O P_{i}$, indicates per capita household OOP spending on health care, and $E_{i}$ represents the per capita total expenditure.

$$
\begin{gathered}
G^{\text {Pre-Payment }}=\frac{1}{N} \sum_{i=1}^{N} P_{i}^{\text {Pre-payment }}\left(P L-E_{i}\right) \\
G^{\text {Post-Payment }}=\sum_{i=1}^{N} P_{i}^{\text {Post-payment }}\left\{P L-\left(E_{i}-O O P_{i}\right)\right\}
\end{gathered}
$$

Therefore, the poverty gap impoverishment of OOP payments on health care is expressed with the difference between the post-payment minus the pre-payment poverty gap, $\mathrm{G}^{\text {Post-Payment }}-G^{\text {Pre-Payment }}$. It is also helpful to normalize the poverty gap on the poverty line, normalized poverty gap (NG), which measures the size of the poverty gap to the poverty line for comparative analysis. Such analysis is useful when making comparisons across countries with different currency units and poverty lines (O’Donnell et al., 2008.

$$
\begin{aligned}
N G^{\text {Pre-Payment }} & =\frac{G^{\text {Pre-Payment }}}{P L} \\
N G^{\text {Post-Payment }} & =\frac{G^{\text {Post-Payment }}}{P L}
\end{aligned}
$$

\subsection{Results}

Table 2-1 shows the average household OOP payments for health care for 2013, which accounted for 11.75 Million Iranian Rial (IRR). The amount of OOP health care expenditures of urban households (14.75 Million-IRR) for their health care services is significantly higher than that of the rural households (9.02 Million-IRR). Moreover, in both urban and rural areas, the households in the highest quintile, the richest, had higher spending. As we have seen before, (see Figure 2-2), OOP expenditures comprise more than $6 \%$ of household budget share. Therefore, this share increases with the total expenditure; specifically, it increases $8.2 \%$ for the richest quintile and $6 \%$ for the poorest quintile of the population. 
Generally, policy makers give more priority to the status of poorest quintile than that of the richest one when incurring the catastrophic OOP payments; hence, they care about how different the levels of such payments are amongst these two groups. To estimate this, we have calculated the concentration index, CI, displayed in Table 2-1. The positive value of the concentration index means that the OOP health expenditure is higher among the rich. As we can see from the table, across rural $(\mathrm{CI}=0.116)$ and urban $(\mathrm{CI}=0.137)$ areas, the richest households are more inclined to make higher OOP health payments. This means that the average of OOP health payments overstate the problem and we should pay more attention to the distribution of OOP health payments among the households as well.

Table 2-1 The Average Out-of-Pocket Payments in IRR (Standard Error) Per Household across Expenditure Quintiles and Rural Urban Areas, 2013

\begin{tabular}{llll}
\hline Quintile & Rural & Urban & Total \\
\hline Poorest & $2,557,231$ & $4,403,457$ & $3,390,928$ \\
& $(68,711)$ & $(102,256)$ & $(60,675)$ \\
2nd & $4,240,990$ & $6,981,844$ & $5,529,800$ \\
& $(101,326)$ & $(143,596)$ & $(87,812)$ \\
Middle & $6,138,470$ & $9,978,033$ & $8,001,479$ \\
& $(140,279)$ & $(207,553)$ & $(125,980)$ \\
4th & $9,338,510$ & $14,440,206$ & $11,813,193$ \\
& $(219,449)$ & $(304,536)$ & $(188,331)$ \\
Richest & $22,112,066$ & $34,872,136$ & $28,346,790$ \\
& $(720,851)$ & $(1,151,633)$ & $(676,693)$ \\
Total & $9,023,903$ & $14,759,618$ & $11,758,632$ \\
& $(167,787)$ & $(276,278)$ & $(159,028)$ \\
CI & 0.116 & 0.137 & 0.130 \\
SE (CI) & $(0.006)$ & $(0.006)$ & $(0.004)$ \\
\hline
\end{tabular}

Table 2-2 presents the incidence of household CHE at different threshold levels for each quintile of household expenditure in urban and rural areas. Incidence of CHE decreased as the threshold level increased from 5\% to $40 \%$ of total expenditure in both rural and urban areas and also in all expenditure quintiles. In $2013,38.8 \%$ of the total households paid health care OOP costs that exceeded $5 \%$ of their total budget and faced CHE, the corresponding value measured higher in urban areas $(41.3 \%)$ than in rural areas $(36.6 \%)$. For all threshold levels, we observe the same 
results, however, at $30 \%$ and $40 \%$ of total expenditure CHE headcount is higher in rural areas compared with urban areas.

It is important to ask whether the households experiencing catastrophic OOP payments belong to the poorest quintiles or the richest ones. This paper calculates the concentration index, CI, displayed in Table 2-2, which can estimate such effect. Thus, the richest households are more probable to incur catastrophic payments in every threshold in both urban and rural areas. We observe a pro-rich incidence of $\mathrm{CHE}$ in all threshold levels (5\%, to $40 \%$ of total expenditure) in both rural and urban areas, indicated by the positive CI for different threshold levels. This result is in line with existing studies such as Hajizadeh and Nghiem (2011). Results show an overall prorich distribution for $\mathrm{CHE}$ incidence (total $\mathrm{CI}=0.341$ at $30 \%$ threshold) in both rural and urban areas, while the former has higher $\mathrm{CI}$.

Table 2-3 provides information on the measures of catastrophic overshoot for rural and urban areas across different measures of CHE. The table shows that the intensity of catastrophic payments drops as the threshold increases from $5 \%$ to $40 \%$ of total expenditure, and the mean overshoot drops respectively from $3.5 \%$ to $0.2 \%$ in the total sample; the richer the household, the higher the intensity (overshoot) of CHE. Further, this intensity follows the same direction in both urban and rural areas, being more pro-rich in rural areas compared with urban areas, $\mathrm{CI}=0.512$ and $\mathrm{CI}=0.479$ respectively at $30 \%$ threshold. 
Table 2-2 The Incidence of Household CHE across Expenditure Quintiles of Urban and Rural Areas, CHE Headcount

\begin{tabular}{|c|c|c|c|c|c|c|c|c|}
\hline Threshold & $5 \%$ & $10 \%$ & $15 \%$ & $20 \%$ & $25 \%$ & $30 \%$ & $35 \%$ & $40 \%$ \\
\hline \multicolumn{9}{|l|}{ Rural } \\
\hline Poorest & $37.0 \%$ & $21.4 \%$ & $12.6 \%$ & $7.5 \%$ & $4.9 \%$ & $2.9 \%$ & $2.1 \%$ & $1.2 \%$ \\
\hline 2nd & $35.0 \%$ & $16.6 \%$ & $9.5 \%$ & $5.3 \%$ & $3.2 \%$ & $2.0 \%$ & $1.3 \%$ & $0.7 \%$ \\
\hline Middle & $34.5 \%$ & $17.3 \%$ & $10.0 \%$ & $5.9 \%$ & $3.6 \%$ & $2.0 \%$ & $1.1 \%$ & $0.6 \%$ \\
\hline 4th & $35.9 \%$ & $18.6 \%$ & $11.3 \%$ & $6.7 \%$ & $4.5 \%$ & $3.0 \%$ & $2.1 \%$ & $1.5 \%$ \\
\hline Richest & $40.2 \%$ & $22.5 \%$ & $15.2 \%$ & $10.3 \%$ & $7.5 \%$ & $5.4 \%$ & $4.1 \%$ & $3.1 \%$ \\
\hline Total & $36.6 \%$ & $19.3 \%$ & $11.7 \%$ & $7.2 \%$ & $4.8 \%$ & $3.1 \%$ & $2.1 \%$ & $1.5 \%$ \\
\hline CI & 0.076 & 0.128 & 0.180 & 0.226 & 0.283 & 0.368 & 0.439 & 0.501 \\
\hline SE (CI) & $(0.005)$ & (0.008) & $(0.011)$ & $(0.015)$ & $(0.019)$ & $(0.022)$ & $(0.027)$ & $(0.032)$ \\
\hline \multicolumn{9}{|l|}{ Urban } \\
\hline Poorest & $43.0 \%$ & $20.7 \%$ & $10.5 \%$ & $6.2 \%$ & $3.6 \%$ & $2.3 \%$ & $1.2 \%$ & $0.6 \%$ \\
\hline 2nd & $40.1 \%$ & $17.5 \%$ & $9.3 \%$ & $5.1 \%$ & $2.9 \%$ & $1.7 \%$ & $1.0 \%$ & $0.6 \%$ \\
\hline Middle & $38.9 \%$ & $19.0 \%$ & $10.8 \%$ & $6.6 \%$ & $3.8 \%$ & $2.5 \%$ & $1.5 \%$ & $1.0 \%$ \\
\hline 4th & $39.9 \%$ & $20.6 \%$ & $12.2 \%$ & $7.4 \%$ & $4.5 \%$ & $3.0 \%$ & $1.7 \%$ & $1.0 \%$ \\
\hline Richest & $44.6 \%$ & $26.2 \%$ & $17.1 \%$ & $11.4 \%$ & $8.2 \%$ & $6.0 \%$ & $4.5 \%$ & $3.5 \%$ \\
\hline Total & $41.3 \%$ & $20.9 \%$ & $12.1 \%$ & $7.5 \%$ & $4.7 \%$ & $3.2 \%$ & $2.1 \%$ & $1.4 \%$ \\
\hline CI & 0.052 & 0.127 & 0.194 & 0.238 & 0.301 & 0.345 & 0.398 & 0.471 \\
\hline SE (CI) & $(0.006)$ & $(0.009)$ & $(0.012)$ & $(0.016)$ & (0.019) & $(0.024)$ & $(0.029)$ & $(0.032)$ \\
\hline \multicolumn{9}{|l|}{ Total } \\
\hline Poorest & $39.7 \%$ & $21.1 \%$ & $11.7 \%$ & $6.9 \%$ & $4.3 \%$ & $2.6 \%$ & $1.7 \%$ & $1.0 \%$ \\
\hline 2nd & $37.4 \%$ & $17.0 \%$ & $9.4 \%$ & $5.2 \%$ & $3.1 \%$ & $1.9 \%$ & $1.1 \%$ & $0.7 \%$ \\
\hline Middle & $36.7 \%$ & $18.1 \%$ & $10.4 \%$ & $6.2 \%$ & $3.7 \%$ & $2.2 \%$ & $1.3 \%$ & $0.8 \%$ \\
\hline 4th & $37.9 \%$ & $19.6 \%$ & $11.7 \%$ & $7.1 \%$ & $4.5 \%$ & $3.0 \%$ & $1.9 \%$ & $1.2 \%$ \\
\hline Richest & $42.3 \%$ & $24.3 \%$ & $16.1 \%$ & $10.9 \%$ & $7.8 \%$ & $5.7 \%$ & $4.3 \%$ & $3.3 \%$ \\
\hline Total & $38.8 \%$ & $20.1 \%$ & $11.9 \%$ & $7.3 \%$ & $4.7 \%$ & $3.1 \%$ & $2.1 \%$ & $1.4 \%$ \\
\hline CI & 0.072 & 0.128 & 0.180 & 0.223 & 0.276 & 0.341 & 0.395 & 0.459 \\
\hline SE (CI) & $(0.004)$ & $(0.006)$ & (0.008) & $(0.011)$ & $(0.014)$ & $(0.016)$ & $(0.020)$ & $(0.023)$ \\
\hline
\end{tabular}


Table 2-3 The Intensity of Household CHE across Expenditure Quintiles of Urban and Rural Areas, CHE Overshoot

\begin{tabular}{lcccccccc}
\hline Threshold & $\mathbf{5 \%}$ & $\mathbf{1 0 \%}$ & $\mathbf{1 5 \%}$ & $\mathbf{2 0 \%}$ & $\mathbf{2 5 \%}$ & $\mathbf{3 0 \%}$ & $\mathbf{3 5 \%}$ & $\mathbf{4 0 \%}$ \\
\hline Rural & & & & & & & & \\
Poorest & $3.6 \%$ & $2.2 \%$ & $1.3 \%$ & $0.8 \%$ & $0.5 \%$ & $0.3 \%$ & $0.2 \%$ & $0.1 \%$ \\
2nd & $2.7 \%$ & $1.5 \%$ & $0.9 \%$ & $0.5 \%$ & $0.3 \%$ & $0.2 \%$ & $0.1 \%$ & $0.1 \%$ \\
Middle & $2.8 \%$ & $1.6 \%$ & $0.9 \%$ & $0.6 \%$ & $0.3 \%$ & $0.2 \%$ & $0.1 \%$ & $0.1 \%$ \\
4th & $3.3 \%$ & $2.0 \%$ & $1.3 \%$ & $0.9 \%$ & $0.6 \%$ & $0.4 \%$ & $0.3 \%$ & $0.2 \%$ \\
Richest & $4.7 \%$ & $3.2 \%$ & $2.3 \%$ & $1.6 \%$ & $1.2 \%$ & $0.9 \%$ & $0.6 \%$ & $0.5 \%$ \\
Total & $3.4 \%$ & $2.1 \%$ & $1.4 \%$ & $0.9 \%$ & $0.6 \%$ & $0.4 \%$ & $0.3 \%$ & $0.2 \%$ \\
CI & 0.195 & 0.259 & 0.320 & 0.384 & 0.450 & 0.512 & 0.566 & 0.614 \\
SE (CI) & $(0.010)$ & $(0.014)$ & $(0.017)$ & $(0.021)$ & $(0.025)$ & $(0.029)$ & $(0.034)$ & $(0.039)$ \\
\hline Urban & & & & & & & & \\
Poorest & $3.2 \%$ & $1.7 \%$ & $1.0 \%$ & $0.6 \%$ & $0.3 \%$ & $0.2 \%$ & $0.1 \%$ & $0.1 \%$ \\
2nd & $2.8 \%$ & $1.5 \%$ & $0.8 \%$ & $0.4 \%$ & $0.3 \%$ & $0.1 \%$ & $0.1 \%$ & $0.0 \%$ \\
Middle & $3.2 \%$ & $1.8 \%$ & $1.1 \%$ & $0.6 \%$ & $0.4 \%$ & $0.2 \%$ & $0.1 \%$ & $0.1 \%$ \\
4th & $3.5 \%$ & $2.1 \%$ & $1.3 \%$ & $0.8 \%$ & $0.5 \%$ & $0.3 \%$ & $0.2 \%$ & $0.1 \%$ \\
Richest & $5.2 \%$ & $3.5 \%$ & $2.5 \%$ & $1.8 \%$ & $1.3 \%$ & $1.0 \%$ & $0.7 \%$ & $0.5 \%$ \\
Total & $3.6 \%$ & $2.2 \%$ & $1.4 \%$ & $0.9 \%$ & $0.6 \%$ & $0.4 \%$ & $0.3 \%$ & $0.2 \%$ \\
CI & 0.191 & 0.259 & 0.317 & 0.375 & 0.430 & 0.479 & 0.533 & 0.581 \\
SE (CI) & $(0.010)$ & $(0.014)$ & $(0.017)$ & $(0.021)$ & $(0.024)$ & $(0.028)$ & $(0.031)$ & $(0.034)$ \\
\hline Total & & & & & & & & \\
Poorest & $3.4 \%$ & $2.0 \%$ & $1.2 \%$ & $0.7 \%$ & $0.4 \%$ & $0.3 \%$ & $0.2 \%$ & $0.1 \%$ \\
2nd & $2.8 \%$ & $1.5 \%$ & $0.9 \%$ & $0.5 \%$ & $0.3 \%$ & $0.2 \%$ & $0.1 \%$ & $0.1 \%$ \\
Middle & $3.0 \%$ & $1.7 \%$ & $1.0 \%$ & $0.6 \%$ & $0.3 \%$ & $0.2 \%$ & $0.1 \%$ & $0.1 \%$ \\
4th & $3.4 \%$ & $2.1 \%$ & $1.3 \%$ & $0.8 \%$ & $0.5 \%$ & $0.4 \%$ & $0.2 \%$ & $0.2 \%$ \\
Richest & $5.0 \%$ & $3.4 \%$ & $2.4 \%$ & $1.7 \%$ & $1.3 \%$ & $0.9 \%$ & $0.7 \%$ & $0.5 \%$ \\
Total & $3.5 \%$ & $2.1 \%$ & $1.4 \%$ & $0.9 \%$ & $0.6 \%$ & $0.4 \%$ & $0.3 \%$ & $0.2 \%$ \\
CI & 0.188 & 0.249 & 0.303 & 0.360 & 0.417 & 0.469 & 0.519 & 0.564 \\
SE (CI) & $(0.007)$ & $(0.010)$ & $(0.012)$ & $(0.015)$ & $(0.018)$ & $(0.021)$ & $(0.024)$ & $(0.027)$ \\
\hline & & & & & & & & \\
\end{tabular}

According to Table 2-4, MPO for households spending more than $10 \%$ of their expenditures on OOP costs is $10.6 \%$, which means that they spent, on average, $20.6 \%$ in OOP expenditures in 2013. At the same threshold level, rural areas (10.9\%) had a higher MPO than urban areas (10.4\%). Maintaining the threshold level, rural areas (20.9\%) had a higher MPO than urban areas (20.4\%). Unlike the headcount and the overshoot, the mean overshoot among those exceeding the threshold (MPO) need not necessarily decline with the raising of the threshold. Those spending more than 5\% of total expenditure on health care, on average spent $14.0 \%$ (5\% 
+9.0\%). Those spending more than $30 \%$ of the household budget on health care, on average spent $42.5 \%(30 \%+12.5 \%)$.

Table 2-4 The Mean Positive Overshoot in urban and Rural Areas

\begin{tabular}{lcccccccc}
\hline Threshold & $\mathbf{5 \%}$ & $\mathbf{1 0 \%}$ & $\mathbf{1 5 \%}$ & $\mathbf{2 0 \%}$ & $\mathbf{2 5 \%}$ & $\mathbf{3 0 \%}$ & $\mathbf{3 5 \%}$ & $\mathbf{4 0 \%}$ \\
\hline Rural & & & & & & & & \\
MPO & $9.4 \%$ & $10.9 \%$ & $11.7 \%$ & $12.8 \%$ & $13.0 \%$ & $13.6 \%$ & $13.1 \%$ & $12.9 \%$ \\
SE(MPO) & $0.2 \%$ & $0.3 \%$ & $0.3 \%$ & $0.4 \%$ & $0.5 \%$ & $0.6 \%$ & $0.8 \%$ & $0.9 \%$ \\
Urban & & & & & & & & \\
MPO & $8.8 \%$ & $10.4 \%$ & $11.4 \%$ & $11.9 \%$ & $12.3 \%$ & $12.1 \%$ & $12.3 \%$ & $12.1 \%$ \\
SE(MPO) & $0.2 \%$ & $0.3 \%$ & $0.3 \%$ & $0.4 \%$ & $0.5 \%$ & $0.6 \%$ & $0.8 \%$ & $0.8 \%$ \\
Total & & & & & & & & \\
MPO & $9.0 \%$ & $10.6 \%$ & $11.4 \%$ & $12.2 \%$ & $12.5 \%$ & $12.5 \%$ & $12.5 \%$ & $12.3 \%$ \\
SE(MPO) & $0.1 \%$ & $0.2 \%$ & $0.3 \%$ & $0.3 \%$ & $0.4 \%$ & $0.5 \%$ & $0.6 \%$ & $0.6 \%$ \\
\hline
\end{tabular}

Figure 2-3, shows health care OOP payments budget share against the cumulative

proportion of populations ranked by decreasing health OOP share. It illustrates for a given threshold; for instance, at the $30 \%$ threshold level more than $3.1 \%$ of households' OOP health expenditures were at least $30 \%$ of household resources. Further, the area below the curve and above the threshold level represents total health care catastrophic overshoot.

Figure 2-3 Health Payment Budget Share against Cumulative Proportion of Population Ranked by Decreasing Health OOP Share

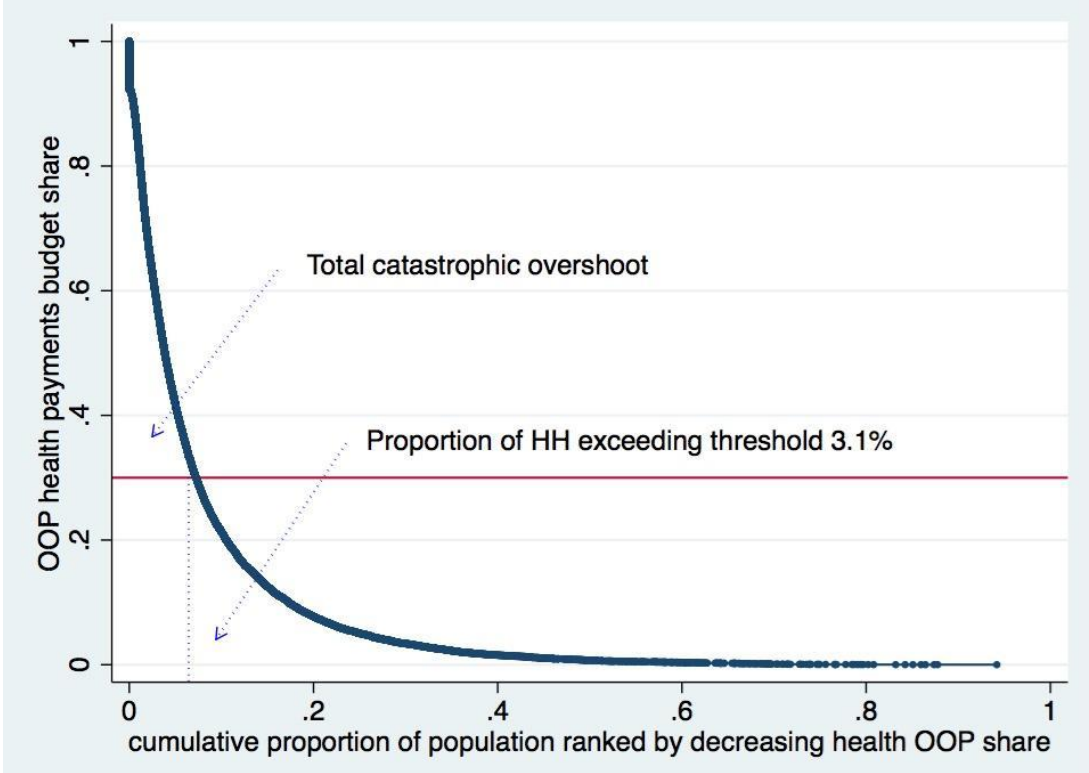

Table 2-5 presents the relevant results for the estimates of different explanatory variables containing the information about demographic and expenditure quintiles that influenced the 
probability of incidence of households facing CHE. As we can see, all coefficients are significant at the levels of $10 \%, 5 \%$, and $1 \%$. The coefficients of expenditure quintiles are positive for the middle, fourth, and richest quintiles at different threshold levels indicating that these households have a higher probability of facing $\mathrm{CHE}$, which is consistent with our results in the previous section. The coefficient of urban areas is positive, reflecting that living in an urban area increases the probability of incurring CHE. The coefficient for age and square of age indicate that between the intervals of natural human age (0 to 140), an increase in age of head of household increases the chances of facing CHE. The gender dummy is negative implying that the household with a male as head has a higher chance of CHE occurrence. This might be due to the fact that females (mothers) care deeply about hygiene and health care and as the head of household allocate more resources to these areas. Education dummies show that secondary education and higher education will decrease the probability of facing CHE relative to base category of elementary education. Activity dummies show that both unemployed and retired groups have a higher chance of incurring CHE, which is as expected. Households with pre-school and school age children faced less CHE, while the presence of elderly people or having a household member undergo surgery within the last year, as expected, increases the chances of incurring CHE. This study also shows that access to media and information decreases the chance of incurring CHE.

The results of the second regression model for CHE overshoot presented in Table 2-6 shows that households in higher expenditure quintiles faced higher CHE overshoot at all the threshold levels; while we observed mixed results for the second quintile at different threshold levels. Further, female head of households, or households with elderly members faced more CHE overshoot. We found similar patterns for different explanatory variables with the same effect on CHE overshoot as incidence of CHE and all are statistically significant at levels of 10\%, 5\%, and $1 \%$. 
Table 2-5 Determinants of Incidence of CHE, Iran 2013

\begin{tabular}{|c|c|c|c|c|}
\hline VARIABLES & $\begin{array}{c}(1) \\
\text { Threshold 10\% }\end{array}$ & $\begin{array}{c}\text { (2) } \\
\text { Threshold 20\% }\end{array}$ & $\begin{array}{c}\text { (3) } \\
\text { Threshold 30\% }\end{array}$ & $\begin{array}{c}\text { (4) } \\
\text { Threshold } 40 \%\end{array}$ \\
\hline Quintile - 2nd & $\begin{array}{c}-0.0154 * * * \\
(0.00216)\end{array}$ & $\begin{array}{c}0.0578 * * * \\
(0.00355)\end{array}$ & $\begin{array}{l}0.114 * * * \\
(0.00579)\end{array}$ & $\begin{array}{l}-0.0236 * * \\
(0.00959)\end{array}$ \\
\hline Quintile - Middle & $\begin{array}{l}0.103 * * * \\
(0.00217)\end{array}$ & $\begin{array}{l}0.502 * * * \\
(0.00342)\end{array}$ & $\begin{array}{l}0.601 * * * \\
(0.00551)\end{array}$ & $\begin{array}{l}0.523 * * * \\
(0.00896)\end{array}$ \\
\hline Quintile - 4th & $\begin{array}{l}0.215 * * * \\
(0.00219)\end{array}$ & $\begin{array}{l}0.605 * * * \\
(0.00345)\end{array}$ & $\begin{array}{l}0.973 * * * \\
(0.00537)\end{array}$ & $\begin{array}{l}1.139 * * * \\
(0.00835)\end{array}$ \\
\hline Quintile - Richest & $\begin{array}{l}0.468 * * * \\
(0.00223)\end{array}$ & $\begin{array}{l}1.083 * * * \\
(0.00342)\end{array}$ & $\begin{array}{l}1.745 * * * \\
(0.00518)\end{array}$ & $\begin{array}{l}2.258^{* * * *} \\
(0.00786)\end{array}$ \\
\hline Urban & $\begin{array}{c}0.0772 * * * \\
(0.00146)\end{array}$ & $\begin{array}{c}0.0476 * * * \\
(0.00220)\end{array}$ & $\begin{array}{c}0.0303 * * * \\
(0.00323)\end{array}$ & $\begin{array}{c}-0.0777 * * * \\
(0.00465)\end{array}$ \\
\hline Age & $\begin{array}{c}-0.00231 * * * \\
(6.61 \mathrm{e}-05)\end{array}$ & $\begin{array}{c}-0.00540 * * * \\
(9.86 \mathrm{e}-05)\end{array}$ & $\begin{array}{c}-0.00994 * * * \\
(0.000144)\end{array}$ & $\begin{array}{l}-0.0209 * * * \\
(0.000207)\end{array}$ \\
\hline Female & $\begin{array}{c}-0.0459 * * * \\
(0.00218)\end{array}$ & $\begin{array}{l}0.0191 * * * \\
(0.00317)\end{array}$ & $\begin{array}{l}0.110 * * * \\
(0.00453)\end{array}$ & $\begin{array}{l}0.0971 * * * \\
(0.00684)\end{array}$ \\
\hline Education-Secondary & $\begin{array}{c}-0.0318 * * * \\
(0.00153)\end{array}$ & $\begin{array}{c}-0.0545 * * * \\
(0.00234)\end{array}$ & $\begin{array}{l}-0.333 * * * \\
(0.00339)\end{array}$ & $\begin{array}{l}-0.362 * * * \\
(0.00485)\end{array}$ \\
\hline Education -Higher & $\begin{array}{c}-0.0383 * * * \\
(0.00163)\end{array}$ & $\begin{array}{c}-0.0882 * * * \\
(0.00242)\end{array}$ & $\begin{array}{l}-0.283 * * * \\
(0.00342)\end{array}$ & $\begin{array}{l}-0.404 * * * \\
(0.00498)\end{array}$ \\
\hline Number of literate & $\begin{array}{l}-0.0873 * * * \\
(0.000749)\end{array}$ & $\begin{array}{r}-0.207 * * * \\
(0.00112)\end{array}$ & $\begin{array}{r}-0.230 * * * \\
(0.00161)\end{array}$ & $\begin{array}{l}-0.182 * * * \\
(0.00235)\end{array}$ \\
\hline Activity-unemployed & $\begin{array}{l}0.222 * * * \\
(0.00421)\end{array}$ & $\begin{array}{l}0.360 * * * \\
(0.00604)\end{array}$ & $\begin{array}{l}0.638 * * * \\
(0.00816)\end{array}$ & $\begin{array}{c}0.768 * * * \\
(0.0110)\end{array}$ \\
\hline Activity-retired & $\begin{array}{c}0.0308^{* * *} * \\
(0.00205)\end{array}$ & $\begin{array}{l}0.130 * * * \\
(0.00306)\end{array}$ & $\begin{array}{l}0.156 * * * \\
(0.00446)\end{array}$ & $\begin{array}{l}0.114 * * * \\
(0.00655)\end{array}$ \\
\hline Number of employed & $\begin{array}{l}-0.177 * * * \\
(0.00106)\end{array}$ & $\begin{array}{l}-0.225 * * * \\
(0.00165)\end{array}$ & $\begin{array}{l}-0.320 * * * \\
(0.00247)\end{array}$ & $\begin{array}{l}-0.422 * * * \\
(0.00368)\end{array}$ \\
\hline Child1 & $\begin{array}{l}-0.282 * * * \\
(0.00132)\end{array}$ & $\begin{array}{l}-0.404 * * * \\
(0.00209)\end{array}$ & $\begin{array}{l}-0.579 * * * \\
(0.00330)\end{array}$ & $\begin{array}{l}-0.628 * * * \\
(0.00484)\end{array}$ \\
\hline Child2 & $\begin{array}{l}-0.143 * * * \\
(0.000928)\end{array}$ & $\begin{array}{l}-0.122 * * * \\
(0.00144)\end{array}$ & $\begin{array}{c}-0.0459 * * * \\
(0.00208)\end{array}$ & $\begin{array}{c}-0.0668 * * * \\
(0.00299)\end{array}$ \\
\hline Elderly & $\begin{array}{l}0.161 * * * \\
(0.00148)\end{array}$ & $\begin{array}{c}0.0785 * * * \\
(0.00212)\end{array}$ & $\begin{array}{l}0.146 * * * \\
(0.00298)\end{array}$ & $\begin{array}{l}0.377 * * * \\
(0.00416)\end{array}$ \\
\hline Surgery -last year & $\begin{array}{l}1.699 * * * \\
(0.00155)\end{array}$ & $\begin{array}{l}1.582 * * * \\
(0.00197)\end{array}$ & $\begin{array}{l}1.552 * * * \\
(0.00275)\end{array}$ & $\begin{array}{l}1.559 * * * \\
(0.00390)\end{array}$ \\
\hline HH size-mid populated & $\begin{array}{l}-0.181 * * * \\
(0.00286)\end{array}$ & $\begin{array}{l}-0.130 * * * \\
(0.00411)\end{array}$ & $\begin{array}{l}-0.312 * * * \\
(0.00586)\end{array}$ & $\begin{array}{l}-0.715 * * * \\
(0.00870)\end{array}$ \\
\hline HH size-high populated & $\begin{array}{c}-0.0554 * * * \\
(0.00432)\end{array}$ & $\begin{array}{l}0.318 * * * \\
(0.00639)\end{array}$ & $\begin{array}{l}0.198 * * * \\
(0.00916)\end{array}$ & $\begin{array}{c}-0.111 * * * \\
(0.0133)\end{array}$ \\
\hline Internet & $\begin{array}{l}-0.288 * * * \\
(0.00185)\end{array}$ & $\begin{array}{l}-0.456 * * * \\
(0.00283)\end{array}$ & $\begin{array}{c}-0.602 * * * \\
(0.00418)\end{array}$ & $\begin{array}{c}-0.516^{* * * *} \\
(0.00588)\end{array}$ \\
\hline TV & $\begin{array}{l}-0.351 * * * \\
(0.00348)\end{array}$ & $\begin{array}{l}-0.282 * * * \\
(0.00513)\end{array}$ & $\begin{array}{l}-0.121 * * * \\
(0.00793)\end{array}$ & $\begin{array}{c}-0.258 * * * \\
(0.0111)\end{array}$ \\
\hline Constant & $\begin{array}{l}-0.523 * * * \\
(0.00672)\end{array}$ & $\begin{array}{l}-1.567 * * * \\
(0.00983)\end{array}$ & $\begin{array}{c}-2.216^{* * *} \\
(0.0144)\end{array}$ & $\begin{array}{c}-2.102 * * * \\
(0.0202)\end{array}$ \\
\hline Observations & $20,485,463$ & $20,485,463$ & $20,485,463$ & $20,297,580$ \\
\hline
\end{tabular}

Notes: $* * * p<0.01, * * p<0.05, * p<0.1$. Standard errors in parentheses. 
Table 2-6 Determinants of CHE Overshoot, Iran 2013

\begin{tabular}{|c|c|c|c|c|}
\hline & (1) & (2) & (3) & (4) \\
\hline VARIABLES & Threshold $10 \%$ & Threshold $20 \%$ & Threshold $30 \%$ & Threshold $40 \%$ \\
\hline Quintile - 2nd & $\begin{array}{c}0.00260 * * * \\
(5.38 \mathrm{e}-05)\end{array}$ & $\begin{array}{c}0.00191 * * * \\
(3.72 \mathrm{e}-05)\end{array}$ & $\begin{array}{c}0.00120 * * * \\
(2.49 \mathrm{e}-05)\end{array}$ & $\begin{array}{c}0.000685 * * * \\
(1.61 \mathrm{e}-05)\end{array}$ \\
\hline Quintile - Middle & $\begin{array}{c}0.00846 * * * \\
(5.45 \mathrm{e}-05)\end{array}$ & $\begin{array}{c}0.00531 * * * \\
(3.77 \mathrm{e}-05)\end{array}$ & $\begin{array}{c}0.00257 * * * \\
(2.53 \mathrm{e}-05)\end{array}$ & $\begin{array}{c}0.00115 * * * \\
(1.63 \mathrm{e}-05)\end{array}$ \\
\hline Quintile - 4th & $\begin{array}{l}0.0129 * * * \\
(5.54 \mathrm{e}-05)\end{array}$ & $\begin{array}{c}0.00834 * * * \\
(3.83 \mathrm{e}-05)\end{array}$ & $\begin{array}{c}0.00476 * * * \\
(2.57 \mathrm{e}-05)\end{array}$ & $\begin{array}{c}0.00242 * * * \\
(1.66 \mathrm{e}-05)\end{array}$ \\
\hline Quintile - Richest & $\begin{array}{l}0.0262 * * * \\
(5.74 \mathrm{e}-05)\end{array}$ & $\begin{array}{l}0.0182 * * * \\
(3.97 \mathrm{e}-05)\end{array}$ & $\begin{array}{l}0.0111 * * * \\
(2.66 \mathrm{e}-05)\end{array}$ & $\begin{array}{c}0.00613 * * * \\
(1.72 \mathrm{e}-05)\end{array}$ \\
\hline Urban & $\begin{array}{c}0.000399 * * * \\
(3.65 \mathrm{e}-05)\end{array}$ & $\begin{array}{c}-0.000113 * * * \\
(2.52 \mathrm{e}-05)\end{array}$ & $\begin{array}{c}-0.000220 * * * \\
(1.69 \mathrm{e}-05)\end{array}$ & $\begin{array}{c}-0.000170 * * * \\
(1.09 \mathrm{e}-05)\end{array}$ \\
\hline Age & $\begin{array}{c}-8.97 \mathrm{e}-05 * * * \\
(1.69 \mathrm{e}-06)\end{array}$ & $\begin{array}{c}-6.62 \mathrm{e}-05 * * * \\
(1.17 \mathrm{e}-06)\end{array}$ & $\begin{array}{c}-4.02 \mathrm{e}-05^{* * *} \\
(7.85 \mathrm{e}-07)\end{array}$ & $\begin{array}{c}-1.85 \mathrm{e}-05^{* * * *} \\
(5.08 \mathrm{e}-07)\end{array}$ \\
\hline Female & $\begin{array}{c}0.000773 * * * \\
(5.72 \mathrm{e}-05)\end{array}$ & $\begin{array}{c}0.00135 * * * \\
(3.96 \mathrm{e}-05)\end{array}$ & $\begin{array}{c}0.000875 * * * \\
(2.65 \mathrm{e}-05)\end{array}$ & $\begin{array}{c}0.000605^{* * *} * \\
(1.72 \mathrm{e}-05)\end{array}$ \\
\hline Education-Secondary & $\begin{array}{c}-0.00263 * * * \\
(3.82 \mathrm{e}-05)\end{array}$ & $\begin{array}{c}-0.00234 * * * \\
(2.64 \mathrm{e}-05)\end{array}$ & $\begin{array}{c}-0.00171 * * * \\
(1.77 \mathrm{e}-05)\end{array}$ & $\begin{array}{c}-0.000922 * * * \\
(1.15 \mathrm{e}-05)\end{array}$ \\
\hline Education-Higher & $\begin{array}{c}-0.00403 * * * \\
(4.13 \mathrm{e}-05)\end{array}$ & $\begin{array}{c}-0.00345 * * * \\
(2.86 \mathrm{e}-05)\end{array}$ & $\begin{array}{c}-0.00251 * * * \\
(1.92 \mathrm{e}-05)\end{array}$ & $\begin{array}{c}-0.00157 * * * \\
(1.24 \mathrm{e}-05)\end{array}$ \\
\hline Number of literate & $\begin{array}{c}-0.00338 * * * \\
(1.86 \mathrm{e}-05)\end{array}$ & $\begin{array}{c}-0.00197 * * * \\
(1.29 \mathrm{e}-05)\end{array}$ & $\begin{array}{c}-0.000867 * * * \\
(8.63 \mathrm{e}-06)\end{array}$ & $\begin{array}{c}-0.000335 * * * \\
(5.58 \mathrm{e}-06)\end{array}$ \\
\hline Activity-unemployed & $\begin{array}{c}0.00866 * * * \\
(0.000108)\end{array}$ & $\begin{array}{c}0.00566 * * * \\
(7.50 \mathrm{e}-05)\end{array}$ & $\begin{array}{c}0.00371 * * * \\
(5.03 \mathrm{e}-05)\end{array}$ & $\begin{array}{c}0.00192 * * * \\
(3.25 \mathrm{e}-05)\end{array}$ \\
\hline Activity-retired & $\begin{array}{c}0.00200 * * * \\
(5.22 \mathrm{e}-05)\end{array}$ & $\begin{array}{c}0.00109 * * * \\
(3.61 \mathrm{e}-05)\end{array}$ & $\begin{array}{c}0.000206 * * * \\
(2.42 \mathrm{e}-05)\end{array}$ & $\begin{array}{l}-1.64 \mathrm{e}-05 \\
(1.57 \mathrm{e}-05)\end{array}$ \\
\hline Number of employed & $\begin{array}{c}-0.00468 * * * \\
(2.55 \mathrm{e}-05)\end{array}$ & $\begin{array}{c}-0.00264 * * * \\
(1.77 \mathrm{e}-05)\end{array}$ & $\begin{array}{c}-0.00148 * * * \\
(1.18 \mathrm{e}-05)\end{array}$ & $\begin{array}{c}-0.000715 * * * \\
(7.66 \mathrm{e}-06)\end{array}$ \\
\hline Child1 & $\begin{array}{c}-0.00714 * * * \\
(3.08 \mathrm{e}-05)\end{array}$ & $\begin{array}{c}-0.00387 * * * \\
(2.13 \mathrm{e}-05)\end{array}$ & $\begin{array}{c}-0.00194 * * * \\
(1.43 \mathrm{e}-05)\end{array}$ & $\begin{array}{c}-0.000842 * * * \\
(9.25 \mathrm{e}-06)\end{array}$ \\
\hline Child2 & $\begin{array}{c}-0.00105 * * * \\
(2.18 \mathrm{e}-05)\end{array}$ & $\begin{array}{c}-0.000227 * * * \\
(1.51 \mathrm{e}-05)\end{array}$ & $\begin{array}{c}-0.000102 * * * \\
(1.01 \mathrm{e}-05)\end{array}$ & $\begin{array}{c}-9.35 \mathrm{e}-05^{* * *} \\
(6.53 \mathrm{e}-06)\end{array}$ \\
\hline Elderly & $\begin{array}{c}0.00383 * * * \\
(3.97 \mathrm{e}-05)\end{array}$ & $\begin{array}{c}0.00218 * * * \\
(2.74 \mathrm{e}-05)\end{array}$ & $\begin{array}{c}0.00162 * * * \\
(1.84 \mathrm{e}-05)\end{array}$ & $\begin{array}{c}0.000959 * * * \\
(1.19 \mathrm{e}-05)\end{array}$ \\
\hline Surgery -last year & $\begin{array}{l}0.0488 * * * \\
(4.69 \mathrm{e}-05)\end{array}$ & $\begin{array}{l}0.0243 * * * \\
(3.24 \mathrm{e}-05)\end{array}$ & $\begin{array}{l}0.0121 * * * \\
(2.17 \mathrm{e}-05)\end{array}$ & $\begin{array}{c}0.00584 * * * \\
(1.41 \mathrm{e}-05)\end{array}$ \\
\hline HH size-mid populated & $\begin{array}{c}-0.00822 * * * \\
(7.92 \mathrm{e}-05)\end{array}$ & $\begin{array}{c}-0.00528 * * * \\
(5.48 \mathrm{e}-05)\end{array}$ & $\begin{array}{c}-0.00377 * * * \\
(3.67 \mathrm{e}-05)\end{array}$ & $\begin{array}{c}-0.00264 * * * \\
(2.37 \mathrm{e}-05)\end{array}$ \\
\hline HH size-high populated & $\begin{array}{c}-0.00226 * * * \\
(0.000111)\end{array}$ & $\begin{array}{c}-0.00183 * * * \\
(7.67 \mathrm{e}-05)\end{array}$ & $\begin{array}{c}-0.00223 * * * \\
(5.14 \mathrm{e}-05)\end{array}$ & $\begin{array}{c}-0.00221 * * * \\
(3.33 \mathrm{e}-05)\end{array}$ \\
\hline Internet & $\begin{array}{c}-0.0104 * * * \\
(4.63 \mathrm{e}-05)\end{array}$ & $\begin{array}{c}-0.00592 * * * \\
(3.20 \mathrm{e}-05)\end{array}$ & $\begin{array}{c}-0.00336 * * * \\
(2.15 \mathrm{e}-05)\end{array}$ & $\begin{array}{c}-0.00173 * * * \\
(1.39 \mathrm{e}-05)\end{array}$ \\
\hline TV & $\begin{array}{c}-0.00574 * * * \\
(9.56 \mathrm{e}-05)\end{array}$ & $\begin{array}{c}-0.00289 * * * \\
(6.61 \mathrm{e}-05)\end{array}$ & $\begin{array}{c}-0.00193 * * * \\
(4.43 \mathrm{e}-05)\end{array}$ & $\begin{array}{c}-0.00147 * * * \\
(2.87 \mathrm{e}-05)\end{array}$ \\
\hline Constant & $\begin{array}{l}0.0476 * * * \\
(0.000178)\end{array}$ & $\begin{array}{l}0.0247 * * * \\
(0.000123)\end{array}$ & $\begin{array}{l}0.0141 * * * \\
(8.26 \mathrm{e}-05)\end{array}$ & $\begin{array}{c}0.00749 * * * \\
(5.34 \mathrm{e}-05)\end{array}$ \\
\hline Observations & $20,485,463$ & $20,485,463$ & $20,485,463$ & $20,485,463$ \\
\hline R-squared & 0.092 & 0.057 & 0.038 & 0.025 \\
\hline
\end{tabular}

Notes: $* * * \mathrm{p}<0.01, * * \mathrm{p}<0.05, * \mathrm{p}<0.1$. Standard errors in parentheses. 
Table 2-7 presents poverty headcounts and the effects of accounting for OOP expenditures for health care on poverty. We estimated the results based on total household expenditure and found that $6.28 \%$ of households in Iran assessed to be in poverty, which is aligned with the existing studies based on the same poverty line (e.g., see, Karakurum-Ozdemir et al., 2016). In the case of total household expenditure net out of OOP spending on health, the rate rises to $7.68 \%$. Therefore, $1.4 \%$ of Iranian households do not count as living in poverty; however, after adjusting household resources for OOP spending on health care, these households fall beneath the poverty line. Moreover, the estimate of the poverty gap rises from (201,166 IRR) to (252,140 IRR), more than a $25 \%$ change in relative term. Normalized poverty gap changed $0.34 \%$ percentage points, which is about a $25 \%$ increase relative to the original rate.

Table 2-7 Impact of Out-Of-Pocket Payments on Incidence and Intensity of Poverty

\begin{tabular}{lllll}
\hline & Pre-payment & Post-payment & Absolute Diff & Relative Diff \\
\hline Poverty Head Count & $6.28 \%$ & $7.68 \%$ & $1.40 \%$ & $22.34 \%$ \\
Standard Error & 0.0013 & 0.0014 & 0.0006 & \\
Poverty Gap (IRR) & $201,166.80$ & $252,140.90$ & $50,974.06$ & $25.34 \%$ \\
Standard Error & 5291.31 & 5938.28 & 1808.39 & \\
Normalized Poverty Gap & $1.32 \%$ & $1.66 \%$ & $0.34 \%$ & $25.34 \%$ \\
Standard Error & 0.0003 & 0.0004 & 0.0001 & \\
\hline
\end{tabular}

Figure 2-4 is a version of Pen's Parade, which shows the impoverishment effects of OOP health care payments. Households rankings ran from poorest to richest based on total expenditure per capita in the y-axis. Many households already below the poverty line, $\$ 5.5$ per day per capita (PPP), based on total expenditure before OOP payments, ended up even further below the threshold after total household expenditures were net out of OOP spending on health. Furthermore, we observe that the number of households close to the poverty line, or even in the middle or top end 
of the distribution above the poverty line, fell below the poverty line when subtracting the OOP expenditures from their total household expenditure.

Figure 2-4 Poverty Impact on Pen's Parade of Total Expenditure before and after Subtracting Health Per-Capita Expenditure using the National Poverty Line

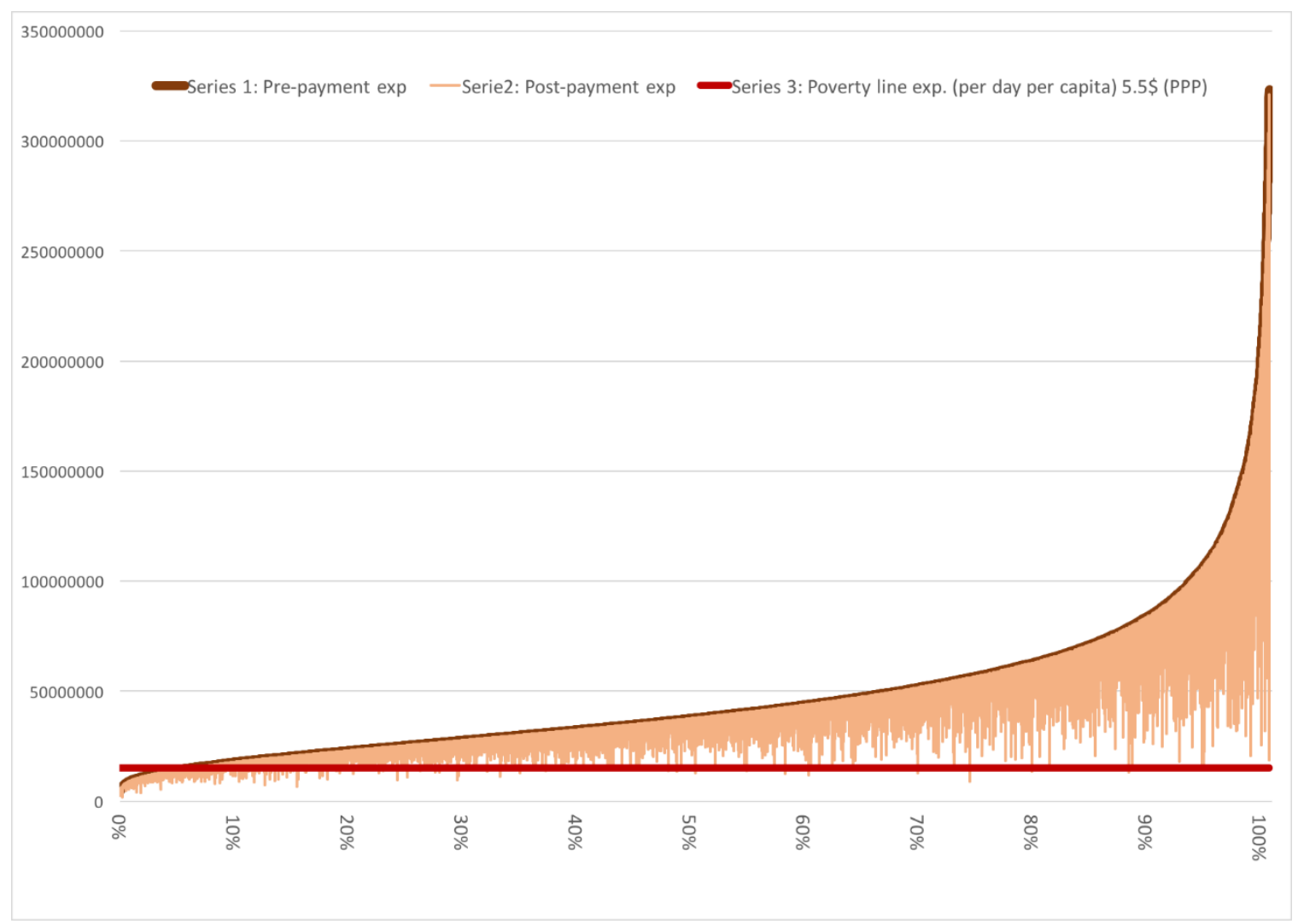

\subsection{Conclusion}

In this study, we measure the financial risks associated with OOP expenditure for health, particularly the impact on incidence and intensity of CHE as well as the effect on impoverishment and poverty. This study also observes that in the absence of universal health insurance in Iran, along with a high share of OOP spending for health care (more than 52\%), the Iranian households facing CHE will eventually face poverty. We find that OOP spending on health care incurred CHE for more than $20 \%$ of the households at the $10 \%$ threshold level; however, this was more concentrated in urban areas (20.9\%) than in rural areas (19.3\%) and in households of the wealthiest segment of the population. Furthermore, this study found that several demographic characteristics, as well as 
expenditure quintiles, contributed to the incidence and intensity of CHE. Findings in this study suggest that $1.4 \%$ of total households fall into poverty annually due to OOP health care spending, which, in relative terms, is about $22.34 \%$ more households. This represses the impoverishment effect of such spending on health care, increasing the poverty gap from 201,166 IRR to 252,140 IRR in the case of total household expenditure net of OOP expenditure for health. This is accountable for $0.34 \%$ increase in the normalized poverty gap.

This study provides a detailed analysis of critical issues related to OOP spending on health care and financial difficulties due to direct health expenditures in Iran. Only a few studies investigate the financial risks of mean CHE headcount and its concentration indices (CI), CHE mean positive overshoot, poverty headcount, and poverty gap by employing nationally representative data. Some of the findings in this study are in line with studies such as KarakurumOzdemir et al. (2016) and Hajizadeh and Nghiem (3011). A detailed investigation of impoverishment and the poverty effects of OOP on health that contribute to this body of literature are explained in this study.

Unlike previous studies in Iran, this paper analyzed data at the national level and took the research a step further by examining urban and rural areas separately. Also, this study provides an understanding of the impacts of OOP payments for health care on CHE and poverty by disaggregating the analysis into urban and rural areas and different socioeconomic segments of the population. Findings suggest a pro-rich incidence and intensity of CHE in all threshold levels (5\%, to $40 \%$ of total expenditure) in both rural and urban areas. Hence, the $\mathrm{CI}$ is positive, meaning households belonging to the wealthiest segment of the population seem to have suffered the most from catastrophic payments throughout the analysis. 


\subsection{REFERENCES}

Berki, S. (1986). A Look at Catastrophic Medical Expenses and the Poor. Health Affairs, 138-145.

Caliendo, M., \& Kopeinig, S. (2008). SOME PRACTICAL GUIDANCE FOR THE IMPLEMENTATION OF PROPENSITY SCORE MATCHING. Journal of Economic Surveys, 199-215.

Chuma, J., \& Maina, T. (2012). Catastrophic health care spending and impoverishment in Kenya. BMC Health Services, 12(413), 9.

Chuma, J., Gilson, L., \& Molyneux, C. (2007). Treatment-seeking behaviour, cost burdens and coping strategies among rural and urban households in Coastal Kenya: an equity analysis. Tropical Medicine and International Health, 673-686.

Doorslaer, E. V., Masseria, C., \& Koolman, X. (2006). countries, Inequalities in access to medical care by income in developed. Canadian Medical Association Journal, 177-183.

Dorjdagva, J., Batbaatar, E., Svensson, M., Dorjsuren, B., \& Kauhanen, J. (2016). Catastrophic health expenditure and impoverishment in Mongolia. International Journal for Equity in Health, 9.

Gertler, P., \& Gruber, J. (2002). Insuring Consumption Against Illness. American Economic Review, 92(1), 51-70.

Hajizadeh, M., \& Nghiem, H. S. (2011). Out-of-pocket expenditures for hospital care in Iran: who is at risk of incurring catastrophic payments? International Journal of Health Care Finance and Economics, 11(4), 267-285. doi:DOI 10.1007/s10754-011-9099-1

Karakurum-Ozdemir, K., Le Borgne, E., Mobasher Fard, S., Hayati, F., Matta, S. N., Kazemi Najaf Abadi, M., . . . Salim, M. A. (2016). Iran economic monitor : towards reintegration. Washington, D.C.: World Bank Group.

Karakurum-Ozdemir, K., Le Borgne, E., Mobasher Fard, S., Hayati, F., Matta, S. N., Kazemi Najaf Abadi, M., . . . Salim, M. A. (2016). Iran economic monitor: towards reintegration. Washington, D.C.: World Bank Group.

Kochar, A. (1995). Explaining Household Vulnerability to Idiosyncratic Income Shocks. The American Economic Review, 85(2), 159-164.

Mehrdad, R. (2009). Health System in Iran. International Medical Community, 52(1), 69-73.

O’Donnell, O., van Doorslaer, E., Wagstaff, A., \& Lindelow, M. (2008). Analyzing Health Equity Using Household Survey Data: A Guide to Techniques and Their Implementation. Washington, D.C.: The World Bank.

Russell, S. (2004). The Economic Burden of Illness for Households in Developing Countries: A Review of Studies Focusing on Malaria, Tuberculosis, and Human Immunodeficiency Virus/Acquired Immunodeficiency Syndrome. American Journal of Tropical Medicine and Hygiene, 147-155. 
Saksena, P., Hsu, J., \& B., E. D. (2014). Financial Risk Protection and Universal Health Coverage: Evidence and Measurement Challenges. PLOS $\mid$ Medicine, 11(9), 1-11.

Saksena, P., Hsu, J., \& Evans, D. B. (2014, September). Financial Risk Protection and Universal Health Coverage: Evidence and Measurement Challenges. PLOS $\mid$ Medicine, 11(9).

Smith, O., \& Nguyen, S. N. (2013). Getting Better : Improving Health System Outcomes in Europe and Central Asia. Washington, D.C.: International Bank for Reconstruction and Development.

Wagstaff, A., \& Doorslaer, E. v. (2002). Catastrophe and Impoverishment. The World Bank, 32.

Wagstaff, A., \& Doorslaer, E. V. (2003). Catastrophe and impoverishment in paying for health care: with applications to Vietnam 1993-1998. Journal of Health Economics, 12(11), 921934.

Wagstaff, A., O'Donnell, O. D., \& Lindelow, M. (2008). Analyzing Health Equity Using Household Survey Data. Washington, D.C.: The International Bank for Reconstruction and Development.

World Bank Group. (n.d.). Health Care Payments and Poverty.

World Health Organization. (2010). The world health report: health systems financing: the path to universal coverage. The world health report: health systems nancing: the path to universal coverage.: World Health Organization.

World Health Organization. (2017, December 31). Universal health coverage . Retrieved from World Health Organization: http://www.who.int/en/news-room/factsheets/detail/universal-health-coverage-(uhc)

World Health Organization. (2018, January). Health Financing. Retrieved from Out-of-pocket payments, user fees and catastrophic expenditure: http://www.who.int/health_financing/topics/financial-protection/out-of-pocketpayments/en/

Worlds Health Organization. (2005, April 7). WHO. Retrieved from Sustainable health financing, universal coverage and social health insurance: http://apps.who.int/iris/bitstream/handle/10665/20302/A58_20-en.pdf?sequence=1

Wyszewianski, L. (1986). Financially Catastrophic and High-Cost Cases: Definitions, Distinctions, and Their Implications for Policy Formulation. Blue Cross and Blue Shield Association, 382-394.

Xu, K., Evans, D. B., Carrin, G. A.-R., Musgrove, P., \& Evans, T. (2007). Protecting Households From Catastrophic Health Spending. Journal of Health Affaird, 26(4), 972-983.

Xu, K., Evans, D. B., Kawabata, K., Zeramdini, R., Klavus, J., \& Murray, C. J. (2003, July 12). Household catastrophic health expenditure: a multicountry analysis. 362, 111-117. 
Xu, K., Evans, D. B., Mald, K. K., Zeramdini, R., Klavus, J., \& Murray, C. J. (2003). Household catastrophic health expenditure: a multicountry analysis. The Lancet, 362(9378), 111-117. 


\section{Chapter 3}

\section{CATASTROPHIC HEALTH CARE EXPENDITURE AND THE HEALTH REFORM IN IRAN}

\subsection{Introduction}

One of the main goals of universal health coverage is the protection against financial risk due to medical expenditure. A good health care system must protect households against CHE that can be brought on by unexpectedly high levels of out-of-pocket health care expenditures ( $\mathrm{Su}$, Kouyate, \& Flessa, 2006; Xu et al., 2003) that forces at-risk household members to cut down their consumption, minimize their needs, and/or face poverty. Household surveys conducted in by the WHO show that, on average, 100 million individuals worldwide are impoverished, and another 150 million individuals face severe financial difficulties during any given year because of direct health care expenditures. Within that picture, the Iranian government carried out health care reform to improve the well-being of its citizens by increasing protection against high levels of out-of-pocket health expenditures and its consequences such as CHE.

With regard to the importance of this issue, our study investigates the effects of the 2014 universal health care insurance program on Iranian households' OOP health care expenditures and incidences of CHE. It is important to know the risk factors and consequences of high, out-of-pocket health care expenditures faced by affected households. An evaluation of this program will shed light on whether the reform health care program has met its goals for improving the health status as well as in providing financial protection for the poorest segment of the population.

Through the HIES, which covers more than 2,400 households, we evaluate the effect of the program on CHE. To estimate the Average Treatment Effect (ATE), we draw on rotating panel data of Iranian household budgets for 2013-2014 and match difference-in-differences (DID) propensity scores to compare households that received the benefit from universal health insurance with households that were not part of the program. Neither of these types of households had any 
health insurance during the first year. The benchmark results show that the program was successful and the effect is negative and significant, implying that the program decreased the rate of CHE. Here we follow the same approach as previous chapter for the occurrence of CHE for different thresholds levels to shed light on CHE and its risk factors among Iranian households.

Besides Iran, many other countries cannot ensure universal health coverage (access to critical health interventions and services) due to the lack of sufficient funds to cover its financial burden. The WHO states that with universal health coverage "all people and communities can use the promotive, preventive, curative, rehabilitative and palliative health services they need, of sufficient quality to be effective, while also ensuring that the use of these services does not expose the user to financial hardship." (World Health Organization, 2017) One of the most important issues is to protect households against financial risks due to out-of-pocket expenditures.

Figure 3-1 shows the degree to which Iranian households suffer from high rates of out-ofpocket health expenditure compared with other regions. Iran incurs a relatively high rate of out-ofpocket health expenditure, i.e. $52.1 \%$ in 2013 - this rate, on average, is $18.6 \%$ worldwide and $34.4 \%$ in the Middle East and North Africa. As a result, Iranian household members have a greater risk of having to use their savings, to borrow money, or to sell their assets to cover health care expenses. 
Figure 3-1 Out-of-Pocket Health Expenditure - 2013

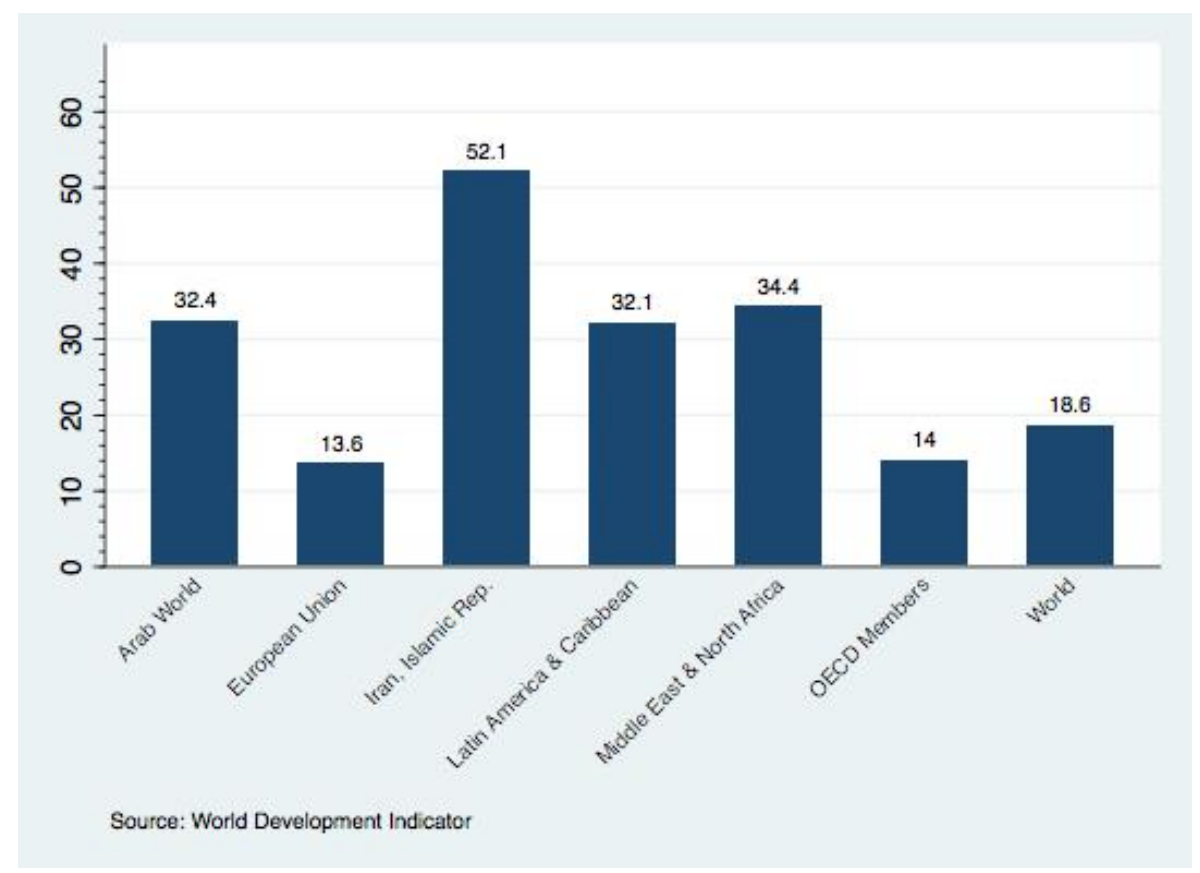

Furthermore, Table 3-1 places Iran among the top 30 countries with the highest rate of outof-pocket health expenditure in 2013. This combined evidence increases the possibility that Iranian households will experience CHE. The need for more financial protection in times of adversity makes strengthening the health financing system essential for this country. There have been few empirical studies related to our study. For example, Piroozi, Moradi, Nouri, Bolbanabad, and Safari (2016) studied this health reform program using data gathered from the Iranian city of Sanandaj utilizing logistic regression and comparing results with previous studies of different provinces of Iran. In this study, we improve upon this earlier research in several ways. First, we use a national panel data that gives us the advantage and ability to evaluate the program at the national level. Second, to identify the average treatment effect, we investigate the impact of the program using DID and DID propensity score matching methods. Moreover, by using a novel dataset, this study seeks to provide new insights into the literature on catastrophic health care expenditure and its welfare impact to evaluate the program and its effect on CHE. 
Table 3-1 Rate of out-of-pocket health expenditure - Country Ranking (2013)

\begin{tabular}{lllllc}
\hline Rank & Country & Value & Rank & Country & Value \\
\hline 01 & Sudan & 75.82 & 16 & Cambodia & 59.74 \\
02 & Yemen & 74.06 & 17 & Morocco & 58.36 \\
03 & Afghanistan & 73.79 & 18 & India & 58.21 \\
04 & Azerbaijan & 71.06 & 19 & Egypt & 57.97 \\
05 & Nigeria & 69.35 & 20 & St. Kitts and Nevis & 57.34 \\
06 & Venezuela & 68.83 & 21 & Singapore & 56.79 \\
07 & Myanmar & 68.20 & 22 & Philippines & 56.67 \\
08 & Georgia & 61.91 & 23 & Paraguay & 56.63 \\
09 & Cameroon & 61.48 & 24 & Guinea & 56.44 \\
10 & Sierra Leone & 61.32 & 25 & Pakistan & 54.87 \\
11 & Chad & 61.02 & 26 & Armenia & 54.69 \\
12 & Bangladesh & 60.23 & 27 & Eritrea & 54.60 \\
13 & Tajikistan & 60.12 & 28 & Syrian Arab Republic & 53.94 \\
14 & Mali & 60.08 & 29 & Niger & 53.08 \\
15 & Sao Tome and Principe & 59.94 & 30 & Iran & 52.11 \\
\hline Souran
\end{tabular}

Source: World Health Organization Global Health Expenditure database

In the following section, we explain in detail the health care reform carried out by the Iranian government with the aim of improving the well-being of its citizens by decreasing CHE. We use a rich panel data of households observed before and after the implementation of the program to examine the impact of universal health insurance on out-of-pocket health expenditure and incidence of CHE among Iranian households. Our aim is for the results to shed light on whether or not the reform program met its goals and, if so, to what extent the program was successful to improve the health status of Iranians.

\subsection{Iranian health system reform ${ }^{4}$}

Since 2014, plans to revolutionize Iran's health sector in order to achieve universal health coverage and reduce out-of-pocket health expenditures as a percentage of total health expenditures have been in place. The program's goal is to provide universal health insurance and those who do not already have health insurance (through the last year) are eligible to register. The program is not

\footnotetext{
${ }^{4}$ We draw all information about Iranian health system reform from the formal webpage of National Institute of Health Research affiliated to Health Ministry, available at here.
} 
mandatory at this stage and those who are eligible can choose to register online. The government will pay all premiums for insurance plans for those who register.

The final goals of this reform are to increase the accountability of the health system, decrease out-of-pocket expenditures and the percentage of households that incur CHE, improve health conditions for urgent care patients, and increase natural childbirth. We follow these goals through eight executive mechanisms. Two of these mechanisms include a decrease in payments for inpatient services, in that, first, all patients with basic health insurance who are hospitalized in public hospitals will pay either $10 \%$ of the hospital bill if they are urban residents, or $5 \%$ of the hospital bill if they are from rural areas or towns with less than 20,000 residents. Patients or their companions won't be referred outside of the hospital for drug provision, lab tests, and imaging. Secondly, financial protection is possible for patients contracting chronic and incurable diseases. In other words, Citizens with specific chronic diseases are financially protected via procedures predicted in this reform (See footnote 4).

These mechanisms show how the program attempts to decrease the out of pocket health expenditures and CHE. Three evaluations by the Iranian government since the inception of the program are available. According to Figure 3-2, in the early months after its inception, an evaluation shows an average out-of-pocket health expenditure rate of about $8 \%$ for Iran. This is a surprisingly low rate compared with the average rate of $52.64 \%$ discussed earlier. 
Figure 3-2 Health Care Expenditure Composition

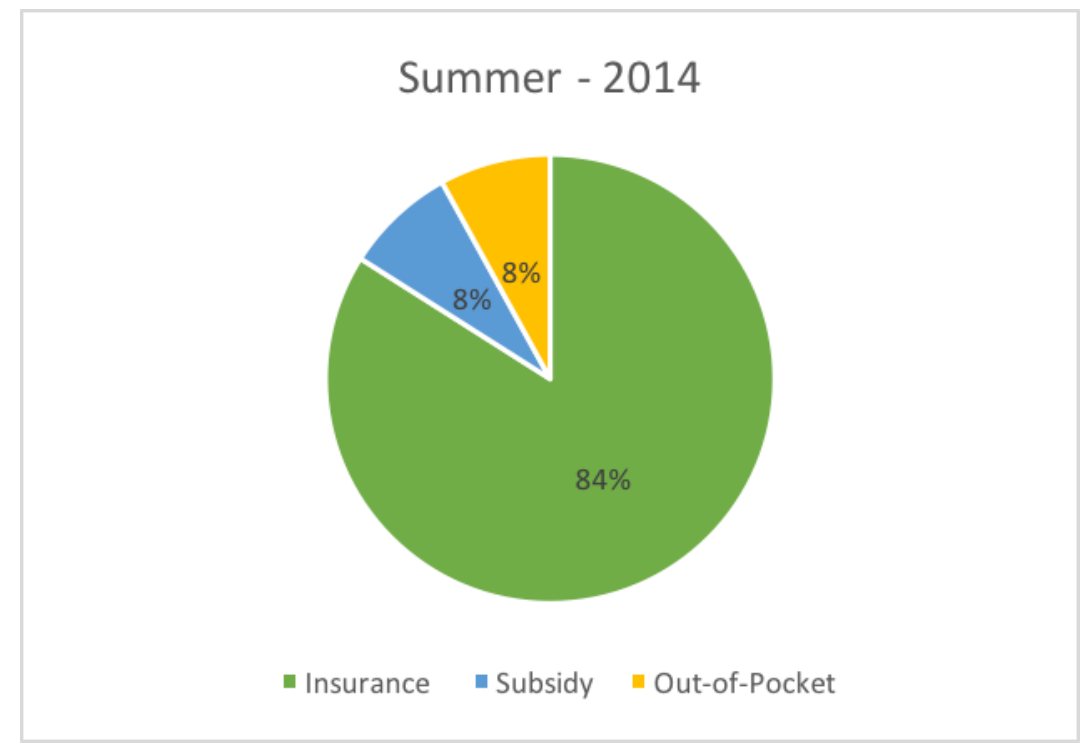

Table 3-2 provides a more detailed accounting of average out-of-pocket health care expenditures from these evaluations. During the spring of 2014, the level of out-of-pocket health care expenditures for both rural and urban areas increased compared with the same time during the previous year. However, this increase is far less than the increase of the summer of 2013. Most importantly, at the end of the summer of 2014, the average out-of-pocket health care expenditure declined to $31.5 \%$ and $32 \%$, respectively, for rural and urban areas, compared with the same time during the previous year. This evidence might suggest that the decline in the level of out-of-pocket health care expenditure could reflect a decline in CHE as well; however, this claim requires examination.

Table 3-2 Annual percentage change of average out-of-pocket health care expenditure

\begin{tabular}{llll}
\hline Household Type & Season & year & Annual Change \% \\
\hline \multirow{4}{*}{ Rural } & \multirow{2}{*}{ Spring } & 2013 & 30.2 \\
& & 2014 & 13.6 \\
\cline { 2 - 4 } & \multirow{2}{*}{ Summer } & 2013 & 41.9 \\
& \multirow{2}{*}{ Spring } & 2014 & -31.5 \\
\cline { 2 - 4 } & \multirow{2}{*}{ Urban } & 2013 & 18.7 \\
& \multirow{2}{*}{ Summer } & 2014 & 2.5 \\
\hline
\end{tabular}




\subsection{Data}

This study uses the HIES for 2013 and 2014 of both urban and rural Iranian households compiled by the SCI. HIES covers national regions without excluding any specific geographic areas. The main purpose of HIES is to estimate household income/expenditures for national accounts at provincial and country levels and the data includes income and expenditures information for both urban and rural households of Iran. The sample size varies from year to year to represent population and demographic changes. Initially, the data collected was a yearly crosssection sample of households representing the country's population; however, since 2010 SCI collects data as a rotating panel. With this change, we can evaluate the health reform program that started in May of 2014. The HIES data we use includes a year prior to the start of the program (2013) and continues a year after the start of the program (2014). The data includes 2,455 households that did not pay a premium for an insurance plan in 2013 (household surveys of both 2013 and 2014 are evaluated).

A possible issue of using this data is the problem of adverse selection that occurs when asymmetric information exists in a market. Individuals who are more susceptible to disease or those who have pre-existing health conditions may register for the program, whereas others might procrastinate or even ignore registering. However, as the program is free for eligible individuals (those who did not have any insurance plan throughout the previous year) the problem of adverse selection will not arise in this case, that is, there is no cost for the program and hence everyone eligible has an incentive to register for it.

Another issue may arise from having free insurance: those individuals with an insurance plan may opt out of their current plan and join the free plan offered by the government. Because, as previously stated, this plan is available only to those who did not have any kind of insurance through the previous year, the only way to become eligible is to resign from one's current plan and wait one year to join the program. This loophole weakens the program but not the evaluation. In 
this paper, we study the average treatment effect of the program on CHE for those who are eligible at the beginning of the program. Those who decide to cheat the program and wait one year to be entitled are not among eligible individuals that are the focus of this study.

\subsubsection{Treatment}

The treatment group includes those who did not pay any kind of health insurance premium in 2013 in which the government paid a premium on their behalf in 2014, which means that the only source of premium paid was by the government, on behalf of the household. The comparison group includes those who did not pay any kind of health insurance premium in either years (2013 and 2014). From our total sample of eligible households (2,455 households), 25 percent of households (609 households) have received treatment in 2014 while others still do not possess any kind of insurance plan. Table 3-3 and Table 3-4 present the summary statistics of the treatment group and contrast them with the characteristics of the comparison group. These characteristics do not show a large difference between the two samples, the groups are similar in their main characteristics, though the program group is larger in urban areas, with slightly less educated individuals having a lower rate of surgery during the last year.

Table 3-3 Summary of data

\begin{tabular}{lllll}
\hline & Treatment & \multicolumn{3}{l}{ Comparison } \\
\cline { 2 - 5 } & Mean & Std. Dev. & Mean & Std. Dev. \\
\hline Urban & .53 & .5 & .90 & .30 \\
Female & .13 & .34 & .15 & .35 \\
Literacy & .7 & .46 & .73 & .44 \\
Household Size & 3.47 & 1.53 & 3.49 & 1.69 \\
Age & 47.6 & 16.6 & 47.5 & 16.9 \\
\# of Literate & 2.44 & 1.54 & 2.5 & 1.57 \\
\# of Employed & .88 & .67 & .89 & .63 \\
\# Pre-School Child & .38 & .64 & .38 & .6 \\
\# Elderly & .27 & .58 & .28 & .59 \\
Surgery (Last Year) & .06 & .23 & .08 & .27 \\
Expenditure Decile & 3.41 & 2.82 & 3.4 & 2.77 \\
Observations & 609 & & 1846 & \\
\hline
\end{tabular}


Table 3-4 Summary of Data

\begin{tabular}{llll}
\hline & & Treatment & Comparison \\
\hline \multirow{3}{*}{ Education } & & \\
& Elementary \& Lower & 66.69 & 56.61 \\
& Secondary & 29.77 & 36.37 \\
& Higher & 3.54 & 7.03 \\
& & & \\
\multirow{5}{*}{ Activity } & Employed & 68.81 & 71.15 \\
& Unemployed & 4.79 & 2.73 \\
& Retired & 26.4 & 26.12 \\
\hline
\end{tabular}

Our motivation comes from studies such as Habicht et al. (2006) and Koch et al. (2017) who researched the effect on out-of-pocket expenditure and financial protection in public health care systems. Specifically, out-of-pocket payments that represent the burden of health care expenditures on households. Therefore, our first step was to compare the average rates of out-ofpocket payments and the significant divergence between these rates at the time of the program. These results motivated us to seek a more detailed investigation on this health reform. In doing so, we hope to increase the awareness of policy makers in targeting ample policy responses in other counties, specifically Iran.

Table 3-5 shows the incidence of CHE on health at different threshold levels across expenditure quintiles in rural and urban areas in 2013. Incidence of CHE drops as threshold levels increase from $5 \%$ to $40 \%$ in both rural and urban areas and also in all expenditure quintiles. We observe a higher incidence of $\mathrm{CHE}$ for the poorest segment of the population in rural areas, while finding a higher incidence of CHE for the better-off households in urban areas. 
Table 3-5 Proportion of households observing CHE on health at different threshold level across expenditure quintiles in rural/urban areas - Headcount 2013

\begin{tabular}{lcccccccc}
\hline Threshold & $\mathbf{5 \%}$ & $\mathbf{1 0 \%}$ & $\mathbf{1 5 \%}$ & $\mathbf{2 0 \%}$ & $\mathbf{2 5 \%}$ & $\mathbf{3 0 \%}$ & $\mathbf{3 5 \%}$ & $\mathbf{4 0 \%}$ \\
\hline Rural & & & & & & & & \\
Poorest & 0.70 & 0.44 & 0.29 & 0.16 & 0.11 & 0.09 & 0.08 & 0.05 \\
2nd & 0.54 & 0.30 & 0.16 & 0.06 & 0.03 & 0.03 & 0.02 & 0.02 \\
Middle & 0.46 & 0.27 & 0.19 & 0.09 & 0.04 & 0.03 & 0.01 & - \\
4th & 0.44 & 0.25 & 0.16 & 0.15 & 0.09 & 0.07 & 0.05 & 0.04 \\
Richest & 0.38 & 0.24 & 0.16 & 0.09 & 0.09 & 0.07 & 0.03 & 0.01 \\
Total & 0.51 & 0.30 & 0.19 & 0.11 & 0.07 & 0.06 & 0.04 & 0.02 \\
\hline Urban & & & & & & & & \\
Poorest & 0.51 & 0.23 & 0.14 & 0.09 & 0.06 & 0.04 & 0.03 & 0.01 \\
2nd & 0.45 & 0.22 & 0.13 & 0.09 & 0.07 & 0.04 & 0.02 & 0.02 \\
Middle & 0.43 & 0.25 & 0.15 & 0.11 & 0.07 & 0.06 & 0.04 & 0.04 \\
4th & 0.38 & 0.20 & 0.13 & 0.10 & 0.07 & 0.05 & 0.04 & 0.04 \\
Richest & 0.49 & 0.34 & 0.23 & 0.18 & 0.14 & 0.13 & 0.07 & 0.05 \\
Total & 0.46 & 0.24 & 0.15 & 0.10 & 0.07 & 0.05 & 0.04 & 0.03 \\
\hline Total & & & & & & & & \\
Poorest & 0.56 & 0.28 & 0.18 & 0.11 & 0.07 & 0.05 & 0.04 & 0.02 \\
2nd & 0.48 & 0.25 & 0.14 & 0.08 & 0.06 & 0.04 & 0.02 & 0.02 \\
Middle & 0.44 & 0.26 & 0.16 & 0.10 & 0.06 & 0.05 & 0.03 & 0.02 \\
4th & 0.40 & 0.22 & 0.14 & 0.12 & 0.08 & 0.06 & 0.05 & 0.04 \\
Richest & 0.44 & 0.30 & 0.20 & 0.14 & 0.12 & 0.10 & 0.05 & 0.03 \\
Total & 0.47 & 0.26 & 0.16 & 0.11 & 0.07 & 0.06 & 0.04 & 0.03 \\
\hline
\end{tabular}

Figure 3-3 shows that during 2013, prior to the health reform and implementation of universal health insurance, the average rate of out-of-pocket health expenditure was very high for both the treatment and comparison group due to lack of any insurance or financial health plan, reflecting the high level of financial risk that can lead to CHE. However, during the first year of the program in 2014, we observe the rate of out-of-pocket health expenditure for the comparison group remains the same while at the same time the average rate of out-of-pocket health expenditure significantly decreases for the treatment group. We use an out-of-pocket health expenditure ratio 
to drive our outcome variable (a dummy variable) to indicate whether or not households face CHE to estimate the average effect of the program on CHE.

Figure 3-3 Moving Average of Out-of-pocket ratio for treatment and comparison groups

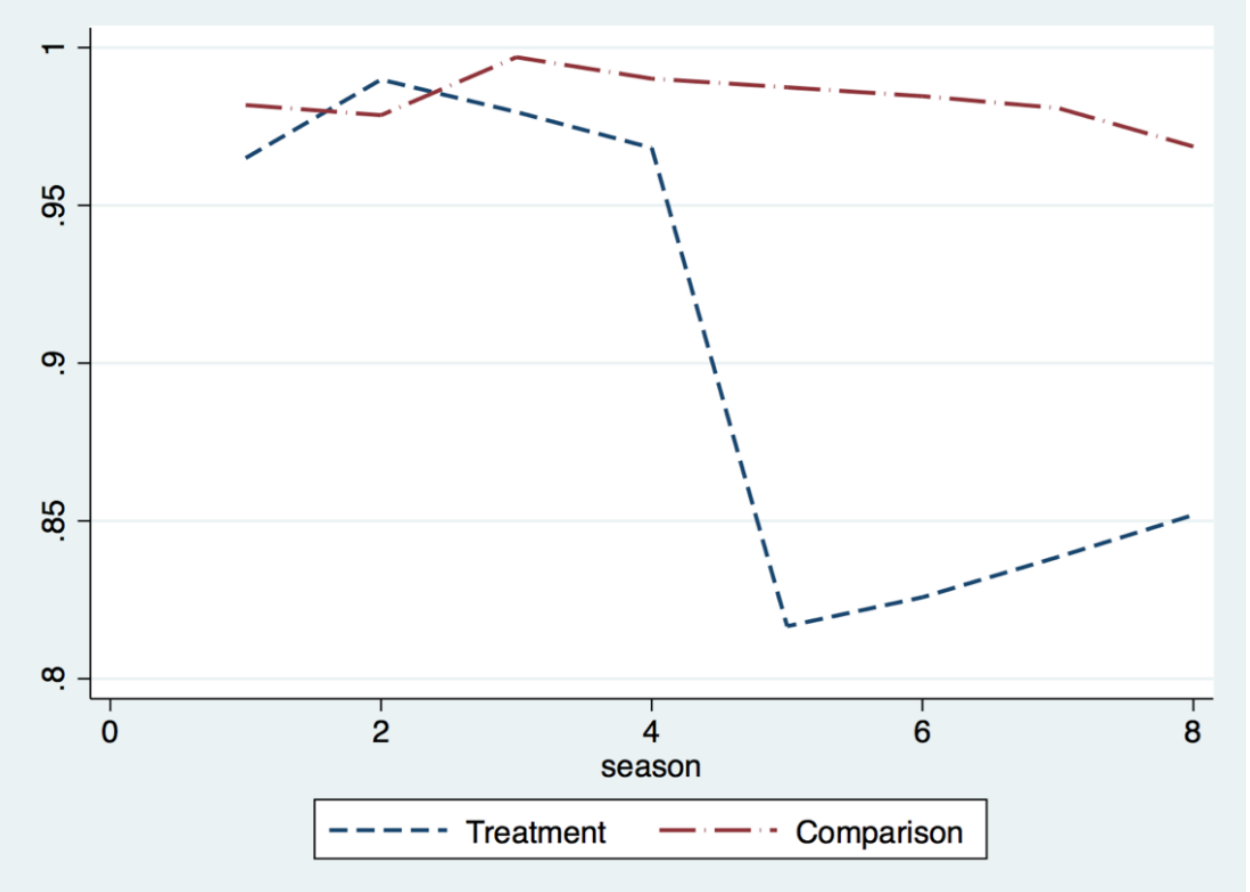

\subsection{Methodology}

Our aim is to measure the difference between participants' outcomes with and without treatment. The problem, however, is that we cannot observe both outcomes for an individual at the same time. Here the problem of selection bias arises as participants and non-participants differ even in the absence of treatment. Several methods exist to estimate the average treatment effect and we will use Propensity Score Matching (PSM) in order to evaluate the effect of health reform on CHE and then will use DID as a better tool to control for selection problem.

\subsubsection{Propensity Score Matching}

As mentioned by Caliendo and Kopeinig (2008, p. 32), “conditioning on all relevant covariates is limited in the case of a high dimensional vector X ('curse of dimensionality') [and] Rosenbaum and Rubin (1983) suggested the use of so-called balancing scores $b(X)$, i.e. functions 
of the relevant observed covariates $\mathrm{X}$ such that the conditional distribution of $X$ given $b(X)$ is independent of assignment into treatment." PSM uses propensity score as the balancing score. The propensity score is the probability of participating in a program conditioned on observed characteristics $X$.

The underlying assumption of PSM is the un-confoundedness or conditional independence assumption (CIA) (Caliendo \& Kopeinig, 2008). We assume that the treatment indicator $D_{i}$ equals 1 if individual $i$ receives treatment and 0 otherwise. The potential outcomes are defined as $Y_{i}\left(D_{i}\right)$ for each individual $i$, where $i=1, \ldots, N$ and $N$ is the total population.

- Un-confoundedness: $Y(0), Y(1) \perp D \mid X$

Given a set of observable covariates $X$, the potential outcomes are independent of treatment assignment. This suggests that the observations of all variables that influence treatment assignment and potential outcomes must be simultaneous. Rosenbaum and Rubin (1983) show that if potential outcomes are independent of treatment condition on covariates $X$, they are also independent of treatment condition on the propensity score as one possible balancing score.

In this study, the treatment is the entitlement of primary health insurance to all Iranian citizens who do not possess any type of health insurance. The program is free for entitled participants; the only cost is the opportunity cost of the time that they need to allocate in order to register for the program online. Hence, two key features exist. First, people who do not have any kind of health insurance are entitled to this program. If they decide not to register for the program, they should pay out-of-pocket expenses at the time that it becomes necessary for them to avail themselves of health care due to contracting a disease, experiencing an accident, or facing other health-threatening events. Second, there is no monetary cost to register for the program and entitled groups are simply required to register online.

Our assumption is that because this program has a net benefit for entitled individuals, some of them have not yet registered for the program due to lack of information. We control access to 
this information by using covariates such as access to television, phone, and the Internet, which ensures that individuals with the same $X$ values have a positive probability of being both participants and nonparticipants.

- Common Support: $0<P(D=1 \mid X<1$

For the binary treatment case, where the probability of participation versus nonparticipation is an estimate, logit and probit models usually yield similar results. Hence, the choice between them is not critical (Caliendo \& Kopeinig, 2008). In this study, we use the logit model in order to estimate the probability of participation in the program.

PSM requires researchers to choose a set of variables that satisfies the CIA. Only variables unaffected by participation or the anticipation of participation comprise the model. To ensure this, variables are either fixed over time or measured before participation. Hence, we use values of variables for 2013 (i.e., the year before enforcement of the program). These are dummy variables for urban areas, province of residency, gender, literacy status, and education level of the head of household, whether any household members experienced any surgery through the last year, the expenditure decile in which the household belongs, together with the age of the head of household, size of household, number of literate individuals in the household, number of employed individuals in the household, number of children below 6-years-old in the household, and number of elderly individuals above 65-years-old in the household.

We use the nearest-neighbor matching (NN) in which researchers match individuals from the comparison group with treated individuals who are closest in terms of propensity score. Several forms of $\mathrm{NN}$ exist, for example, NN matching with replacement and without replacement. In the former, an untreated individual can participate more than once as a match, while in the latter the same individual can participate only once.

In Table 3-6, we present the result for PSM with the assumption that we have just selection on observable variables (the assumption will be relaxed when using DID). As we can see, the 
program decreased the percentage of those who have faced CHE for all different threshold levels. Moreover, the average treatment effect on different thresholds is significant for all 90, 95, and 99 confidence levels.

Table 3-6 Average Treatment Effect on different thresholds of CHE (PSM)

\begin{tabular}{cccccc}
\hline Thresholds & $20 \%$ & $25 \%$ & $30 \%$ & $35 \%$ & $40 \%$ \\
ATET & $-.019^{* * *}$ & $-.021^{* * *}$ & $-.03^{* * *}$ & $-.019^{* * *}$ & $-.013^{* * *}$ \\
\hline
\end{tabular}

As previously mentioned, one assumption to use PSM is the overlap assumption, or the common support assumption stating that each individual has a positive probability of receiving treatment. In the following figure, we plot the estimated densities of receiving treatment in order to check whether or not the overlap assumption is broken. As we can see, the tails are narrow when approaching 0 and 1, implying all observations have a positive probability of falling into any of treatment or control group. This justifies the matching of an observation in a treatment group with an observation in a control group as a hypothetical equivalent of each other.

Figure 3-4 The overlap condition

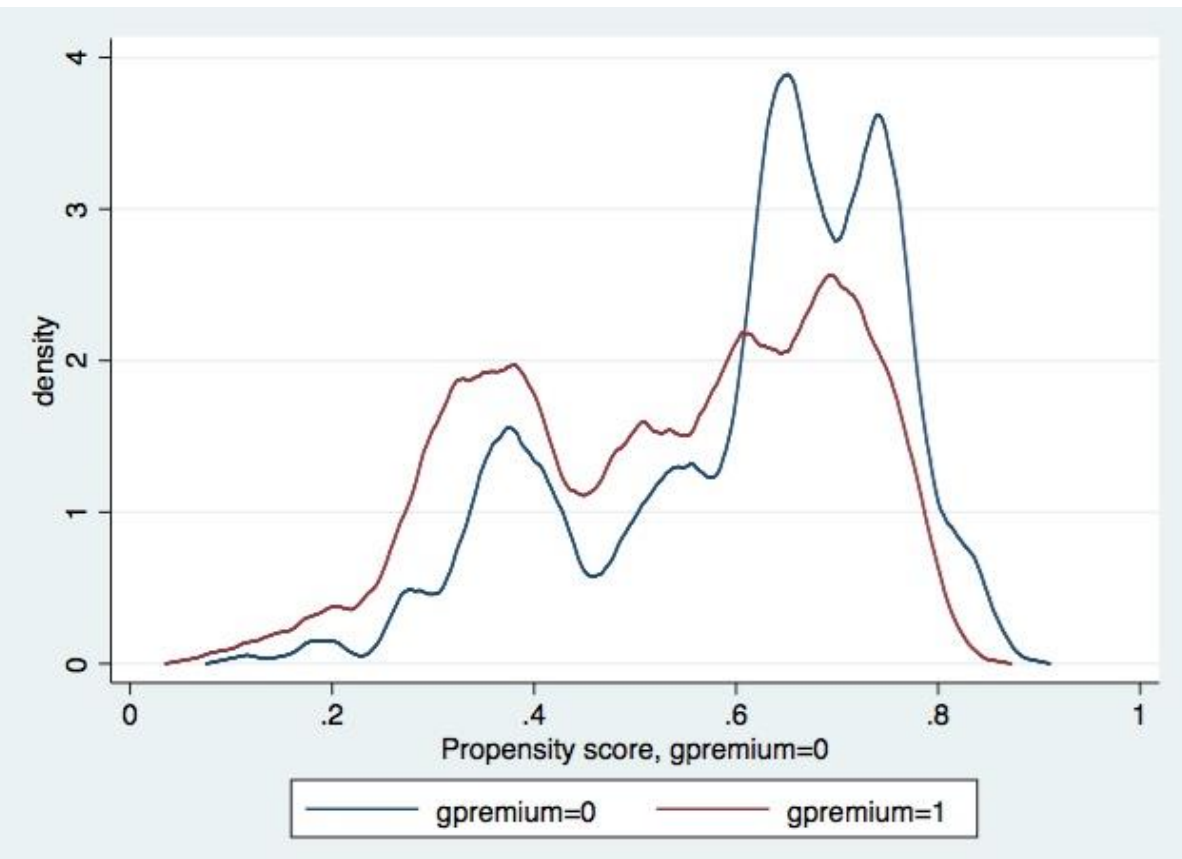




\subsubsection{Difference-in-Differences}

DID is a well-known program evaluation method that eliminates individual fixed effects through differentiating and controlling observable differences and time trends for individuals. As previously explained, we have two groups, one not affected by the program in the first period but affected in the second (treatment) and the other group not affected in either year (comparison). We can distinguish between the two groups by an indicator variable in our regressions. Given the assumption of the exogeneity of the treatment, we can estimate the effect of the program by comparing the rate of CHE for these two groups. Since the treatment assignment is not completely random, we also control other characteristics that would affect household health status. In turn, we control observable characteristics such as household expenditures, size, region, and some head of household characteristics such as age and gender. These characteristics are the same as those used in the PSM method. For empirical estimation, in order to estimate the effects using DID, we utilize the following equation:

$$
Y_{i t}=\beta_{0}+\beta_{1} X_{i t}+\gamma D_{i}+\mu T_{i}+\delta D_{i} T_{i}+\varepsilon_{i t}
$$

Where $Y_{i t}$ is our outcome variable, which is a dummy variable indicating if household faces catastrophic health care expenditure or not, $X_{i t}$ is observable characteristics, $D_{i}$ is treatment dummy, and $T_{i}$ is time dummy that captures the time trend. Our coefficient of interest is $\delta$ and captures average treatment effect on the treated group, that is, the effect of receiving a universal health insurance plan via a health reform program on CHE for those who have received it.

Angrist and Pischke (2008) discuss a key assumption underlying DID; the two groups must have the same time trend in their outcome variable in the absence of the treatment. Known as "parallel trends" we assume that the assumption holds for this step of our study. Of course, this is a strong assumption that needs strong justification. This reform program relates to the health status, an area in which many unobservable factors play a role, and evaluation of the program calls for 
more caution. At this step, we assume that these assumptions hold and the next step to develop this study is to deal with selection on unobservable and parallel trends.

\subsubsection{Difference-in-Differences PSM}

Matching estimators, in particular combined with the DID approach, are arguably more appropriate compared with a simple PSM or DID approach. Such an estimation approach is novel for health policy evaluation analysis. Since our data set enjoys the advantage of using panel data, we can find benefits of both DID and matching by using a DID matching estimator on the matched households. The standard matching estimation cannot address the "selection bias" problem, but as Blundell and Costa Dias (2000) mention, the matching estimator in combination with DID can have the potential to "improve the quality of nonexperimental evaluation results significantly."

On the other hand, the concern with DID models is that the control and treatment groups may differ in ways that could affect their trends over time, thus violating the time parallel assumption. Propensity score estimation is combined with DID to handle this problem. For instance, Stuart and colleagues (2014, p. 181) introduce "the use of four group propensity score weighting in [DID] models as a way to control for confounding due to observed covariates that differ either across groups in the pre period, or even over time due to changes in group composition."

\subsection{Results}

The benchmark results in Table 3-7 show evidence of a decrease in the out-of-pocket health expenditure ratio of about 17.3\%, which is in line with existing studies such as Piroozi, et al. (2016), or Galárraga et al. (2009). Literacy and higher education as well as a female-head of household will decrease the out-of-pocket health expenditure ratio, while elderly household members will increase it. Moreover, the government of Iran implemented the program as a comprehensive health reform to provide financial protection in health care for the poorest segment of the population. Based on 
the result, in terms of out-of-pocket expenditure ratio, the program impact evaluation shows an average decrease of $17.5 \%$ for the lowest income quintile in comparison to just $10.1 \%$ decrease for the highest quintile. Thus, the results show the protective effect of the program for the poor.

In Table 3-8, we present the results of DID where the estimate of average treatment effect on $\mathrm{CHE}$ is defined at a threshold of $15 \%$ for different income quintiles. The coefficient of interest is the estimated coefficient for interaction of year and treatment, which is negative and significant and supports the fact that the program was successful in decreasing CHE in Iran. Based on the results, all the differences between participants and nonparticipants are negative and significant. Furthermore, the Probit estimation of the effect of the program on CHE was protective, and the coefficient of interest has higher magnitude for the poor, suggesting that lower income quintiles are less likely to suffer from CHE if enrolled in the program.

Moreover, we ran DID estimation of average treatment effect on CHE for different threshold levels. Generally, for all the CHE thresholds, households insured with the universal health care program were less likely to face CHE; in Table 3-9, results are consistent with the aims of the program to decrease the percentage of households incurring CHE and provide financial protection against high levels of out-of-pocket health expenditure and its consequences. The results in this paper show that health reforms for households, especially for those of the poor in Iran, have a protective effect on excessive health expenditures and reduce the out-of-pocket health expenditure ratio for the Iranian population.

Finally, we identify the average treatment effect of the program on CHE using a DID propensity score matching approach and our results suggest that the program has been successful in terms of incidence of CHE. The DID matching estimates reported in Table 3-10 reveal that at the higher threshold levels of CHE, the out-of-pocket ratio has dropped and that reduces the probability of incurring CHE. In particular, comparing insured and uninsured, we found differences 
in the percentage of households experiencing CHE economically and statistically significant at the $30 \%$ and $35 \%$ thresholds levels. 
Table 3-7 DID estimate of out-of-pocket health expenditure ratio

\begin{tabular}{|c|c|c|c|c|c|c|}
\hline VARIABLES & $\begin{array}{c}(1) \\
\text { Total sample }\end{array}$ & $\begin{array}{c}(2) \\
\text { Quintile 1 }\end{array}$ & $\begin{array}{c}\text { (3) } \\
\text { Quintile 2 }\end{array}$ & $\begin{array}{c}(4) \\
\text { Quintile } 3\end{array}$ & $\begin{array}{c}\text { (5) } \\
\text { Quintile 4 }\end{array}$ & $\begin{array}{c}(6) \\
\text { Quintile 5 }\end{array}$ \\
\hline Time $*$ Treatment & $\begin{array}{l}-0.173 * * * \\
(0.000396)\end{array}$ & $\begin{array}{l}-0.175 * * * \\
(0.000744)\end{array}$ & $\begin{array}{l}-0.179 * * * \\
(0.000793)\end{array}$ & $\begin{array}{l}-0.187 * * * \\
(0.000836)\end{array}$ & $\begin{array}{l}-0.172 * * * \\
(0.000813)\end{array}$ & $\begin{array}{l}-0.101 * * * \\
(0.00130)\end{array}$ \\
\hline Urban & $\begin{array}{c}-0.00821 * * * \\
(0.000235)\end{array}$ & $\begin{array}{l}-0.000540 \\
(0.000525)\end{array}$ & $\begin{array}{l}0.0198 * * * \\
(0.000467)\end{array}$ & $\begin{array}{r}-0.0127 * * * \\
(0.000467)\end{array}$ & $\begin{array}{c}-0.0234 * * * \\
(0.000465)\end{array}$ & $\begin{array}{c}-0.00699 * * * \\
(0.000737)\end{array}$ \\
\hline Female-headed & $\begin{array}{l}-0.0255^{* * *} \\
(0.000261)\end{array}$ & $\begin{array}{c}-0.0126 * * * \\
(0.000396)\end{array}$ & $\begin{array}{l}-0.0407 * * * \\
(0.000559)\end{array}$ & $\begin{array}{l}0.0213 * * * \\
(0.000614)\end{array}$ & $\begin{array}{c}-0.0121 * * * \\
(0.000657)\end{array}$ & $\begin{array}{l}-0.102 * * * \\
(0.000972)\end{array}$ \\
\hline Age & $\begin{array}{c}-0.00143 * * * \\
(3.34 \mathrm{e}-05)\end{array}$ & $\begin{array}{c}-0.00236 * * * \\
(5.29 \mathrm{e}-05)\end{array}$ & $\begin{array}{c}-0.00157 * * * \\
(6.54 \mathrm{e}-05)\end{array}$ & $\begin{array}{c}-0.000664 * * * \\
(8.06 \mathrm{e}-05)\end{array}$ & $\begin{array}{c}-0.00224 * * * \\
(9.40 \mathrm{e}-05)\end{array}$ & $\begin{array}{c}-0.00122 * * * \\
(0.000145)\end{array}$ \\
\hline 2. HH size-cat & $\begin{array}{l}-0.0182 * * * \\
(0.000354)\end{array}$ & $\begin{array}{c}-0.00826 * * * \\
(0.000490)\end{array}$ & $\begin{array}{c}-0.00439 * * * \\
(0.000824)\end{array}$ & $\begin{array}{c}0.00830 * * * \\
(0.000969)\end{array}$ & $\begin{array}{c}-0.0513 * * * \\
(0.00114)\end{array}$ & $\begin{array}{c}-0.0587 * * * \\
(0.00137)\end{array}$ \\
\hline 3. HH size-cat & $\begin{array}{l}0.00180 * * * \\
(0.000505)\end{array}$ & $\begin{array}{c}0.00762 * * * \\
(0.00102)\end{array}$ & $\begin{array}{c}0.0495 * * * \\
(0.00119)\end{array}$ & $\begin{array}{c}-0.00369 * * * \\
(0.00119)\end{array}$ & $\begin{array}{c}-0.0500 * * * \\
(0.00134)\end{array}$ & $\begin{array}{c}0.0120 * * * \\
(0.00173)\end{array}$ \\
\hline $\mathrm{N}$ literate & $\begin{array}{c}-0.00358 * * * \\
(7.63 \mathrm{e}-05)\end{array}$ & $\begin{array}{c}-0.00206 * * * \\
(0.000173)\end{array}$ & $\begin{array}{c}-0.00616 * * * \\
(0.000161)\end{array}$ & $\begin{array}{c}-0.00299 * * * \\
(0.000166)\end{array}$ & $\begin{array}{c}0.00635 * * * \\
(0.000158)\end{array}$ & $\begin{array}{l}-0.0215 * * * \\
(0.000233)\end{array}$ \\
\hline N employed & $\begin{array}{c}4.31 \mathrm{e}-05 \\
(0.000135)\end{array}$ & $\begin{array}{c}0.000592 * * \\
(0.000278)\end{array}$ & $\begin{array}{c}-0.00628 * * * \\
(0.000308)\end{array}$ & $\begin{array}{c}0.00376 * * * \\
(0.000336)\end{array}$ & $\begin{array}{c}0.00900 * * * \\
(0.000273)\end{array}$ & $\begin{array}{c}-0.00120 * * * \\
(0.000359)\end{array}$ \\
\hline Elderly & $\begin{array}{l}0.00489 * * * \\
(0.000219)\end{array}$ & $\begin{array}{c}0.00480 * * * \\
(0.000401)\end{array}$ & $\begin{array}{c}0.00924 * * * \\
(0.000444)\end{array}$ & $\begin{array}{l}0.0110 * * * \\
(0.000514)\end{array}$ & $\begin{array}{l}-0.000181 \\
(0.000513)\end{array}$ & $\begin{array}{l}0.0105 * * * \\
(0.000727)\end{array}$ \\
\hline Surgery (Last Year) & $\begin{array}{l}-0.0205 * * * \\
(0.000245)\end{array}$ & $\begin{array}{l}-0.0133 * * * \\
(0.000524)\end{array}$ & $\begin{array}{l}-0.0250 * * * \\
(0.000529)\end{array}$ & $\begin{array}{l}0.00698 * * * \\
(0.000515)\end{array}$ & $\begin{array}{l}0.0160 * * * \\
(0.000495)\end{array}$ & $\begin{array}{l}-0.0947 * * * \\
(0.000686)\end{array}$ \\
\hline 2. Quintile & $\begin{array}{c}-0.000674 * * * \\
(0.000230)\end{array}$ & & & & & \\
\hline 3. Quintile & $\begin{array}{l}0.00568 * * * \\
(0.000249)\end{array}$ & & & & & \\
\hline 4. Quintile & $\begin{array}{c}0.00184 * * * \\
(0.000263)\end{array}$ & & & & & \\
\hline 5. Quintile & $\begin{array}{l}-0.0108 * * * \\
(0.000280)\end{array}$ & & & & & \\
\hline Constant & $\begin{array}{l}1.057 * * * \\
(0.000967)\end{array}$ & $\begin{array}{l}1.036 * * * \\
(0.00163)\end{array}$ & $\begin{array}{l}1.017 * * * \\
(0.00192)\end{array}$ & $\begin{array}{l}0.994 * * * \\
(0.00237)\end{array}$ & $\begin{array}{l}1.073 * * * \\
(0.00266)\end{array}$ & $\begin{array}{l}1.217 * * * \\
(0.00410)\end{array}$ \\
\hline $\begin{array}{l}\text { Observations } \\
\text { R-squared }\end{array}$ & $\begin{array}{c}2,054,457 \\
0.260\end{array}$ & $\begin{array}{c}499,253 \\
0.266\end{array}$ & $\begin{array}{c}464,304 \\
0.401\end{array}$ & $\begin{array}{c}395,974 \\
0.327\end{array}$ & $\begin{array}{c}372,504 \\
0.361\end{array}$ & $\begin{array}{c}322,422 \\
0.291\end{array}$ \\
\hline
\end{tabular}

Notes: $* * * \mathrm{p}<0.01, * * \mathrm{p}<0.05, * \mathrm{p}<0.1$. Robust standard errors are in parentheses 
Table 3-8 DID estimate of ATE on CHE for different quintiles (15\% Threshold)

\begin{tabular}{|c|c|c|c|c|c|}
\hline VARIABLES & $\begin{array}{c}(1) \\
\text { Quintile 1 }\end{array}$ & $\begin{array}{c}\text { (2) } \\
\text { Quintile 2 }\end{array}$ & $\begin{array}{c}\text { (3) } \\
\text { Quintile } 3\end{array}$ & $\begin{array}{c}\text { (4) } \\
\text { Quintile } 4\end{array}$ & $\begin{array}{c}\text { (5) } \\
\text { Quintile 5 }\end{array}$ \\
\hline Time * Treatment & $\begin{array}{c}-1.288^{* * *} \\
(0.0243)\end{array}$ & $\begin{array}{c}-0.281 * * * \\
(0.0247)\end{array}$ & $\begin{array}{c}-0.398^{* * * *} \\
(0.0323)\end{array}$ & $\begin{array}{c}-0.881^{* * * *} \\
(0.0308)\end{array}$ & $\begin{array}{c}-0.272 * * * \\
(0.0325)\end{array}$ \\
\hline Urban & $\begin{array}{c}-0.446 * * * \\
(0.0155)\end{array}$ & $\begin{array}{c}-0.353 * * * \\
(0.0137)\end{array}$ & $\begin{array}{c}-0.0304 * \\
(0.0158)\end{array}$ & $\begin{array}{c}-0.306^{* * *} \\
(0.0182)\end{array}$ & $\begin{array}{c}0.575^{* * *} \\
(0.0206)\end{array}$ \\
\hline Female-headed & $\begin{array}{c}0.0415^{* * * *} \\
(0.0119)\end{array}$ & $\begin{array}{c}0.155^{* * *} \\
(0.0148)\end{array}$ & $\begin{array}{c}0.359^{* * * *} \\
(0.0184)\end{array}$ & $\begin{array}{c}-0.940 * * * \\
(0.0261)\end{array}$ & $\begin{array}{c}-1.186^{* * * *} \\
(0.0285)\end{array}$ \\
\hline Age & $\begin{array}{c}0.0422 * * * \\
(0.00185)\end{array}$ & $\begin{array}{l}-0.104 * * * \\
(0.00181)\end{array}$ & $\begin{array}{c}-0.189 * * * \\
(0.00237)\end{array}$ & $\begin{array}{l}-0.159 * * * \\
(0.00327)\end{array}$ & $\begin{array}{c}-0.147 * * * \\
(0.00369)\end{array}$ \\
\hline Educode3 & $\begin{array}{c}0.0700^{* * * *} \\
(0.0184)\end{array}$ & $\begin{array}{c}-0.154 * * * \\
(0.0128)\end{array}$ & $\begin{array}{c}-0.581 * * * \\
(0.0140)\end{array}$ & $\begin{array}{c}0.287 * * * \\
(0.0144)\end{array}$ & $\begin{array}{c}-0.324 * * * * \\
(0.0158)\end{array}$ \\
\hline Educode3 & $\begin{array}{c}-0.106 * * * \\
(0.0140)\end{array}$ & $\begin{array}{c}-0.240 * * * \\
(0.0144)\end{array}$ & $\begin{array}{c}0.312 * * * \\
(0.0136)\end{array}$ & $\begin{array}{c}-1.455^{* * *} \\
(0.0240)\end{array}$ & $\begin{array}{c}-0.781 * * * \\
(0.0190)\end{array}$ \\
\hline $\mathrm{N}$ literate & $\begin{array}{c}-0.585^{* * *} \\
(0.00667)\end{array}$ & $\begin{array}{c}-0.398 * * * \\
(0.00487)\end{array}$ & $\begin{array}{c}-0.350 * * * \\
(0.00495)\end{array}$ & $\begin{array}{c}0.0290^{* * * *} \\
(0.00564)\end{array}$ & $\begin{array}{c}-0.213 * * * \\
(0.00513)\end{array}$ \\
\hline $\mathrm{N}$ employed & $\begin{array}{c}-0.513 * * * \\
(0.0107)\end{array}$ & $\begin{array}{c}-0.317^{* * *} \\
(0.0104)\end{array}$ & $\begin{array}{c}0.275^{* * * *} \\
(0.0109)\end{array}$ & $\begin{array}{c}-0.703 * * * \\
(0.0121)\end{array}$ & $\begin{array}{l}0.384 * * * \\
(0.00838)\end{array}$ \\
\hline Child1 & $\begin{array}{c}-0.183^{* * *} \\
(0.0119)\end{array}$ & $\begin{array}{c}-0.137 * * * \\
(0.0102)\end{array}$ & $\begin{array}{c}-0.211 * * * \\
(0.00991)\end{array}$ & $\begin{array}{c}-0.953 * * * \\
(0.0165)\end{array}$ & $\begin{array}{c}-0.0493 * * * \\
(0.0126)\end{array}$ \\
\hline Elderly & $\begin{array}{c}0.609 * * * \\
(0.0112)\end{array}$ & $\begin{array}{c}0.442 * * * \\
(0.0115)\end{array}$ & $\begin{array}{c}0.600 * * * \\
(0.0150)\end{array}$ & $\begin{array}{c}-0.0882 * * * \\
(0.0220)\end{array}$ & $\begin{array}{c}-0.864 * * * \\
(0.0237)\end{array}$ \\
\hline Surgery (Last Year) & $\begin{array}{c}2.800 * * * \\
(0.0147)\end{array}$ & $\begin{array}{l}1.151 * * * \\
(0.0134)\end{array}$ & $\begin{array}{c}1.630 * * * \\
(0.0142)\end{array}$ & $\begin{array}{c}1.206 * * * \\
(0.0175)\end{array}$ & $\begin{array}{c}2.335 * * * \\
(0.0153)\end{array}$ \\
\hline Constant & $\begin{array}{c}-1.665^{* * *} \\
(0.0600)\end{array}$ & $\begin{array}{c}2.547 * * * \\
(0.0513)\end{array}$ & $\begin{array}{c}5.044 * * * \\
(0.0660)\end{array}$ & $\begin{array}{c}4.409 * * * \\
(0.0892)\end{array}$ & $\begin{array}{c}3.348 * * * \\
(0.0892)\end{array}$ \\
\hline Observations & 484,434 & 444,044 & 382,409 & 353,178 & 281,904 \\
\hline
\end{tabular}

Notes: $* * * \mathrm{p}<0.01, * * \mathrm{p}<0.05,{ }^{*} \mathrm{p}<0.1$. Robust standard errors are in parentheses. 
Table 3-9 DID estimate of ATE on CHE for different thresholds

\begin{tabular}{|c|c|c|c|c|c|c|c|c|}
\hline & (1) & (2) & (3) & (4) & (5) & (6) & (7) & (8) \\
\hline VARIABLES - Threshold & $5 \%$ & $10 \%$ & $15 \%$ & $20 \%$ & $25 \%$ & $30 \%$ & $35 \%$ & $40 \%$ \\
\hline \multirow[t]{2}{*}{ Time * Treatment } & $-0.393 * * *$ & $-0.282 * * *$ & $-0.715 * * *$ & $-0.193 * * *$ & $-0.448 * * *$ & $-0.462 * * *$ & $-0.408 * * *$ & $-0.139 * * *$ \\
\hline & $(0.00814)$ & $(0.00913)$ & $(0.0113)$ & $(0.0132)$ & $(0.0173)$ & $(0.0200)$ & $(0.0219)$ & $(0.0241)$ \\
\hline \multirow[t]{2}{*}{ Urban } & $-0.155^{* * *}$ & $-0.151 * * *$ & $-0.168 * * *$ & $0.0580 * * *$ & 0.0145 & $-0.207 * * *$ & $-0.0928 * * *$ & $-0.217 * * *$ \\
\hline & $(0.00489)$ & $(0.00536)$ & $(0.00647)$ & $(0.00772)$ & $(0.00979)$ & $(0.0111)$ & $(0.0132)$ & $(0.0146)$ \\
\hline \multirow[t]{2}{*}{ Female-headed } & $0.0382 * * *$ & $-0.112 * * *$ & $0.0171^{* *}$ & $0.0794 * * *$ & $0.410 * * *$ & $0.172 * * *$ & $0.308 * * *$ & $0.240 * * *$ \\
\hline & $(0.00533)$ & $(0.00607)$ & $(0.00718)$ & $(0.00836)$ & $(0.0100)$ & $(0.0120)$ & $(0.0136)$ & $(0.0153)$ \\
\hline \multirow[t]{2}{*}{ Age } & $-0.0481 * * *$ & $-0.0488 * * *$ & $-0.0594 * * *$ & $-0.0596 * * *$ & $-0.0761 * * *$ & $-0.0465 * * *$ & $-0.0740 * * *$ & $-0.0991 * * *$ \\
\hline & $(0.000707)$ & $(0.000749)$ & $(0.000874)$ & $(0.00102)$ & $(0.00124)$ & $(0.00149)$ & $(0.00169)$ & $(0.00187)$ \\
\hline \multirow[t]{2}{*}{ Educode 3} & $-0.0325 * * *$ & $0.0121 * * *$ & $-0.104 * * *$ & $-0.240 * * *$ & $-0.283^{* * *}$ & $-0.228 * * *$ & $-0.253 * * *$ & $-0.172 * * *$ \\
\hline & $(0.00394)$ & $(0.00466)$ & $(0.00593)$ & $(0.00707)$ & $(0.00900)$ & $(0.0106)$ & $(0.0132)$ & $(0.0140)$ \\
\hline \multirow[t]{2}{*}{ Educode 3} & $0.0127 * * *$ & $-0.319 * * *$ & $-0.236^{* * *}$ & $-0.567 * * *$ & $-0.480 * * *$ & $-0.780 * * *$ & $-0.754 * * *$ & $-0.987 * * *$ \\
\hline & $(0.00430)$ & $(0.00499)$ & $(0.00592)$ & $(0.00716)$ & $(0.00870)$ & $(0.0107)$ & $(0.0125)$ & $(0.0146)$ \\
\hline \multirow[t]{2}{*}{$\mathrm{N}$ literate } & $-0.146^{* * *}$ & $-0.177 * * *$ & $-0.343 * * *$ & $-0.323 * * *$ & $-0.321 * * *$ & $-0.326 * * *$ & $-0.380 * * *$ & $-0.323 * * *$ \\
\hline & $(0.00161)$ & $(0.00187)$ & $(0.00230)$ & $(0.00268)$ & $(0.00345)$ & $(0.00404)$ & $(0.00525)$ & $(0.00572)$ \\
\hline \multirow[t]{2}{*}{$\mathrm{N}$ employed } & $-0.0838 * * *$ & $-0.133 * * *$ & $-0.135 * * *$ & $-0.157 * * *$ & -0.00587 & $-0.219 * * *$ & $-0.492 * * *$ & $-0.683 * * *$ \\
\hline & $(0.00279)$ & $(0.00318)$ & $(0.00391)$ & $(0.00459)$ & $(0.00551)$ & $(0.00658)$ & $(0.00864)$ & $(0.00992)$ \\
\hline \multirow[t]{2}{*}{ Child1 } & $-0.0150 * * *$ & $-0.222 * * *$ & $-0.336^{* * *}$ & $-0.518 * * *$ & $-0.609 * * *$ & $-0.509 * * *$ & $-0.593 * * *$ & $-0.412 * * *$ \\
\hline & $(0.00316)$ & $(0.00381)$ & $(0.00475)$ & $(0.00600)$ & $(0.00805)$ & $(0.00971)$ & $(0.0124)$ & $(0.0126)$ \\
\hline \multirow[t]{2}{*}{ Elderly } & $0.0741 * * *$ & $0.249 * * *$ & $0.217 * * *$ & $0.382 * * *$ & $0.625 * * *$ & $0.363 * * *$ & $0.597 * * *$ & $0.0776 * * *$ \\
\hline & $(0.00456)$ & $(0.00481)$ & $(0.00572)$ & $(0.00639)$ & $(0.00763)$ & $(0.00905)$ & $(0.0106)$ & $(0.0130)$ \\
\hline \multirow[t]{2}{*}{ Surgery (Last Year) } & $1.623 * * *$ & $1.664 * * *$ & $1.550 * * *$ & $1.442 * * *$ & $1.553 * * *$ & $1.435 * * *$ & $1.342 * * *$ & $1.009 * * *$ \\
\hline & $(0.00596)$ & $(0.00511)$ & $(0.00550)$ & $(0.00617)$ & $(0.00728)$ & $(0.00828)$ & $(0.00981)$ & $(0.0113)$ \\
\hline \multirow[t]{2}{*}{ Constant } & $1.860 * * *$ & $1.145^{* * *}$ & $1.021 * * *$ & $0.175 * * *$ & $-0.0724 *$ & $-0.990 * * *$ & $-0.710 * * *$ & $-0.746 * * *$ \\
\hline & $(0.0203)$ & $(0.0220)$ & $(0.0259)$ & $(0.0308)$ & $(0.0383)$ & $(0.0463)$ & $(0.0547)$ & $(0.0602)$ \\
\hline Observations & $2,054,457$ & $2,054,457$ & $2,048,337$ & $2,048,337$ & $1,965,282$ & $1,909,180$ & $1,909,180$ & $1,872,799$ \\
\hline
\end{tabular}

Notes: $* * * \mathrm{p}<0.01, * * \mathrm{p}<0.05, * \mathrm{p}<0.1$. Robust standard errors are in parentheses. 
Table 3-10 DID PSM estimate of ATE on CHE for different thresholds

\begin{tabular}{c|cccccccc}
\hline $\begin{array}{c}\text { Outcome } \\
\begin{array}{c}\text { Variable } \\
\text { Threshold }\end{array}\end{array}$ & $5 \%$ & $10 \%$ & $15 \%$ & $20 \%$ & $25 \%$ & $30 \%$ & $35 \%$ & $40 \%$ \\
\hline $\begin{array}{c}\text { Program } \\
\text { Effect }\end{array}$ & 0.016 & $0.001-$ & $0.020-$ & $0.032-$ & $0.026-$ & $* * 0.039-$ & $* 0.025-$ & $0.013-$ \\
\hline Notes: *** $p<0.01, * * \mathrm{p}<0.05, * \mathrm{p}<0.1$. Robust standard errors are in parentheses.
\end{tabular}

\subsection{Conclusion}

A high rate of out-of-pocket health care expenditure can lead to catastrophic health care expenditure (CHE), forcing household members to either cut their consumption and minimum needs or face poverty. This makes financial protection against high levels of out-of-pocket health expenditure an important goal for some governments including Iran. Since May of 2014, the Iranian government has carried out the health reform program aimed at many targets including the provision of universal health insurance, the decrease of out-of-pocket health expenditure, and a decrease in the rate of CHE.

Even though the program offers only basic health insurance and has not yet been able to reach all targeted groups, the results show that the program significantly decreased the out-ofpocket health expenditure ratio by about $17.3 \%$ for the treatment group at the national level. This is in line with other studies (e.g., Piroozi et al., 2016) that investigated this program at the province level. Furthermore, our results suggest that the program is successful in providing financial protection in healthcare for the poorest segment of the population. Based on the result in terms of out-of-pocket expenditure ratio, the program impact evaluation shows an average decrease of $17.5 \%$ for the poor (the lowest quintile) in comparison with just a $10.1 \%$ decrease for the highest quintile. Therefore, the results show higher protective effect of the program for the lowest income quintile.

This study uses DID strategy to estimate the average effect of the health reform on catastrophic health care expenditure. The average incidence of CHE significantly decreased for 
households in the treatment group which reflects lower level of financial risk associated with health care expenditures for different threshold levels. For all the CHE thresholds, universal health care insurance reduces percentage of households that face $\mathrm{CHE}$ which was one of the main goals of the program to protect the Iranian households against high levels of out-of-pocket health expenditure and its consequences such as CHE.

Moreover, we ran DID propensity score matching and with comparing insured and uninsured to identify the average treatment effect of the program on CHE and our results show differences in the percentage of households experiencing CHE which are both economically and statistically significant at the $30 \%$ and $35 \%$ thresholds levels. Finally, the program includes goals and initiatives not discussed in this paper as we simply explore its effect on catastrophic health care expenditure. Hence, there is a need for further research to evaluate the achievements of other goals.

\subsection{REFERENCES}

Angrist, J. D., \& Pischke, J.-S. (2008). Mostly Harmless Econometrics: An Empiricist's Companion. Princeton, NJ: Princeton University Press.

Blundell, R., \& Costa Dias, M. (2000). Evaluation methods for non-experimental data. Fiscal Studies, 2(4), 427-468.

Caliendo, M., \& Kopeinig, S. (2008). Some practical guidance for the implementation of propensity score matching. Journal of Economic Surveys, 22(1), 31-72. doi: 10.1111/j.14676419.2007.00527.x.

Chuma, J., Lucy, G., \& Molyneux, C. (2007). Treatment-seeking behaviour, cost burdens and coping strategies among rural and urban households in Coastal Kenya: An equity analysis. Tropical Medicine \& International Health, 12(5), 673-686. doi:10.1111/j.13653156.2007.01825.x.

Chuma, J., \& Maina, T. (2012, November 16). Catastrophic health care spending and impoverishment in Kenya. BMC Health Services Research, 12(413). doi: 10.1186/14726963-12-413.

Dorjdagva, J., Batbaatar, E., Svensson, M., Bayarsaikhan, D., \& Kauhanen, J. (2016). Catastrophic health expenditure and impoverishment in Mongolia. International Journal for Equity in Health, 15(1), 105-113. doi: 10.1186/s12939-016-0395-8. 
Galárraga, O., Sosa-Rubi, S. G., Salinas-Rodríguez, A., \& Sesma-Vázquez, S. (2010). Health insurance for the poor: Impact on catastrophic and out-of-pocket health expenditures in Mexico. European Journal of Health Economics, 11(5), 437-447. doi: 10.1007/s10198009-0180-3.

Habicht, J., Xu, K., Couffinhal, A., \& Kutzin, J. (2006). Detecting changes in financial protection: Creating evidence for policy in Estonia. Health Policy and Planning, 21(6), 421-431. doi:10.1093/heapol/czl026.

Koch, K. J., Pedraza, C. C., \& Schmid, A. (2017). Out-of-pocket expenditure and financial protection in the Chilean health care system-A systematic review. Health Policy, 12(1), 481-494. doi:10.1016/j.healthpol.2017.02.013.

Piroozi, B., Moradi, G., Nouri, B., Bolbanabad, A. M., \& Safari, H. (2016). Catastrophic health expenditure after the implementation of health sector evolution plan: A case study in the west of Iran. International Journal of Health Policy and Management, 5(7), 417-423. doi: 10.15171/ijhpm.2016.31.

Pradhan, M., \& Prescott, N. (2002, April 18). Social risk management options for medical care in Indonesia. Health Economics, 11(5), 431-446. doi: 10.1002/hec.689.

Rosenbaum, P. R., \& Rubin, D. B. (1983). The central role of the propensity score in observational studies for causal effects. Biometrika, 70(1), 41-55.

Russell, S. (2004). The economic burden of illness for households in developing countries: A review of studies focusing on malaria, tuberculosis, and human immunodeficiency virus/acquired immunodeficiency syndrome. American Journal of Tropical Medicine and Hygiene, 71(suppl. 2), 147-155.

Smith, O., \& Nguyen, S. N. (2013). Getting Better: Improving Health System Outcomes in Europe and Central Asia. Washington, DC: World Bank Publications.

Stuart, E. A., Huskamp, H. A., Duckworth, K., Simmons, J., Song, Z., Chernew, M. E, \& Barry, C. L. (2014). Using propensity scores in difference-in-differences models to estimate the effects of a policy change. Health Services and Outcomes Research Methodology, 14(4), 166-182. doi: 10.1007/s10742-014-0123-z.

Su, T. T., Kouyaté, B., \& Flessa, S. (2006). Catastrophic household expenditure for health care in a low-income society: A study from Nouna District, Burkina Faso. Bulletin of the World Health Organization, 84(1), 21-27.

Wagstaff, A., \& van Doorslaer, E. (2003). Catastrophe and impoverishment in paying for health care: With applications to Vietnam 1993-1998. Health Economics, 12(11), 921-934. doi:10.1002/hec.776.

World Health Organization. (2017, December 31). Universal health coverage . Retrieved from World Health Organization: http://www.who.int/en/news-room/factsheets/detail/universal-health-coverage-(uhc) 
Wyszewianski, L. (1986). Financially catastrophic and high-cost cases: Definitions, dis- tinctions and their implications for policy formulation. Inquiry, 23(4), 382-394.

Xu, K., Evans, D. B., Carrin, G., Aguilar-Rivera, A. M., Musgrove, P., \& Evans, T. (2007). Protecting households from catastrophic health spending. Health Affairs, 26(4), 972-983.

Xu, K., Evans, D. B., Kawabata, K., Zeramdini, R., Klavus, J., \& Murray, C. J. (2003). Household catastrophic health expenditure: A multicountry analysis. The Lancet, 362(9378), 111-117. 


\section{Chapter 4}

\section{DAILY EXCHANGE RATE PASS-THROUGH INTO MICRO PRICES}

\subsection{Introduction}

Exchange rate pass-through (ERPT) is the standard measure used to represent the relationship between nominal exchange rates (NER) and the prices of internationally traded goods. The ERPT is the percentage change in local currency import prices resulting from a one percentage change in the NER between the exporting and importing countries (Goldberg \& Knetter, 1997). Long a subject of interest in international economics, ERPT has a significant impact on both a country's microeconomic and macroeconomic indicators. Thus, it is important to understand the way changes in exchange rates affect import prices (pass through). Such knowledge is essential for setting both monetary and trade policy. Therefore, central banks with the objective of price stability can intervene in the exchange rate market to have full or partial control over the value of their currency; policy makers would simply like to know how prices react to changes in NER. It is particularly important for emerging markets such as Turkey that have adopted an inflation targeting regime, that the dependence of the ERPT on the inflation regime should be considered in designing monetary policy rules.

This paper investigates ERPT at the product-level by introducing a new daily wholesale price for 52 agricultural products imported into Turkey between January 2005 and August 2015. The data set distinguishes between imported products and products that are domestically produced in Turkey. Therefore, by using daily data for domestically produced agricultural products, we achieve a method of identification to estimate the pure effects of NER changes on prices with respect to other macroeconomic developments. Thus, having such high-frequency data (daily prices) with the ability to control for the domestic inflation variable makes this data set one of the few rich data sets on micro prices and a perfect fit for our daily ERPT investigation. Due to the 
perishable nature of these products, it is necessary to have a high frequency setup to measure daily ERPT. We also use the corresponding data on NER (between the Turkish Lira and the U.S. dollar) by daily frequencies.

This study combines the daily import price data of agricultural products with the corresponding data on NER, frequency of price change (measured over the sample period, due to the micro-price nature of the data), and storage life (a concept that is the opposite of perishability/depreciation) to estimate ERPT, where we consider potential nonlinearities through estimated thresholds in these variables. Since several criteria and the estimated coefficients show that only the current changes in NER are effective on product-level price changes, we accept the corresponding coefficients as our ERPT measure; this is similar to the daily evidence based on eBay transactions of U.S. imports from Australia, Canada, Germany, Japan and the U.K. provided by Lott and Einav (2013). As a result, we find evidence for incomplete ERPT with estimated positive and significant coefficients (of about 5\%) that are similar to the existing studies based on goods-level data sets (e.g., see Aron, Farrell, Muellbauer, \& Sinclair, 2014; Gopinath, Itskhoki, \& Rigobon, 2010; or Lott \& Einav, 2013), although the coefficients are lower compared with the studies based on aggregate-level data sets (e.g., see Goldberg \& Knetter, 1997; or Menon, 1995). The literature also shows that ERPT estimates can be conditional on price changes; ERPT estimates increase when measured at the time of a price change (e.g., see Gopinath et al., 2010). Our corresponding results are also in line with these studies by showing that when only non-zero price changes are considered, the estimated ERPT measures are higher when comparing them with the measures obtained by using all price changes.

This paper is akin to the recent empirical ERPT literature that uses nonlinear/threshold models. Within this literature, by estimating a nonlinear time series model for the United States, Shintani, Terada-Hagiwara, and Yabu (2013) suggest that the period of low ERPT during the 1980s and 1990s is likely associated with low inflation. Similarly, Cheikh and Louhichi (2016), using a 
panel threshold framework for 63 countries, show that the category of countries with higher inflation rates experiences higher degrees of ERPT; Ben Cheikh and Rault (2016) show, using logistic smooth transition models for five heavily indebted countries, that ERPT is higher when sovereign bond yield spreads exceed a given threshold; and Donayre and Panovska (2016) show, using a Bayesian threshold vector auto-regression for Canada and Mexico, that ERPT is higher when the growth rate of output is larger. This study contributes to this literature by considering thresholds in alternative variables of NER, frequency of price change, and storage life. Moreover, whereas the aforesaid papers have considered low frequency macro-level data sets, this paper considers a daily micro-level data set that avoids any aggregation/measurement problem due to converting daily observations into lower frequency data sets.

The corresponding threshold analyses further show that ERPT is about $11 \%$ when NER changes are above $0.55 \%$. This result is consistent with studies such as Burstein, Eichenbaum, and Rebelo (2005) who have shown that the magnitude of NER changes may be effective in the determination of ERPT. Moreover, ERPT is about $9.1 \%$ when the frequency of price change is higher than 3.12\% (consistent with studies such as Gopinath \& Itskhoki, 2010; and Antoniades \& Zaniboni, 2016 who have shown that there is a positive relationship between frequency of price change and ERPT), or about $9.4 \%$ when storage life is higher than 10 weeks (which is new in this paper, suggesting that ERPT decreases with perishability/depreciation). When the investigation is restricted to non-zero price changes as in studies such as Gopinath et al. (2010), the tables turn with evidence of complete ERPT for observations with values above such thresholds.

\subsection{Data and Empirical Methodology}

This study employs micro-price daily data for 52 agricultural products imported into Turkey between January 2005 and August 2015. The data has been collected from the web page of 
Istanbul Metropolitan Municipality. ${ }^{5}$ From this data base, we have both low and high prices for each of these goods. Having high-frequency data (daily prices) and the ability to distinguish between imported products and products that are domestically produced in Turkey makes this data set a perfect fit for our daily ERPT investigation. Accordingly, in order to control for local macroeconomic developments, we construct the daily domestic inflation rate that we will introduce as a control variable in the next sections. A good example of how prices of imported commodities are affected by NER changes (the motivation for this investigation) are the daily price movements shown in Figure 4-1 that track the price of domestic bananas and the price of imported bananas during this period of time.

Figure 4-1 (a-b). Price of domestic bananas and price of imported bananas from January 2005 to August 2015
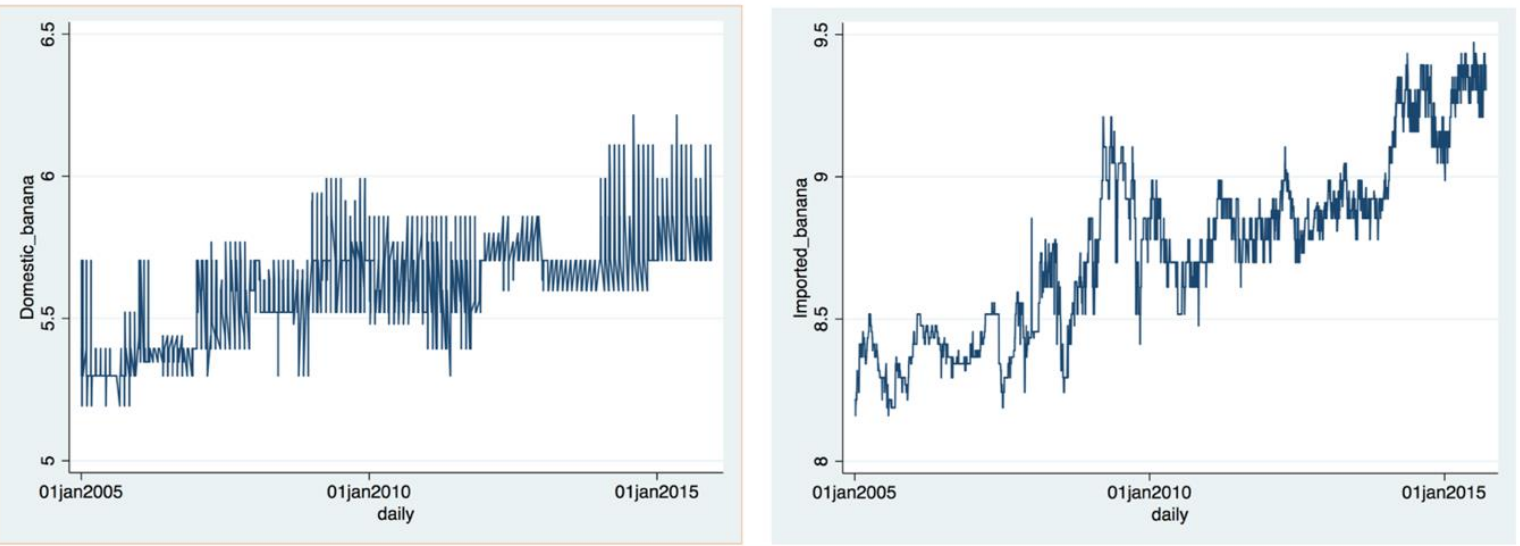

(a)

(b)

\subsubsection{Nominal Exchange Rate between the Turkish Lira and the U.S. dollar}

We also use the corresponding data on NER between the Turkish Lira and the U.S. dollar (which is the main currency used for Turkish imports) by daily frequencies ${ }^{6}$ motivated by studies such as Nazlioglu and Soytas (2011), Richards, Myers, Swinton, and Walker (2012) and Schaffnit-

\footnotetext{
${ }^{5}$ The web page of Istanbul Metropolitan Municipality is www.ibb.gov.tr

${ }^{6}$ The web page of The Central Bank of the Republic of Turkey is www.tcmb.gov.tr
} 
Chatterjee, Schneider, Peter, and Mayer (2010) all of which show that agricultural products are globally traded in U.S. dollars. Moreover, as shown in Gopinath (2015), the majority (60\%) of Turkish imports are invoiced in U.S. dollars, while only $3 \%$ of them are invoiced in Turkish liras. Since Turkish imports from the United States represent only $6 \%$ of total Turkish imports, it implies that the U.S. dollar is the main foreign currency used for Turkish imports, independent of the source country and product considered. Further, Figure 4-2 shows that exchange rate movement during the period of January 2005 to August 2015 has mostly been increasing, volatile, and unstable.

Figure 4-2 Daily nominal exchange rate between Turkish Lira and U.S. dollar

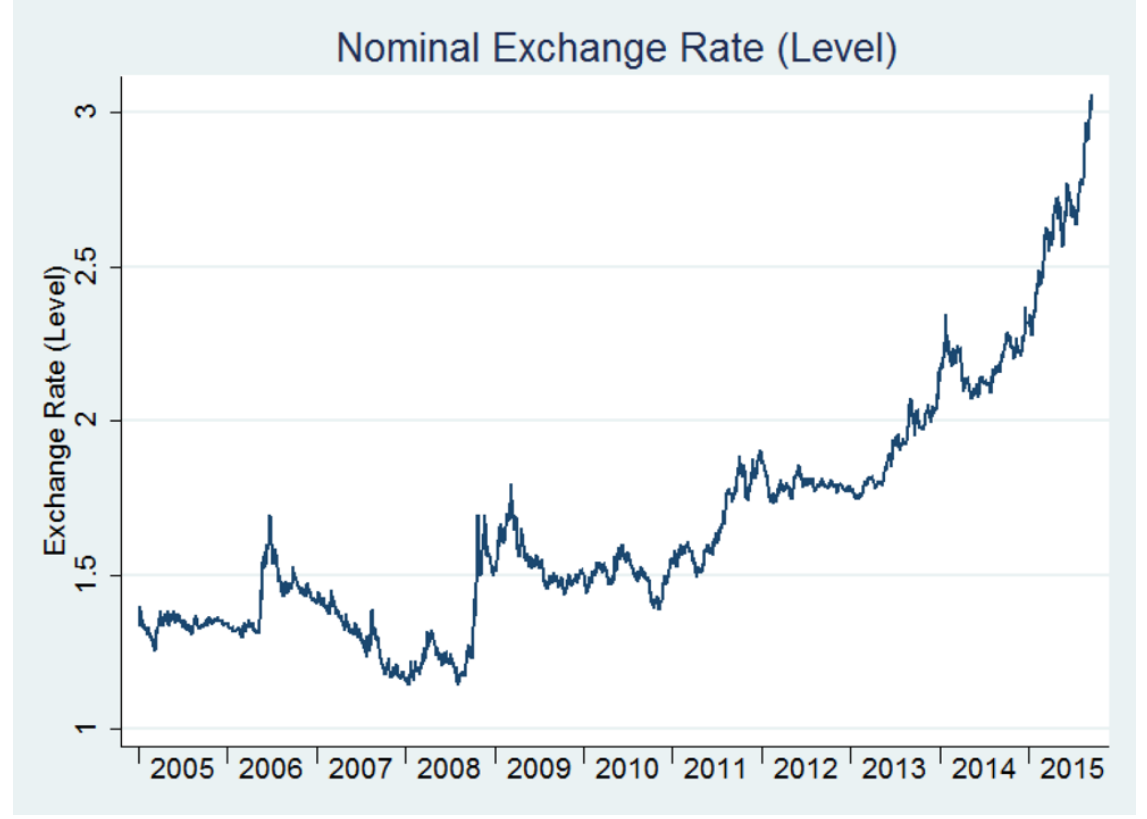

The average of the daily exchange rate movement was $0.03 \%$ and the maximum $7.04 \%$, which shows that exchange rate shocks in Turkey were large, persistent, and mostly unexpected during these 10 years. Therefore, we believe that Turkey is a good case study and motivates us to investigate ERPT of NER on imported prices empirically. Since different years in the sample have experienced different percentage changes in prices and exchange rates, as shown in Figures 4-3 (ab), we will also consider year-specific ERPT in order to understand different dimensions of the data set. 
Figure 4-3 (a-b). Average daily log changes in price and NER from January 2005 to August 2015

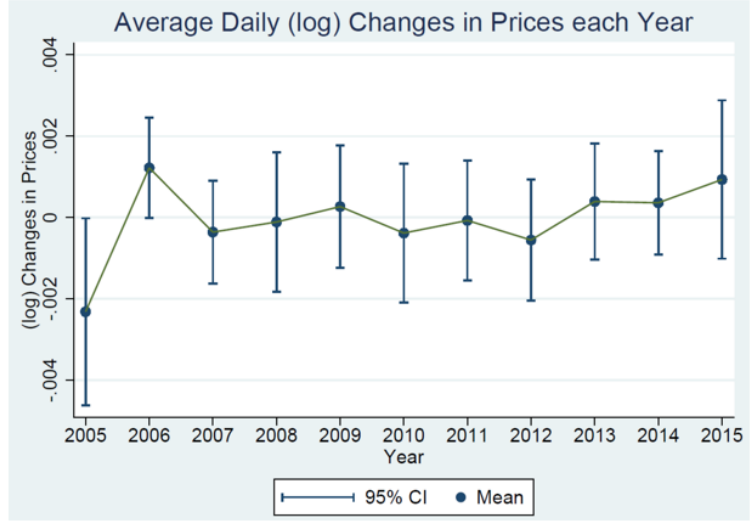

(a)

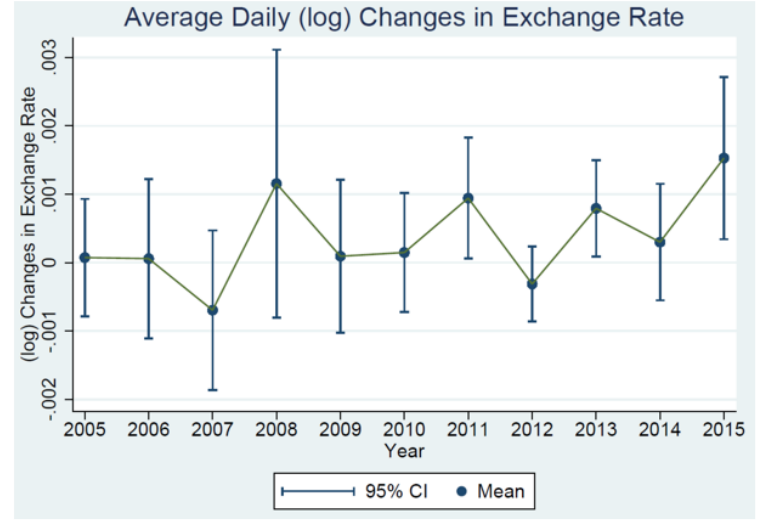

(b)

\subsubsection{Local Macroeconomic Developments; Daily Domestic Inflation Rate}

For each day, we calculated the average percentage change in goods-level prices after ignoring the outlier goods - defined as those that have price changes more than two standard deviations away from the average inflation rate. We constructed a domestic daily inflation rate out of daily price data for 311 agricultural commodities produced within Turkey. For each commodity, we calculated the daily price percentage change. Then, for each day, we calculated the mean price percentage change across commodities. We used this preliminary average in order to get rid of within-day outliers. Within a given day, a price percentage change was considered an outlier if it fell less than or more than two standard deviations away from the preliminary mean price percentage change for that day. Finally, once we eliminated the outliers, we took the simple average of the daily price percentage change across the 311 commodities (again) in order to obtain the daily inflation rate.

\subsubsection{The Storage Life of a Commodity - Perishability}

To investigate the effect of perishability, given that our data set consists of agricultural imported commodities, we also study whether ERPT varies with respect to the storage life of a 
commodity. ${ }^{7}$ This investigation motivated by studies such as by Kryvtsov and Midrigan (2012) and Alessandria, Kaboski, and Midrigan (2013), who have shown that the optimal price (and thus markups) of any seller decreases with the depreciation rate of inventories. Intuitively, since sellers may want to sell more perishable goods as soon as possible due to their high depreciation rate, they may accept lower price offers, independent of NER changes. This translates into an ERPT that is higher for less-perishable products in relative terms. Therefore, we use the storage life measures provided by Cantwell (2001) that cover all of our agricultural products. Table 4-1, shows the storage life for each one of these imported commodities. The storage potential of produce depends on several physiological and environmental factors, chief among them are respiration rates, transpiration, ethylene production, storage conditions, temperature, and humidity.

\footnotetext{
${ }^{7}$ Indeed, there exists a mapping between the storage potential of a commodity and its degree of perishability; the lower the storage potential the higher the degree of perishability, while the higher the storage potential the lower the degree of perishability.
} 
Table 4-1 Descriptive Statistics

\begin{tabular}{|c|c|c|c|c|c|c|c|}
\hline \multirow[b]{2}{*}{ Imported Good Name - Unit } & \multicolumn{7}{|c|}{ Daily Price Change } \\
\hline & Average & Median & Minimum & Maximum & $\begin{array}{l}\text { Standard } \\
\text { Deviation }\end{array}$ & Storage Life in Weeks & $\begin{array}{l}\text { Frequency of Daily } \\
\text { Price Change }\end{array}$ \\
\hline Apple (Gransimit) - Box & $0.02 \%$ & $0.00 \%$ & $-51.08 \%$ & $44.18 \%$ & $4.30 \%$ & 6 & $15.31 \%$ \\
\hline Apple (Gransimit) - Kilogram & $0.03 \%$ & $0.00 \%$ & $-28.77 \%$ & $28.77 \%$ & $5.43 \%$ & 6 & $16.73 \%$ \\
\hline Apple (Red) - Box & $0.06 \%$ & $0.00 \%$ & $-28.77 \%$ & $32.54 \%$ & $4.40 \%$ & 6 & $9.49 \%$ \\
\hline Apple (Red) - Kilogram & $0.00 \%$ & $0.00 \%$ & $0.00 \%$ & $0.00 \%$ & $0.00 \%$ & 6 & $0.00 \%$ \\
\hline Apple (Red) - Number & $-0.89 \%$ & $0.00 \%$ & $-22.31 \%$ & $0.00 \%$ & $4.46 \%$ & 6 & $4.00 \%$ \\
\hline Apple (Starking) - Box & $0.01 \%$ & $0.00 \%$ & $-28.77 \%$ & $25.13 \%$ & $3.63 \%$ & 6 & $11.55 \%$ \\
\hline Apple (Starking) - Kilogram & $-2.39 \%$ & $0.00 \%$ & $-11.78 \%$ & $0.00 \%$ & $4.47 \%$ & 6 & $23.53 \%$ \\
\hline Apricot - Kilogram & $0.00 \%$ & $0.00 \%$ & $0.00 \%$ & $0.00 \%$ & $0.00 \%$ & 2 & $0.00 \%$ \\
\hline Asparagus - Box & $0.00 \%$ & $0.00 \%$ & $0.00 \%$ & $0.00 \%$ & $0.00 \%$ & 3 & $0.00 \%$ \\
\hline Asparagus - Kilogram & $0.01 \%$ & $0.00 \%$ & $-55.96 \%$ & $51.08 \%$ & $6.15 \%$ & 3 & $16.75 \%$ \\
\hline Avocado - Quantity & $-0.11 \%$ & $0.00 \%$ & $-40.55 \%$ & $40.55 \%$ & $5.41 \%$ & 3 & $6.21 \%$ \\
\hline Banana (1st Quality) - Box & $0.05 \%$ & $0.00 \%$ & $-39.83 \%$ & $28.77 \%$ & $4.71 \%$ & 3 & $40.33 \%$ \\
\hline Banana (2nd Quality) - Box & $0.04 \%$ & $0.00 \%$ & $-18.23 \%$ & $40.55 \%$ & $2.40 \%$ & 3 & $3.12 \%$ \\
\hline Banana (2nd Quality) - Kilogram & $0.02 \%$ & $0.00 \%$ & $-25.13 \%$ & $18.23 \%$ & $2.03 \%$ & 3 & $1.94 \%$ \\
\hline Carambola - Box & $-0.04 \%$ & $0.00 \%$ & $-26.24 \%$ & $33.65 \%$ & $1.71 \%$ & 4 & $0.91 \%$ \\
\hline Cherry - Kilogram & $0.00 \%$ & $0.00 \%$ & $0.00 \%$ & $0.00 \%$ & $0.00 \%$ & 7 & $0.00 \%$ \\
\hline Coconut - Quantity & $0.02 \%$ & $0.00 \%$ & $-51.08 \%$ & $69.31 \%$ & $3.50 \%$ & 6 & $1.61 \%$ \\
\hline Fresh Coconut - Quantity & $0.00 \%$ & $0.00 \%$ & $0.00 \%$ & $0.00 \%$ & $0.00 \%$ & 6 & $0.00 \%$ \\
\hline Garlic - Box & $-0.07 \%$ & $0.00 \%$ & $-18.23 \%$ & $20.07 \%$ & $2.87 \%$ & 26 & $5.39 \%$ \\
\hline Garlic - Kilogram & $-0.02 \%$ & $0.00 \%$ & $-31.85 \%$ & $35.67 \%$ & $2.75 \%$ & 26 & $2.18 \%$ \\
\hline Ginger (Ginger) - Kilogram & $-0.02 \%$ & $0.00 \%$ & $-61.90 \%$ & $69.31 \%$ & $3.88 \%$ & 24 & $3.44 \%$ \\
\hline Ginger (Ginger) - Number & $0.02 \%$ & $0.00 \%$ & $0.00 \%$ & $6.06 \%$ & $0.38 \%$ & 24 & $0.38 \%$ \\
\hline Grape (Red) - Box & $-0.12 \%$ & $0.00 \%$ & $-47.00 \%$ & $18.23 \%$ & $5.46 \%$ & 14 & $8.93 \%$ \\
\hline Grape (Red) - Kilogram & $0.00 \%$ & $0.00 \%$ & $0.00 \%$ & $0.00 \%$ & $0.00 \%$ & 14 & $0.00 \%$ \\
\hline Grapefruit - Kilogram & $0.48 \%$ & $0.00 \%$ & $-22.31 \%$ & $47.00 \%$ & $7.11 \%$ & 7 & $9.93 \%$ \\
\hline Grapes - Kilogram & $0.18 \%$ & $0.00 \%$ & $-30.54 \%$ & $33.65 \%$ & $5.25 \%$ & 14 & $13.35 \%$ \\
\hline Grapes (Black) - Kilogram & $-0.31 \%$ & $0.00 \%$ & $-45.20 \%$ & $33.65 \%$ & $4.44 \%$ & 14 & $3.62 \%$ \\
\hline Grapes (seedless) - Box & $-0.08 \%$ & $0.00 \%$ & $-47.00 \%$ & $18.23 \%$ & $6.44 \%$ & 14 & $10.14 \%$ \\
\hline Grapes (seedless) - Kilogram & $-0.05 \%$ & $0.00 \%$ & $-10.54 \%$ & $4.08 \%$ & $1.04 \%$ & 14 & $1.68 \%$ \\
\hline Iceberg - Box & $-0.63 \%$ & $0.00 \%$ & $-40.55 \%$ & $23.64 \%$ & $6.33 \%$ & 3 & $9.73 \%$ \\
\hline Iceberg - Fund & $-2.03 \%$ & $0.00 \%$ & $-18.23 \%$ & $10.54 \%$ & $6.05 \%$ & 3 & $20.69 \%$ \\
\hline Kiwi - Package & $0.00 \%$ & $0.00 \%$ & $-51.08 \%$ & $43.08 \%$ & $5.88 \%$ & 16 & $21.16 \%$ \\
\hline Kiwi (30s) - Package & $0.07 \%$ & $0.00 \%$ & $-35.67 \%$ & $61.31 \%$ & $5.96 \%$ & 16 & $3.27 \%$ \\
\hline Limes - Box & $0.07 \%$ & $0.00 \%$ & $-40.55 \%$ & $54.86 \%$ & $3.31 \%$ & 7 & $1.75 \%$ \\
\hline Limes - Kilogram & $0.04 \%$ & $0.00 \%$ & $-51.08 \%$ & $30.23 \%$ & $5.34 \%$ & 7 & $15.29 \%$ \\
\hline Mango - Quantity & $-0.09 \%$ & $0.00 \%$ & $-281.34 \%$ & $40.55 \%$ & $6.55 \%$ & 3 & $3.60 \%$ \\
\hline Melon - Kilogram & $-0.35 \%$ & $0.00 \%$ & $-34.83 \%$ & $35.67 \%$ & $4.15 \%$ & 3 & $7.96 \%$ \\
\hline Nectarine - Kilogram & $-0.05 \%$ & $0.00 \%$ & $-15.42 \%$ & $15.42 \%$ & $1.82 \%$ & 3 & $1.81 \%$ \\
\hline Papaya - Quantity & $0.07 \%$ & $0.00 \%$ & $-51.08 \%$ & $69.31 \%$ & $3.79 \%$ & 2 & $2.74 \%$ \\
\hline Pears - Kilogram & $-0.04 \%$ & $0.00 \%$ & $-28.77 \%$ & $36.77 \%$ & $4.27 \%$ & 18 & $6.12 \%$ \\
\hline Pears - Package & $-0.54 \%$ & $0.00 \%$ & $-30.54 \%$ & $13.35 \%$ & $7.35 \%$ & 18 & $13.64 \%$ \\
\hline Pepino - Kilogram & $-0.01 \%$ & $0.00 \%$ & $-69.31 \%$ & $69.31 \%$ & $5.71 \%$ & 4 & $3.39 \%$ \\
\hline Pineapple - Quantity & $0.01 \%$ & $0.00 \%$ & $-53.06 \%$ & $58.78 \%$ & $6.16 \%$ & 3 & $21.82 \%$ \\
\hline Pomegranate - Kilogram & $-0.09 \%$ & $0.00 \%$ & $-55.00 \%$ & $28.77 \%$ & $6.58 \%$ & 10 & $11.51 \%$ \\
\hline Pomelo - Quantity & $-0.03 \%$ & $0.00 \%$ & $-28.77 \%$ & $87.55 \%$ & $5.21 \%$ & 7 & $3.09 \%$ \\
\hline Physalis - Box & $-0.03 \%$ & $0.00 \%$ & $-51.08 \%$ & $61.90 \%$ & $4.55 \%$ & 4 & $3.91 \%$ \\
\hline Physalis - Kilogram & $-0.13 \%$ & $0.00 \%$ & $-15.42 \%$ & $0.00 \%$ & $1.38 \%$ & 4 & $0.92 \%$ \\
\hline Physalis - Quantity & $0.00 \%$ & $0.00 \%$ & $0.00 \%$ & $0.00 \%$ & $0.00 \%$ & 4 & $0.00 \%$ \\
\hline Raspberry - Box & $0.00 \%$ & $0.00 \%$ & $0.00 \%$ & $0.00 \%$ & $0.00 \%$ & 1 & $0.00 \%$ \\
\hline Tangerines - Kilogram & $-0.31 \%$ & $0.00 \%$ & $-13.35 \%$ & $0.00 \%$ & $2.04 \%$ & 3 & $2.33 \%$ \\
\hline $\begin{array}{l}\text { Watermelon (1st Quality) - } \\
\text { Kilogram }\end{array}$ & $-0.53 \%$ & $0.00 \%$ & $-69.31 \%$ & $56.80 \%$ & $9.51 \%$ & 3 & $7.28 \%$ \\
\hline $\begin{array}{l}\text { Watermelon (2nd Quality) - } \\
\text { Kilogram }\end{array}$ & $-1.20 \%$ & $0.00 \%$ & $-28.77 \%$ & $0.00 \%$ & $5.87 \%$ & 3 & $4.17 \%$ \\
\hline Daily Exchange Rate & $0.03 \%$ & $-0.02 \%$ & $-11.94 \%$ & $7.04 \%$ & $0.86 \%$ & & \\
\hline Daily Domestic Inflation & $-0.07 \%$ & $0.00 \%$ & $-19.15 \%$ & $8.82 \%$ & $1.70 \%$ & & \\
\hline
\end{tabular}




\subsubsection{Benchmark Empirical Methodology}

Following studies such as Campa and Goldberg (2005) and Burstein and Gopinath (2014), we use the following standard specification in order to measure ERPT with control for domestic inflation:

$$
\Delta P_{g, t}=\alpha+\left(\sum_{k=0}^{T} \beta_{k} \Delta e_{t-k}\right)+\gamma \pi_{t}+\delta_{g}+S_{t}+\varepsilon_{t}
$$

where $\Delta P_{g, t}$ is the daily change in log wholesale price of imported goods, $\mathrm{g}, \beta_{k}$ measures the exchange rate pass through of the k'th lag of the log NER change, $\Delta e_{t-k}$ is the k'th lag of the $\log$ NER change, $\pi_{t}$ is the daily domestic inflation rate (as a control variable), $\delta_{g}$ are goods fixed effects, $S_{t}$ represents seasonality controls, and $\varepsilon_{t}$ is the error term. Augmented Dickey-Fuller null hypothesis and Phillips-Perron unit root tests suggest that the level of prices and exchange rates are non-stationarity, but both variables become stationary after considering daily log changes; this is the reason behind our specification. Co-integration tests based on the Engle-Granger procedure suggest that residuals are I (0).

The number of daily lags $\mathrm{T}$ in the benchmark equation is determined by using the Akaike information criterion (AIC) and the Bayesian information criterion (BIC), together with the significance of the corresponding coefficients. Moreover, the usage of the domestic inflation rate $\pi_{t}$ as a control variable is essential to identify the pure effects of NER changes as a source of daily foreign shocks. Goods fixed effects of $\delta_{g}$ are useful to control for goods-specific factors. Following studies using daily data sets such as Al-Khazali (2008), Al-Ississ (2010), Anson, Boffa, and Helble (2014), and Ali and Akhter (2016) seasonality controls $S_{t}$ include weekday fixed effects, monthly fixed effects, and Ramadan fixed effects, where the period of Ramadan changes each year with respect to the religious calendar. Although the first equation is the benchmark equation, we consider several alternatives in order to understand different dimensions of the data set. We introduce such alternative specification in Section 4.3. 


\subsubsection{Daily ERPT with Threshold Methodology}

We consider potential nonlinearities in the determination of ERPT, studies of which (Ben Cheikh \& Rault, 2016; Cheikh \& Louhichi, 2016; Donayre \& Panovska, 2016; Shintani et al., 2013) have made use of both the threshold approach and the smooth transition framework. While the transition from one regime to the next is instantaneous in the sense that the nonlinearity kicks in fully and immediately once the transition variable passes its threshold value in a threshold regression, the transition across extreme regimes is gradual in a smooth transition regression. The choice of one approach over another depends on whether the analysis is at the macro or microeconomic level as discussed in detail by Ben Cheikh and Rault (2017). Within this context, since we employ micro-price data, we consider the following threshold regression:

$$
\begin{aligned}
\Delta P_{g, t}=\alpha+\left(\sum_{k=0}^{T} \beta_{k} \Delta e_{t-k} I\left(q_{g, t} \leq \tau\right)\right)+\left(\sum_{k=0}^{T} \beta_{k} \Delta e_{t-k} I\left(q_{g, t}>\tau\right)\right)+\gamma \pi_{t}+\delta_{g}+S_{t} \\
\quad+\varepsilon_{t}
\end{aligned}
$$

where $q_{g, t}$ is the threshold variable (representing NER, frequency of price change, or storage life), $\tau$ is the corresponding threshold value, $\mathrm{I}\left(q_{g, t} \leq \tau\right)$ is an indicator function taking a value of 1 if $q_{g, t} \leq \tau$ and 0 otherwise, and $\mathrm{I}\left(q_{g, t}>\tau\right)$ is an indicator function taking a value of 1

if $q_{g, t}>\tau$ and 0 otherwise. Following studies such as Chan (1993) and Hansen (2000), we estimate $\tau$ using least squares with the objective of minimizing the residual sum of squares.

\subsection{Empirical Results}

As is standard in the literature, this section depicts the empirical results of daily ERPT based on alternative control variables, alternative lags on NER, and alternative subsamples.

\subsubsection{Daily Lag Selection}

The results for the benchmark empirical specification are given in Table 4-2, where we consider lags of NER up to $\mathrm{T}=8$; where the criteria of AIC and BIC both select $\mathrm{T}=1$ (followed 
by $\mathrm{T}=0$ ), and the corresponding coefficient of lagged NER is statistically insignificant in all specifications. Accordingly, we consider the lag selection of $\mathrm{T}=0$ for the rest of our investigation, which is in line with studies based on daily data such as Lott and Einav (2013). Therefore, the coefficient of the current log NER change $\beta_{0}$ corresponds to the measure of ERPT as well. Although, in the case of non-zero price changes, we observe in Table 4-3 that both the AIC and the BIC select $\mathrm{T}=1$, however, the first lag is statistically insignificant. Thus, we consider following the contemporaneous exchange rate $\mathrm{T}=0$.

It is implied that the coefficient of the current log NER change corresponds to the measure of ERPT as well. Within this context, the results in Table 4-2 show that ERPT is about 5\%, which suggests that a $1 \%$ change in NER corresponds to a $0.05 \%$ change in prices on average. Compared with existing studies in the literature, ERPT measures in this paper are similar to those estimated at the goods level, especially for the category of food (e.g., Aron et al., 2014; Gopinath et al., 2010; Lott \& Einav, 2013), although the coefficients are lower compared with the studies based on aggregate-level data sets for which there is evidence for even complete ERPT (e.g., Goldberg \& Knetter, 1997; Menon, 1995). Although, the coefficients for the contemporaneous exchange rate in the case of non-zero price changes regressions (see Table 4-3) vary more in magnitude across specifications than do the coefficients for the contemporaneous exchange rate from all price changes regressions. Furthermore, coefficients in the case of non-zero price changes, are significantly larger than the coefficients from the case of all price changes regressions. Indeed, using only actual changes in prices in the estimation of the ERPT coefficients amplifies the ERPT effect. 
Table 4-2 Daily ERPT with Alternative Lags, All Price Changes

\begin{tabular}{|c|c|c|c|c|c|c|c|c|c|}
\hline VARIABLES & $\begin{array}{l}(1) \\
\text { Price }\end{array}$ & $\begin{array}{l}(2) \\
\text { Price }\end{array}$ & $\begin{array}{l}(3) \\
\text { Price }\end{array}$ & $\begin{array}{l}(4) \\
\text { Price }\end{array}$ & $\begin{array}{l}(5) \\
\text { Price }\end{array}$ & $\begin{array}{l}(6) \\
\text { Price }\end{array}$ & $\begin{array}{l}(7) \\
\text { Price }\end{array}$ & $\begin{array}{l}(8) \\
\text { Price }\end{array}$ & $\begin{array}{l}(9) \\
\text { Price }\end{array}$ \\
\hline Exchange Rate & $\begin{array}{l}0.0490 * * \\
(0.0230)\end{array}$ & $\begin{array}{l}0.0438 * \\
(0.0255)\end{array}$ & $\begin{array}{l}0.0520 * \\
(0.0271)\end{array}$ & $\begin{array}{l}0.0598 * * \\
(0.0272)\end{array}$ & $\begin{array}{l}0.0623 * * \\
(0.0291)\end{array}$ & $\begin{array}{l}0.0585^{*} \\
(0.0300)\end{array}$ & $\begin{array}{l}0.0616^{*} \\
(0.0314)\end{array}$ & $\begin{array}{l}0.0594^{*} \\
(0.0325)\end{array}$ & $\begin{array}{l}0.0582 * \\
(0.0337)\end{array}$ \\
\hline Exchange Rate, Lag 1 & & $\begin{array}{l}-0.0386 \\
(0.0289)\end{array}$ & $\begin{array}{l}-0.00581 \\
(0.0289)\end{array}$ & $\begin{array}{l}-0.0157 \\
(0.0293)\end{array}$ & $\begin{array}{l}-0.00894 \\
(0.0278)\end{array}$ & $\begin{array}{l}-0.0155 \\
(0.0292)\end{array}$ & $\begin{array}{l}-0.0166 \\
(0.0294)\end{array}$ & $\begin{array}{l}-0.0167 \\
(0.0294)\end{array}$ & $\begin{array}{l}-0.0238 \\
(0.0294)\end{array}$ \\
\hline Exchange Rate, Lag 2 & & & $\begin{array}{l}0.0542 * \\
(0.0296)\end{array}$ & $\begin{array}{l}0.0795 * * * \\
(0.0272)\end{array}$ & $\begin{array}{l}0.0740 * * * \\
(0.0268)\end{array}$ & $\begin{array}{l}0.0546 * * \\
(0.0269)\end{array}$ & $\begin{array}{l}0.0507 * \\
(0.0291)\end{array}$ & $\begin{array}{l}0.0526 \\
(0.0315)\end{array}$ & $\begin{array}{l}0.0451 \\
(0.0312)\end{array}$ \\
\hline Exchange Rate, Lag 3 & & & & $\begin{array}{l}-0.00991 \\
(0.0284)\end{array}$ & $\begin{array}{l}0.000741 \\
(0.0301)\end{array}$ & $\begin{array}{l}2.69 \mathrm{e}-06 \\
(0.0306)\end{array}$ & $\begin{array}{l}-0.00303 \\
(0.0291)\end{array}$ & $\begin{array}{l}-0.000575 \\
(0.0301)\end{array}$ & $\begin{array}{l}-0.00185 \\
(0.0303)\end{array}$ \\
\hline Exchange Rate, Lag 4 & & & & & $\begin{array}{l}-0.00601 \\
(0.0287)\end{array}$ & $\begin{array}{l}-0.0257 \\
(0.0275)\end{array}$ & $\begin{array}{l}-0.0210 \\
(0.0265)\end{array}$ & $\begin{array}{l}-0.0273 \\
(0.0270)\end{array}$ & $\begin{array}{l}-0.0239 \\
(0.0266)\end{array}$ \\
\hline Exchange Rate, Lag 5 & & & & & & $\begin{array}{l}0.0418 \\
(0.0264)\end{array}$ & $\begin{array}{l}0.0432 \\
(0.0281)\end{array}$ & $\begin{array}{l}0.0345 \\
(0.0277)\end{array}$ & $\begin{array}{l}0.0258 \\
(0.0268)\end{array}$ \\
\hline Exchange Rate, Lag 6 & & & & & & & $\begin{array}{l}-0.0362 \\
(0.0217)\end{array}$ & $\begin{array}{l}-0.0248 \\
(0.0253)\end{array}$ & $\begin{array}{l}-0.0255 \\
(0.0262)\end{array}$ \\
\hline Exchange Rate, Lag 7 & & & & & & & & $\begin{array}{l}0.0194 \\
(0.0309)\end{array}$ & $\begin{array}{l}0.0179 \\
(0.0327)\end{array}$ \\
\hline Exchange Rate, Lag 8 & & & & & & & & & $\begin{array}{l}0.00297 \\
(0.0229)\end{array}$ \\
\hline Inflation & $\begin{array}{l}0.335 * * * \\
(0.0694)\end{array}$ & $\begin{array}{l}0.325^{* * * *} \\
(0.0684)\end{array}$ & $\begin{array}{l}0.328 * * * \\
(0.0695)\end{array}$ & $\begin{array}{l}0.334 * * * \\
(0.0709)\end{array}$ & $\begin{array}{l}0.339 * * * \\
(0.0716)\end{array}$ & $\begin{array}{l}0.344 * * * \\
(0.0713)\end{array}$ & $\begin{array}{l}0.334 * * * \\
(0.0712)\end{array}$ & $\begin{array}{l}0.336 * * * \\
(0.0708)\end{array}$ & $\begin{array}{l}0.335 * * * \\
(0.0714)\end{array}$ \\
\hline Constant & $\begin{array}{l}-0.00435 * * * \\
(0.000739)\end{array}$ & $\begin{array}{l}-0.00361 * * * \\
(0.000702)\end{array}$ & $\begin{array}{l}-0.00372 * * * \\
(0.000758)\end{array}$ & $\begin{array}{l}-0.00396 * * * \\
(0.000778)\end{array}$ & $\begin{array}{l}-0.00293 * * * \\
(0.000659)\end{array}$ & $\begin{array}{l}-0.00353 * * * \\
(0.000728)\end{array}$ & $\begin{array}{l}-0.00361 * * * \\
(0.000788)\end{array}$ & $\begin{array}{l}-0.00372^{* * * *} \\
(0.000812)\end{array}$ & $\begin{array}{l}-0.00410 * * * \\
(0.000829)\end{array}$ \\
\hline Observations & 37,806 & 36,950 & 36,058 & 35,164 & 34,291 & 33,503 & 32,743 & 31,997 & 31,253 \\
\hline R-squared & 0.019 & 0.021 & 0.021 & 0.021 & 0.021 & 0.021 & 0.021 & 0.021 & 0.021 \\
\hline Goods FE & YES & YES & YES & YES & YES & YES & YES & YES & YES \\
\hline Seasonality & YES & YES & YES & YES & YES & YES & YES & YES & YES \\
\hline AIC & -123466 & -124685 & -121932 & -118911 & -116218 & -113645 & -110946 & -108199 & -105873 \\
\hline $\mathrm{BIC}$ & -123312 & -124523 & -121762 & -118733 & -116032 & -113452 & -110744 & -107989 & -105656 \\
\hline
\end{tabular}

Notes: $* * * \mathrm{p}<0.01, * * \mathrm{p}<0.05, * \mathrm{p}<0.1$, Robust standard errors in parentheses. 
Table 4-3 Daily ERPT with Alternative Lags, Non-zero Price Changes

\begin{tabular}{|c|c|c|c|c|c|c|c|c|c|}
\hline VARIABLES & $\begin{array}{l}(1) \\
\text { Price }\end{array}$ & $\begin{array}{l}(2) \\
\text { Price }\end{array}$ & $\begin{array}{l}(3) \\
\text { Price }\end{array}$ & $\begin{array}{l}(4) \\
\text { Price }\end{array}$ & $\begin{array}{l}(5) \\
\text { Price }\end{array}$ & $\begin{array}{l}(6) \\
\text { Price }\end{array}$ & $\begin{array}{l}(7) \\
\text { Price }\end{array}$ & $\begin{array}{l}(8) \\
\text { Price }\end{array}$ & $\begin{array}{l}(9) \\
\text { Price }\end{array}$ \\
\hline Exchange Rate & $\begin{array}{l}0.639 * * \\
(0.294)\end{array}$ & $\begin{array}{l}0.550 * * \\
(0.270)\end{array}$ & $\begin{array}{l}0.675^{* *} * \\
(0.302)\end{array}$ & $\begin{array}{l}0.775^{* *} \\
(0.305)\end{array}$ & $\begin{array}{l}0.800 * * \\
(0.307)\end{array}$ & $\begin{array}{l}0.807 * * * \\
(0.298)\end{array}$ & $\begin{array}{l}0.889 * * \\
(0.337)\end{array}$ & $\begin{array}{l}0.863 * * \\
(0.328)\end{array}$ & $\begin{array}{l}0.802 * * \\
(0.327)\end{array}$ \\
\hline Exchange Rate, Lag 1 & & $\begin{array}{l}-0.524^{*} \\
(0.261)\end{array}$ & $\begin{array}{l}-0.276 \\
(0.313)\end{array}$ & $\begin{array}{l}-0.420 \\
(0.314)\end{array}$ & $\begin{array}{l}-0.385 \\
(0.300)\end{array}$ & $\begin{array}{l}-0.467 \\
(0.312)\end{array}$ & $\begin{array}{l}-0.423 \\
(0.303)\end{array}$ & $\begin{array}{l}-0.436 \\
(0.309)\end{array}$ & $\begin{array}{l}-0.478 \\
(0.306)\end{array}$ \\
\hline Exchange Rate, Lag 2 & & & $\begin{array}{l}0.305 \\
(0.334)\end{array}$ & $\begin{array}{l}0.656^{*} \\
(0.329)\end{array}$ & $\begin{array}{l}0.595^{*} \\
(0.316)\end{array}$ & $\begin{array}{l}0.350 \\
(0.306)\end{array}$ & $\begin{array}{l}0.290 \\
(0.326)\end{array}$ & $\begin{array}{l}0.301 \\
(0.336)\end{array}$ & $\begin{array}{l}0.162 \\
(0.334)\end{array}$ \\
\hline Exchange Rate, Lag 3 & & & & $\begin{array}{l}0.141 \\
(0.284)\end{array}$ & $\begin{array}{l}0.326 \\
(0.307)\end{array}$ & $\begin{array}{l}0.277 \\
(0.314)\end{array}$ & $\begin{array}{l}0.245 \\
(0.302)\end{array}$ & $\begin{array}{l}0.306 \\
(0.307)\end{array}$ & $\begin{array}{l}0.327 \\
(0.309)\end{array}$ \\
\hline Exchange Rate, Lag 4 & & & & & $\begin{array}{l}0.110 \\
(0.289)\end{array}$ & $\begin{array}{l}-0.155 \\
(0.235)\end{array}$ & $\begin{array}{l}-0.154 \\
(0.226)\end{array}$ & $\begin{array}{l}-0.202 \\
(0.233)\end{array}$ & $\begin{array}{l}-0.130 \\
(0.241)\end{array}$ \\
\hline Exchange Rate, Lag 5 & & & & & & $\begin{array}{l}0.534 * \\
(0.272)\end{array}$ & $\begin{array}{l}0.602 * \\
(0.307)\end{array}$ & $\begin{array}{l}0.531 \\
(0.325)\end{array}$ & $\begin{array}{l}0.432 \\
(0.316)\end{array}$ \\
\hline Exchange Rate, Lag 6 & & & & & & & $\begin{array}{l}-0.328 \\
(0.250)\end{array}$ & $\begin{array}{l}-0.198 \\
(0.302)\end{array}$ & $\begin{array}{l}-0.198 \\
(0.312)\end{array}$ \\
\hline Exchange Rate, Lag 7 & & & & & & & & $\begin{array}{l}0.0858 \\
(0.360)\end{array}$ & $\begin{array}{l}0.0153 \\
(0.378)\end{array}$ \\
\hline Exchange Rate, Lag 8 & & & & & & & & & $\begin{array}{l}0.142 \\
(0.233)\end{array}$ \\
\hline Inflation & $\begin{array}{l}1.681 * * * \\
(0.101)\end{array}$ & $\begin{array}{l}1.646 * * * \\
(0.105)\end{array}$ & $\begin{array}{l}1.633 * * * \\
(0.0986)\end{array}$ & $\begin{array}{l}1.645^{* * *} \\
(0.103)\end{array}$ & $\begin{array}{l}1.682 * * * \\
(0.1000)\end{array}$ & $\begin{array}{l}1.707 * * * \\
(0.102)\end{array}$ & $\begin{array}{l}1.664 * * * \\
(0.106)\end{array}$ & $\begin{array}{l}1.678 * * * \\
(0.108)\end{array}$ & $\begin{array}{l}1.670 \text { *** } \\
(0.111)\end{array}$ \\
\hline Constant & $\begin{array}{l}-0.0361 * * \\
(0.0143)\end{array}$ & $\begin{array}{l}-0.0216^{* *} \\
(0.00808)\end{array}$ & $\begin{array}{l}-0.0234 * * * \\
(0.00804)\end{array}$ & $\begin{array}{l}-0.0243 * * * \\
(0.00827)\end{array}$ & $\begin{array}{l}-0.0230 * * * \\
(0.00777)\end{array}$ & $\begin{array}{l}-0.0254 * * * \\
(0.00715)\end{array}$ & $\begin{array}{l}-0.0271 * * * \\
(0.00721)\end{array}$ & $\begin{array}{l}-0.0271 * * * \\
(0.00760)\end{array}$ & $\begin{array}{l}-0.0316 * * * \\
(0.00853)\end{array}$ \\
\hline Observations & 3,989 & 3,897 & 3,792 & 3,698 & 3,596 & 3,507 & 3,430 & 3,361 & 3,278 \\
\hline R-squared & 0.115 & 0.124 & 0.123 & 0.124 & 0.125 & 0.129 & 0.128 & 0.128 & 0.129 \\
\hline Goods FE & YES & YES & YES & YES & YES & YES & YES & YES & YES \\
\hline Seasonality & YES & YES & YES & YES & YES & YES & YES & YES & YES \\
\hline AIC & -4433 & -4785 & -4664 & -4551 & -4444 & -4349 & -4237 & -4137 & -4049 \\
\hline $\mathrm{BIC}$ & -4319 & -4666 & -4539 & -4420 & -4307 & -4208 & -4090 & -3984 & -3891 \\
\hline
\end{tabular}

Notes: $* * * \mathrm{p}<0.01, * * \mathrm{p}<0.05, * \mathrm{p}<0.1$, Robust standard errors in parentheses. 


\subsubsection{Control Variables Selection}

After setting the NER lags selection, we set the control variables (inflation, seasonality, and goods fixed effects). We include different specification for the benchmark equation to justify the usage of the domestic inflation rate, seasonality variables, and goods fixed effects as control variables to identify the pure effects of NER as a source of daily foreign shocks. Therefore, in the benchmark regression we include different control variables and further consider several numbers of lag terms of exchange rate changes. Table 4-4 and Table 4-5 present the estimation of ERPT based on the benchmark regression model with inclusion of a domestic inflation control variable, $\pi_{t}$, while neither seasonality control variables nor goods fixed effects are included in the model for two different specifications (all price changes and non-zero price changes) discussed in the previous section. These tables serve to demonstrate that the model fits significantly better when inflation is controlled for. The R-squared indicates that we should control for domestic inflation; by including a domestic inflation control variable, we observe higher R-squared.

Moreover, once the model controls for inflation, the AIC and BIC suggest we should at most consider including up to the first exchange rate lag in future specifications. Among the five models considered here, Model (4) is the most parsimonious based on the AIC and BIC model selection criteria. Based on the results, we can observe that the ERPT is incomplete and about 5\% in the case of all price changes. The coefficients for contemporaneous exchange rate do not vary significantly across specifications for this version. However, the daily ERPT in the case of nonzero price changes regressions vary more in magnitude across specifications and are significantly larger than the coefficients from the case of all price changes regressions. In particular, for each specification the contemporaneous ERPT coefficient in the case of non-zero price changes regression has a magnitude that is about 10 times as large as the magnitude of the contemporaneous ERPT coefficient in the case of all price changes regressions. 
Table 4-4 Daily ERPT with Alternative Lags and Inflation Control Variable, All Price Changes

\begin{tabular}{llllll}
\hline & $(1)$ & $(2)$ & $(3)$ & $(4)$ & $(5)$ \\
VARIABLES & Price & Price & Price & Price & Price \\
\hline Exchange Rate & & & & & \\
& $0.0466^{* *}$ & 0.0372 & $0.0480^{*}$ & $0.0454^{*}$ & $0.0542^{*}$ \\
Exchange Rate, Lag 1 & $(0.0220)$ & $(0.0242)$ & $(0.0259)$ & $(0.0254)$ & $(0.0271)$ \\
& & -0.0354 & -0.000344 & -0.0363 & -0.00455 \\
Exchange Rate, Lag 2 & & $(0.0278)$ & $(0.0282)$ & $(0.0278)$ & $(0.0285)$ \\
& & & $0.0610^{*}$ & & $0.0628^{* *}$ \\
Inflation & & & $(0.0306)$ & & $(0.0306)$ \\
& & & & $0.351^{* * *}$ & $0.356^{* * *}$ \\
Constant & $-8.87 \mathrm{e}-05$ & $4.45 \mathrm{e}-05$ & $-5.02 \mathrm{e}-06$ & $0.000269^{*}$ & 0.000195 \\
& $(0.000124)$ & $(0.000111)$ & $(0.000110)$ & $(0.000136)$ & $(0.000133)$ \\
Observations & 37,806 & 36,950 & 36,058 & 36,950 & 36,058 \\
R-squared & 0.000 & 0.000 & 0.000 & 0.017 & 0.017 \\
AIC & -122766 & -123944 & -121222 & -124572 & -121830 \\
BIC & -122748 & -123918 & -121188 & -124538 & -121787 \\
\hline
\end{tabular}

Notes: $* * * \mathrm{p}<0.01, * * \mathrm{p}<0.05, * \mathrm{p}<0.1$, Robust standard errors in parentheses.

Table 4-5 Daily ERPT with Alternative Lags and Inflation Control Variable, Non-zero Price Changes

\begin{tabular}{llllll}
\hline & $(1)$ & $(2)$ & $(3)$ & $(4)$ & $(5)$ \\
VARIABLES & Price & Price & Price & Price & Price \\
\hline Exchange Rate & & & & & \\
& $0.475^{* *}$ & 0.347 & $0.480^{*}$ & $0.594^{* *}$ & $0.749^{* *}$ \\
Exchange Rate, Lag 1 & $(0.215)$ & $(0.222)$ & $(0.248)$ & $(0.258)$ & $(0.295)$ \\
& & -0.324 & 0.0546 & $-0.546^{*}$ & -0.325 \\
Exchange Rate, Lag 2 & & $(0.244)$ & $(0.320)$ & $(0.286)$ & $(0.326)$ \\
& & & $0.610^{*}$ & & 0.424 \\
Inflation & & & $(0.345)$ & & $(0.352)$ \\
& & & & $1.837^{* * *}$ & $1.848^{* * *}$ \\
Constant & -0.000929 & 0.000391 & $-8.25 \mathrm{e}-06$ & 0.000932 & 0.000505 \\
& $(0.00128)$ & $(0.00104)$ & $(0.00106)$ & $(0.00120)$ & $(0.00116)$ \\
Observations & 3,989 & 3,897 & 3,792 & 3,897 & 3,792 \\
R-squared & 0.001 & 0.001 & 0.002 & 0.090 & 0.089 \\
AIC & -3981 & -4304 & -4208 & -4665 & -4551 \\
BIC & -3969 & -4285 & -4183 & -4640 & -4520 \\
\hline
\end{tabular}

Notes: $* * * \mathrm{p}<0.01, * * \mathrm{p}<0.05, * \mathrm{p}<0.1$, Robust standard errors in parentheses. 
In Table 4-6 and Table 4-7, the results are robust to the consideration of alternate control variables; we include different specification of exchange rate pass-through measures. We include seasonality controls (weekdays, months, and Ramadan or any special religious events that stimulates demand for essential products), goods fixed effects (to allow us to capture affects by different goods), and perishability. These tables seek to demonstrate that once we control for inflation, we should also control for seasonality and goods fixed effects, but not perishability. Table 4-6 shows different models including each of these control variables separately and also in a big regression. In models (2), (3), and (4), we include each of the control variables separately, and find that inclusion of seasonality and goods fixed effects shows better performance based on model selection criteria. In models (5), (6), (7), and (8), we include at least two of them together, and model selection criteria suggests not to include perishability as a control variable. Further, model (5) shows that when controlling for seasonal issues and also goods-specific characteristics, on average, ERPT is incomplete and about $4.4 \%$ for all price changes. The coefficients for contemporaneous exchange rate do not vary significantly across specifications for this case.

Moreover, in Table 4-7 for non-zero price changes, the AIC selection criteria selects model (5) where we account for both seasonality and goods fixed effects; however, the BIC selection criteria selects model (4) where we account only for goods fixed effects. To be consistent with all price changes of these specifications we should choose model (5). The contemporaneous ERPT coefficient does not vary much across specifications, fluctuating around 55\% and are significantly larger than the previous case, these estimates are closer to the ones in the literature estimated using aggregate-level data sets. Once more, using only actual changes in prices in the estimation of the ERPT coefficients amplifies the ERPT effect. 
Table 4-6 Daily ERPT with Alternative Lags and Control (Perishability, Seasonality, and Goods Fixed Effects), All Price Changes

\begin{tabular}{|c|c|c|c|c|c|c|c|c|}
\hline & (1) & (2) & (3) & (4) & (5) & (6) & (7) & (8) \\
\hline VARIABLES & Price & Price & Price & Price & Price & Price & Price & Price \\
\hline \multirow[t]{2}{*}{ Exchange Rate } & $0.0454 *$ & $0.0595^{*}$ & $0.0445^{*}$ & $0.0446 *$ & $0.0438 *$ & $0.0580^{*}$ & $0.0584 *$ & $0.0567 *$ \\
\hline & $(0.0254)$ & $(0.0303)$ & $(0.0255)$ & $(0.0253)$ & $(0.0255)$ & $(0.0303)$ & $(0.0305)$ & $(0.0305)$ \\
\hline \multirow[t]{2}{*}{ Exchange Rate, Lag 1} & -0.0363 & -0.0410 & -0.0382 & -0.0367 & -0.0386 & -0.0421 & -0.0435 & -0.0446 \\
\hline & $(0.0278)$ & $(0.0284)$ & $(0.0289)$ & $(0.0277)$ & $(0.0289)$ & $(0.0283)$ & $(0.0294)$ & $(0.0293)$ \\
\hline \multirow[t]{2}{*}{ Inflation } & $0.351 * * *$ & $0.400 * * *$ & $0.325 * * *$ & $0.350 * * *$ & $0.325 * * *$ & $0.400 * * *$ & $0.374 * * *$ & $0.374 * * *$ \\
\hline & $(0.0737)$ & $(0.0857)$ & $(0.0683)$ & $(0.0740)$ & $(0.0684)$ & $(0.0860)$ & $(0.0801)$ & $(0.0803)$ \\
\hline \multirow[t]{2}{*}{ Constant } & $0.000269^{*}$ & $0.000201 * * *$ & $-0.00227 * * *$ & $-0.00122 * * *$ & $-0.00361 * * *$ & $-0.00138 * * *$ & $-0.00212 * *$ & $-0.00377 * * *$ \\
\hline & $(0.000136)$ & $(2.98 \mathrm{e}-05)$ & $(0.000746)$ & $(0.000261)$ & $(0.000702)$ & $(0.000302)$ & $(0.000941)$ & $(0.000877)$ \\
\hline Observations & 36,950 & 25,082 & 36,950 & 36,950 & 36,950 & 25,082 & 25,082 & 25,082 \\
\hline R-squared & 0.017 & 0.023 & 0.020 & 0.018 & 0.021 & 0.024 & 0.027 & 0.028 \\
\hline AIC & -124572 & -85889 & -124656 & -124599 & -124685 & -85919 & -85962 & -85994 \\
\hline $\mathrm{BIC}$ & -124538 & -85832 & -124486 & -124574 & -124523 & -85895 & -85775 & -85840 \\
\hline Perishability & & YES & & & & YES & YES & YES \\
\hline Seasonality & & & YES & & YES & & YES & YES \\
\hline Goods FE & & & & YES & YES & YES & & YES \\
\hline
\end{tabular}

Notes: $* * * \mathrm{p}<0.01, * * \mathrm{p}<0.05, * \mathrm{p}<0.1$, Robust standard errors in parentheses. 
Table 4-7 Daily ERPT with Alternative Lags and Control (Perishability, Seasonality, and Goods Fixed Effects), Non-zero Price Changes

\begin{tabular}{|c|c|c|c|c|c|c|c|c|}
\hline & (1) & (2) & (3) & (4) & (5) & (6) & (7) & (8) \\
\hline VARIABLES & Price & Price & Price & Price & Price & Price & Price & Price \\
\hline \multirow[t]{2}{*}{ Exchange Rate } & $0.594 * *$ & $0.584 * *$ & $0.556^{* *}$ & $0.586 * *$ & $0.550 * *$ & $0.568 * *$ & $0.538^{*}$ & $0.527^{*}$ \\
\hline & $(0.258)$ & $(0.269)$ & $(0.271)$ & $(0.256)$ & $(0.270)$ & $(0.267)$ & $(0.275)$ & $(0.276)$ \\
\hline \multirow[t]{2}{*}{ Exchange Rate, Lag 1} & $-0.546 *$ & $-0.392 *$ & $-0.484 *$ & $-0.588 *$ & $-0.524^{*}$ & $-0.447 *$ & $-0.396^{*}$ & $-0.444 * *$ \\
\hline & $(0.286)$ & $(0.218)$ & $(0.257)$ & $(0.294)$ & $(0.261)$ & $(0.227)$ & $(0.201)$ & $(0.205)$ \\
\hline \multirow[t]{2}{*}{ Inflation } & $1.837 * * *$ & $1.767 * * *$ & $1.609 * * *$ & $1.869 * * *$ & $1.646^{* * *}$ & $1.799 * * *$ & $1.574 * * *$ & $1.610 * * *$ \\
\hline & $(0.147)$ & $(0.144)$ & (0.107) & $(0.146)$ & $(0.105)$ & $(0.141)$ & $(0.102)$ & $(0.0986)$ \\
\hline \multirow[t]{2}{*}{ Constant } & 0.000932 & $0.00217 * * *$ & $-0.0207 * *$ & $0.000774 * * *$ & $-0.0216^{* *}$ & -0.00136 & -0.0111 & $-0.0214 * *$ \\
\hline & $(0.00120)$ & $(0.000332)$ & $(0.00854)$ & $(0.000168)$ & $(0.00808)$ & $(0.00106)$ & $(0.00772)$ & $(0.00897)$ \\
\hline Observations & 3,897 & 3,094 & 3,897 & 3,897 & 3,897 & 3,094 & 3,094 & 3,094 \\
\hline R-squared & 0.090 & 0.104 & 0.113 & 0.101 & 0.124 & 0.116 & 0.131 & 0.143 \\
\hline AIC & -4665 & -4374 & -4733 & -4715 & -4785 & -4424 & -4436 & -4490 \\
\hline $\mathrm{BIC}$ & -4640 & -4332 & -4607 & -4697 & -4666 & -4406 & -4297 & -4375 \\
\hline Perishability & & YES & & & & YES & YES & YES \\
\hline Seasonality & & & YES & & YES & & YES & YES \\
\hline Goods FE & & & & YES & YES & YES & & YES \\
\hline
\end{tabular}

Notes: $* * * \mathrm{p}<0.01, * * \mathrm{p}<0.05, * \mathrm{p}<0.1$, Robust standard errors in parentheses. 


\subsubsection{Daily ERPT in Different Years}

Since our daily sample covers the years between 2005 and 2015, our ERPT results may be driven by year-specific foreign shocks represented by the corresponding changes in NER. Accordingly, as an alternative estimation strategy, we estimate the benchmark equation for each individual year. In Table 4-8 and Table 4-9, we observe the results based on year-specific daily ERPT for all price changes and none-zero price changes. This study found that the ERPT coefficient is statistically insignificant for the first few years and then only the years of 2009, 2010, and 2015 show the largest and statistically significant ERPT coefficients. We base the results for these regressions on considering inflation, seasonality, and goods fixed effects control variables where ERPT measures in 2009, 2010, and 2015 significantly dominate others. The results in Table 4-8 show that the corresponding ERPT for 2009, 2010, and 2015 are about 23\%, 38\%, and 29\%, respectively.

Considering different years in the sample have experienced different percentage changes in prices and exchange rates (as shown in Figures 4-2 and 4-3 (a-b)) one possible explanation for the difference in year-specific ERPT measures may be the size of foreign shocks represented by the magnitude of changes in NER (as in studies such as Burstein et al., 2005). Another possible explanation may be ERPT that is conditional on price changes (as in studies such as Gopinath et al., 2010). Accordingly, in the next subsection, we focus on ERPT measures based on alternative sign and magnitude of NER changes in order to have a systematic explanation for year-specific results. 
Table 4-8 Daily ERPT by each Year, All Price Changes

\begin{tabular}{|c|c|c|c|c|c|c|c|c|c|c|c|}
\hline VARIABLES & $\begin{array}{c}(1) \\
\text { Price }\end{array}$ & $\begin{array}{c}(2) \\
\text { Price }\end{array}$ & $\begin{array}{c}(3) \\
\text { Price }\end{array}$ & $\begin{array}{c}(4) \\
\text { Price }\end{array}$ & $\begin{array}{c}(5) \\
\text { Price }\end{array}$ & $\begin{array}{c}(6) \\
\text { Price }\end{array}$ & $\begin{array}{c}(7) \\
\text { Price }\end{array}$ & $\begin{array}{c}(8) \\
\text { Price }\end{array}$ & $\begin{array}{c}(9) \\
\text { Price }\end{array}$ & $\begin{array}{l}(10) \\
\text { Price }\end{array}$ & $\begin{array}{l}(11) \\
\text { Price }\end{array}$ \\
\hline Exchange Rate & $\begin{array}{l}-0.0354 \\
(0.121)\end{array}$ & $\begin{array}{c}-0.108 \\
(0.0730)\end{array}$ & $\begin{array}{c}-0.00401 \\
(0.111)\end{array}$ & $\begin{array}{l}-0.0503 \\
(0.0556)\end{array}$ & $\begin{array}{l}0.231 * * \\
(0.0926)\end{array}$ & $\begin{array}{l}0.379 * * \\
(0.157)\end{array}$ & $\begin{array}{l}-0.0778 \\
(0.155)\end{array}$ & $\begin{array}{l}-0.172 \\
(0.190)\end{array}$ & $\begin{array}{l}-0.0199 \\
(0.151)\end{array}$ & $\begin{array}{c}0.116 \\
(0.0970)\end{array}$ & $\begin{array}{c}0.290 * * \\
(0.135)\end{array}$ \\
\hline Inflation & $\begin{array}{c}0.0353 \\
(0.0736)\end{array}$ & $\begin{array}{c}0.159 * \\
(0.0882)\end{array}$ & $\begin{array}{c}0.116 * * * \\
(0.0375)\end{array}$ & $\begin{array}{c}0.358 * * * \\
(0.107)\end{array}$ & $\begin{array}{l}0.397 * * \\
(0.162)\end{array}$ & $\begin{array}{c}0.476^{* * *} \\
(0.121)\end{array}$ & $\begin{array}{c}0.517 * * * \\
(0.147)\end{array}$ & $\begin{array}{c}0.397 * * * \\
(0.136)\end{array}$ & $\begin{array}{c}0.448 * * * \\
(0.116)\end{array}$ & $\begin{array}{c}0.428 * * * \\
(0.128)\end{array}$ & $\begin{array}{c}0.126 \\
(0.115)\end{array}$ \\
\hline Constant & $\begin{array}{c}-0.0183 \\
(0.0126)\end{array}$ & $\begin{array}{r}0.000395 \\
(0.00217)\end{array}$ & $\begin{array}{c}-0.00127 \\
(0.00114)\end{array}$ & $\begin{array}{c}-0.00986 * * * \\
(0.00332)\end{array}$ & $\begin{array}{l}-0.000845 \\
(0.00209)\end{array}$ & $\begin{array}{c}-0.00252 \\
(0.00226)\end{array}$ & $\begin{array}{c}-0.00808 * * * \\
(0.00191)\end{array}$ & $\begin{array}{l}-0.00486 \\
(0.00287)\end{array}$ & $\begin{array}{c}0.00223 \\
(0.00198)\end{array}$ & $\begin{array}{l}0.000920 \\
(0.00202)\end{array}$ & $\begin{array}{c}-0.00849 * * * \\
(0.00286)\end{array}$ \\
\hline Observations & 3,173 & 2,516 & 3,102 & 3,156 & 3,478 & 3,389 & 3,973 & 3,918 & 3,886 & 4,209 & 3,006 \\
\hline R-squared & 0.010 & 0.016 & 0.022 & 0.044 & 0.030 & 0.040 & 0.029 & 0.031 & 0.022 & 0.033 & 0.051 \\
\hline Goods FE & YES & YES & YES & YES & YES & YES & YES & YES & YES & YES & YES \\
\hline Seasonality & YES & YES & YES & YES & YES & YES & YES & YES & YES & YES & YES \\
\hline Year & 2005 & 2006 & 2007 & 2008 & 2009 & 2010 & 2011 & 2012 & 2013 & 2014 & 2015 \\
\hline AIC & -8233 & -10244 & -11867 & -10174 & -11732 & -10704 & -13019 & -12825 & -13065 & -14814 & -9097 \\
\hline BIC & -8124 & -10139 & -11758 & -10071 & -11621 & -10593 & -12912 & -12712 & -12953 & -14700 & -9006 \\
\hline
\end{tabular}


Table 4-9 Daily ERPT by each Year, Non-zero Price Changes

\begin{tabular}{|c|c|c|c|c|c|c|c|c|c|c|c|}
\hline VARIABLES & $\begin{array}{c}(1) \\
\text { Price }\end{array}$ & $\begin{array}{c}(2) \\
\text { Price }\end{array}$ & $\begin{array}{c}(3) \\
\text { Price }\end{array}$ & $\begin{array}{c}(4) \\
\text { Price }\end{array}$ & $\begin{array}{c}(5) \\
\text { Price }\end{array}$ & $\begin{array}{c}(6) \\
\text { Price }\end{array}$ & $\begin{array}{c}(7) \\
\text { Price }\end{array}$ & $\begin{array}{c}(8) \\
\text { Price }\end{array}$ & $\begin{array}{c}(9) \\
\text { Price }\end{array}$ & $\begin{array}{l}(10) \\
\text { Price }\end{array}$ & $\begin{array}{l}(11) \\
\text { Price }\end{array}$ \\
\hline Exchange Rate & $\begin{array}{l}-0.833 \\
(1.983)\end{array}$ & $\begin{array}{l}-0.975 \\
(1.029)\end{array}$ & $\begin{array}{c}0.473 \\
(1.744)\end{array}$ & $\begin{array}{l}0.0582 \\
(0.527)\end{array}$ & $\begin{array}{c}3.057 \\
(1.780)\end{array}$ & $\begin{array}{c}1.874 \\
(1.566)\end{array}$ & $\begin{array}{l}-0.435 \\
(1.266)\end{array}$ & $\begin{array}{l}-0.444 \\
(0.926)\end{array}$ & $\begin{array}{l}-0.219 \\
(1.459)\end{array}$ & $\begin{array}{c}0.782 \\
(1.167)\end{array}$ & $\begin{array}{c}0.988 \\
(0.874)\end{array}$ \\
\hline Inflation & $\begin{array}{l}-0.231 \\
(0.857)\end{array}$ & $\begin{array}{c}2.979 * \\
(1.467)\end{array}$ & $\begin{array}{c}1.622 * * * \\
(0.536)\end{array}$ & $\begin{array}{c}1.321 * * * \\
(0.205)\end{array}$ & $\begin{array}{c}3.574 * * * \\
(0.984)\end{array}$ & $\begin{array}{c}2.530 * * * \\
(0.436)\end{array}$ & $\begin{array}{c}2.368 * * * \\
(0.288)\end{array}$ & $\begin{array}{c}2.258 * * * \\
(0.316)\end{array}$ & $\begin{array}{c}3.015 * * * \\
(0.893)\end{array}$ & $\begin{array}{c}3.171 * * * \\
(0.463)\end{array}$ & $\begin{array}{c}0.176 \\
(0.428)\end{array}$ \\
\hline Constant & $\begin{array}{l}-0.177 \\
(0.135)\end{array}$ & $\begin{array}{c}0.0273 \\
(0.0317)\end{array}$ & $\begin{array}{l}-0.00679 \\
(0.0360)\end{array}$ & $\begin{array}{l}-0.129 * * \\
(0.0453)\end{array}$ & $\begin{array}{l}-0.0338 \\
(0.0243)\end{array}$ & $\begin{array}{l}-0.0167 \\
(0.0176)\end{array}$ & $\begin{array}{c}-0.0473 * * \\
(0.0175)\end{array}$ & $\begin{array}{l}-0.0194 \\
(0.0187)\end{array}$ & $\begin{array}{l}0.00661 \\
(0.0164)\end{array}$ & $\begin{array}{c}0.0101 \\
(0.0254)\end{array}$ & $\begin{array}{c}-0.0802 * * * \\
(0.0186)\end{array}$ \\
\hline Observations & 193 & 140 & 185 & 309 & 239 & 408 & 533 & 675 & 462 & 439 & 406 \\
\hline R-squared & 0.204 & 0.378 & 0.305 & 0.244 & 0.341 & 0.261 & 0.179 & 0.174 & 0.188 & 0.270 & 0.288 \\
\hline GoodsFE & YES & YES & YES & YES & YES & YES & YES & YES & YES & YES & YES \\
\hline Seasonality & YES & YES & YES & YES & YES & YES & YES & YES & YES & YES & YES \\
\hline Year & 2005 & 2006 & 2007 & 2008 & 2009 & 2010 & 2011 & 2012 & 2013 & 2014 & 2015 \\
\hline AIC & 21.55 & -215.4 & -225.7 & -319.9 & -233.1 & -500.1 & -736 & -1101 & -624 & -646 & -507.1 \\
\hline BIC & 70.49 & -186 & -183.8 & -256.5 & -184.4 & -427.9 & -663.3 & -1019 & -549.6 & -576.6 & -447 \\
\hline
\end{tabular}




\subsubsection{Daily ERPT by Positive/ Negative Exchange rate Changes}

Using observations in the whole NER changes sample, we categorize the changes in NER with respect to their sign, for which we split the corresponding distribution into two sections; exchange rate increases and exchange rate decreases. Therefore, while the first subsample corresponds to negative changes in NER, the second corresponds to positive changes in NER. Such a distinction is important to capture asymmetric ERPT measures as discussed in studies such as Burstein et al. (2005), which show that large devaluations are more effective on ERPT.

The results are given in Table 4-10, where only the log NER increases are significant, independent of the control variables considered; the corresponding ERPT is about $9 \%$ in Model (4). It is further implied that negative changes in NER are not reflected much in daily prices. When we restrict our investigation to only non-zero changes in prices, the results in Table 4-10 are replaced with the ones in Table 4-11. As is evident, although only the exchange rate increases enter significantly to the regressions as in Table 4-10, independent of the control variables considered, ERPT measures are much higher in Table 4-11. Further, the incomplete ERPT measures (of about 9\%) in Table 4-10 for exchange rate increases are replaced with complete ERPT measures (of about 102\%) in Table 4-11 (since such measures are not statistically different from 1). It suggests that the ERPT estimates in this paper become more comparable to those in the literature based on aggregatelevel data when considering the effects of positive NER changes on non-zero price changes. 
Table 4-10 ERPT by Positive/ Negative Exchange Rate Changes, All Price Changes

\begin{tabular}{|c|c|c|c|c|}
\hline VARIABLES & $\begin{array}{l}(1) \\
\text { Price }\end{array}$ & $\begin{array}{l}\text { (2) } \\
\text { Price }\end{array}$ & $\begin{array}{l}\text { (3) } \\
\text { Price }\end{array}$ & $\begin{array}{l}(4) \\
\text { Price }\end{array}$ \\
\hline Inflation & & $\begin{array}{l}0.357 * * * \\
(0.0743)\end{array}$ & & $\begin{array}{l}0.333 * * * \\
(0.0692)\end{array}$ \\
\hline Exchange Rate Increases & $\begin{array}{c}0.0656^{*} \\
(0.0337)\end{array}$ & $\begin{array}{l}0.0807 * * \\
(0.0346)\end{array}$ & $\begin{array}{l}0.0750 * * \\
(0.0363)\end{array}$ & $\begin{array}{l}0.0869^{* *} \\
(0.0370)\end{array}$ \\
\hline Exchange Rate Decreases & $\begin{array}{c}0.0230 \\
(0.0425)\end{array}$ & $\begin{array}{r}0.0155 \\
(0.0426)\end{array}$ & $\begin{array}{l}0.00892 \\
(0.0424)\end{array}$ & $\begin{array}{l}0.00290 \\
(0.0424)\end{array}$ \\
\hline Constant & $\begin{array}{c}-0.000191 \\
(0.000245)\end{array}$ & $\begin{array}{c}-2.95 \mathrm{e}-05 \\
(0.000261)\end{array}$ & $\begin{array}{c}-0.00441^{* * * *} \\
(0.000802)\end{array}$ & $\begin{array}{r}-0.00458^{* * *} \\
(0.000805)\end{array}$ \\
\hline Observations & 37,685 & 37,685 & 37,685 & 37,685 \\
\hline R-squared & 0.000 & 0.016 & 0.006 & 0.019 \\
\hline AIC & -122451 & -123044 & -122661 & -123145 \\
\hline BIC & -122426 & -123010 & -122508 & -122983 \\
\hline Goods FE & & & YES & YES \\
\hline Seasonality & & & YES & YES \\
\hline
\end{tabular}

Notes: $* * * \mathrm{p}<0.01, * * \mathrm{p}<0.05, * \mathrm{p}<0.1$, Robust standard errors in parentheses.

Table 4-11 ERPT by Positive/ Negative Exchange Rate Changes, Non-zero Price Changes

\begin{tabular}{lcccc}
\hline VARIABLES & $(1)$ & $(2)$ & $(3)$ & $(4)$ \\
& Price & Price & Price & Price \\
Inflation & & & & \\
& & $1.851^{* * *}$ & & $1.670^{* * *}$ \\
Exchange Rate Increases & 0.611 & $(0.144)$ & & $(0.102)$ \\
& $(0.374)$ & $\left(0.495^{* *}\right.$ & 0.752 & $1.021^{* *}$ \\
Exchange Rate Decreases & 0.282 & 0.251 & $(0.451)$ & $(0.496)$ \\
& $(0.425)$ & $(0.400)$ & 0.0496 & 0.114 \\
Constant & -0.00165 & -0.00236 & $-0.0499 *$ & $-0.0380)$ \\
& $(0.00257)$ & $(0.00270)$ & $(0.0167)$ & $(0.0154)$ \\
Observations & 3,977 & 3,977 & 3,977 & 3,977 \\
R-squared & 0.001 & 0.082 & 0.056 & 0.114 \\
AIC & -3977 & -4313 & -4175 & -4423 \\
BIC & -3958 & -4288 & -4061 & -4304 \\
Goods FE & & & YES & YES \\
Seasonality & & & YES & YES \\
\hline
\end{tabular}

Notes: $* * * \mathrm{p}<0.01, * * \mathrm{p}<0.05, * \mathrm{p}<0.1$, Robust standard errors in parentheses. 


\subsubsection{Threshold Regression}

The results for the threshold analyses represented by the second equation appear in Table 4-12, where we distinguish between all price changes and non-zero price changes similar to studies such as Gopinath et al. (2010). ${ }^{8}$ When all price changes are included in the regression (including zero price changes), there is evidence for incomplete ERPT of around $10 \%$ only when log daily NER changes are above $0.55 \%$. When goods with frequency of price changes over $3.12 \%$ or goods with storage life of more than 10 weeks are considered, ERPT is statistically insignificant below these threshold values. When only non-zero price changes are included in the regression, the tables turn, showing evidence for complete ERPT, since a positive and significant coefficient of 1 (i.e., $100 \%$ ) is within any coefficient interval. In this case, the consideration of a threshold in storage life contributes most to the investigation by leading into an ERPT of about $155 \%$ for products with storage life of more than 10 weeks, followed by an ERPT of about $120 \%$ for days when the NER change is higher than $0.55 \%$, and an ERPT of about $73 \%$ for products with a frequency of price change larger than $3.12 \%$.

${ }^{8}$ In order to focus on daily ERPT, we use a slightly different approach compared with Gopinath et al. (2010) who consider cumulative changes in nominal exchange rates when observing a price change, whereas we consider daily (instantaneous) changes in the nominal exchange rate. 
Table 4-12 Daily ERPT with Threshold and Non-zero Price Changes

\begin{tabular}{|c|c|c|c|c|c|c|}
\hline \multirow[b]{3}{*}{ VARIABLES } & \multicolumn{6}{|c|}{ Dependent Variable: $\Delta$ Log Daily Product-level Price } \\
\hline & \multicolumn{3}{|c|}{ All Price Changes } & \multicolumn{3}{|c|}{ Non-zero Price Changes } \\
\hline & $(1)$ & (2) & (3) & (4) & $(5)$ & (6) \\
\hline$\Delta$ Log Daily Exchange Rate > Threshold of $0.55 \%$ & $\begin{array}{c}0.110 * * * \\
(0.0389)\end{array}$ & & & $\begin{array}{l}1.201 * * \\
(0.494)\end{array}$ & & \\
\hline$\Delta$ Log Daily Exchange Rate $<=$ Threshold of $0.55 \%$ & $\begin{array}{l}-0.0166 \\
(0.0392)\end{array}$ & & & $\begin{array}{l}-0.0329 \\
(0.342)\end{array}$ & & \\
\hline ( $\Delta$ Log Daily Exchange Rate) & & $0.0905 * * *$ & & & $0.732 * *$ & \\
\hline$x$ (Frequency of Price Change > Threshold of 3.12\%) & & $(0.0245)$ & & & $(0.317)$ & \\
\hline ( $\Delta$ Log Daily Exchange Rate) & & -0.0307 & & & -0.712 & \\
\hline $\mathrm{x}$ (Frequency of Price Change $<=$ Threshold of $3.12 \%$ ) & & $(0.0328)$ & & & $(1.521)$ & \\
\hline ( $\Delta$ Log Daily Exchange Rate) & & & $0.0940^{* *}$ & & & $1.553 * *$ \\
\hline $\mathrm{x}$ (Storage Life $>$ Threshold of 10 weeks) & & & $(0.0361)$ & & & $(0.647)$ \\
\hline ( $\Delta$ Log Daily Exchange Rate) & & & 0.0356 & & & 0.432 \\
\hline $\mathrm{x}$ (Storage Life $<=$ Threshold of 10 weeks) & & & $(0.0269)$ & & & $(0.280)$ \\
\hline Daily Domestic Inflation & $\begin{array}{c}0.335^{* * *} \\
(0.0694)\end{array}$ & $\begin{array}{c}0.335^{* * *} \\
(0.0694)\end{array}$ & $\begin{array}{c}0.335^{* * * *} \\
(0.0694)\end{array}$ & $\begin{array}{c}1.680 * * * \\
(0.101)\end{array}$ & $\begin{array}{c}1.674 * * * \\
(0.0993)\end{array}$ & $\begin{array}{c}1.681 * * * \\
(0.0999)\end{array}$ \\
\hline Good FE & YES & YES & YES & YES & YES & YES \\
\hline Seasonality & YES & YES & YES & YES & YES & YES \\
\hline AIC & -123467 & -123468 & -123464 & -4434 & -4432 & -4431 \\
\hline BIC & -123305 & -123305 & -123302 & -4315 & -4313 & -4311 \\
\hline R-squared & 0.019 & 0.019 & 0.019 & 0.116 & 0.115 & 0.115 \\
\hline Observations & 37,806 & 37,806 & 37,806 & 3,989 & 3,989 & 3,989 \\
\hline
\end{tabular}
estimating by minimizing the overall residual sum of squares 


\subsection{Conclusion}

Policy makers are interested in ERPT measures not only because of price-stability concerns in especially small open economies but also because ERPT measures map into real effects of NER changes. By using daily goods-level wholesale price data on imported agricultural products, this paper shows that ERPT is incomplete and about 5\% on average across goods and time in Turkey, robust to the consideration of nonlinearities or control variables such as daily domestic inflation rate.

Additionally, when the investigations consider nonlinearities through threshold analyses, the results show that ERPT is about $10 \%$ when daily NER changes are above $0.55 \%$, frequency of price changes is above $3.12 \%$, and storage life is above 10 weeks, while ERPT is statistically insignificant below these threshold values. When we further consider these threshold values for non-zero price changes, ERPT becomes complete since $100 \%$ is included within the estimated confidence intervals. Here the consideration of a threshold in storage life contributes most to the investigation by leading into an ERPT of about $155 \%$ for products with storage life of more than 10 weeks, followed by an ERPT of about $120 \%$ for days when the NER change is higher than $0.55 \%$, and an ERPT of about $73 \%$ for products with a frequency of price changes larger than $3.12 \%$.

These results are in line with existing studies in the literature that employ lower frequency data sets such as: (i) Burstein et al. (2005), who have shown that the magnitude of NER changes may be effective in the determination of ERPT; (ii) Gopinath and Itskhoki (2010) and Antoniades and Zaniboni (2016), who have shown that there is a positive relationship between frequency of price changes and ERPT; and (iii) Kryvtsov and Midrigan (2012) and Alessandria et al. (2013), who have shown that the optimal price (and thus markup) of any seller decreases with the depreciation rate of inventories. Intuitively, since sellers may want to sell the more perishable goods as soon as possible due to their high depreciation rate, they may accept lower price offers, 
independent of NER changes. This translates into an ERPT that is higher for less-perishable products in relative terms, which is new in this paper.

These results can also be perceived as positive for Turkish policy makers, since low and incomplete pass-through as seen in this paper (i) ensures that NER shocks do not destabilize the price level and thus facilitates the prediction of future Turkish inflation, (ii) helps the stabilization of Consumer Price Index inflation (targeting) rather than that of non-traded goods prices, and (iii) provides higher degrees of freedom to the monetary authority to conduct an independent policy, without having a trade-off between real stability and inflation stability, because high nominal exchange rate volatility is allowed to stabilize the real economy in face of external shocks (e.g., see Choudhri \& Hakura, 2006; Devereux, Lane, \& Xu, 2006; Vega et al., 2005; Winkelried, 2014).

\subsection{REFERENCES}

Alessandria, G., Kaboski, J. \& Midrigan, V. (2013). Trade wedges, inventories, and international business cycles. Journal of Monetary Economics, 60(1), 1-20.

Al-Ississ, M. (2010): “The impact of religious experience on financial markets," Harvard Kennedy School of Government, mimeo.

Ali, M. I., and W. Akhter (2016): "The Impact of Muslim Holy days on Stock Market Performance: Evidence from Asian and African Markets," mimeo.

Al-Khazali, O.M. (2008): "The impact of thin trading on day-of-the-week effect: Evidence from the United Arab Emirates," Review of accounting and Finance, 7(3), 270.284.

Anson, J., M. Boffa, and M. C. Helble (2014): "A Short-Run Analysis of Exchange Rates and International Trade with an Application to Australia, New Zealand, and Japan," ADBI Working Paper 471.

Antoniades, A., and N. Zaniboni (2016): "Exchange Rate Pass-Through into Retail Prices," International Economic Review, 57(4), 1425.1447.

Aron, J., G. Farrell, J. Muellbauer, and P. Sinclair (2014): "Exchange rate pass- through to import prices, and monetary policy in South Africa," Journal of Development Studies, 50(1), 144.164. 
Ben Cheikh, N., and C. Rault (2016): "The Pass-through of Exchange Rate in the Context of the European Sovereign Debt Crisis," International Journal of Finance \& Economics, 21(2), 154.166.

Ben Cheikh, N., \& C. Rault, C. (2017). Investigating first-stage exchange rate pass-through: Sectoral and macro evidence from euro area countries. The World Economy, 40(12), 26112638.

Burstein, A., M. Eichenbaum, and S. Rebelo (2005): "Large Devaluations and the Real Exchange Rate," Journal of Political Economy, 113(4), 742.784.

Burstein, A., and G. Gopinath (2014): "International Prices and Exchange Rates," Handbook of International Economics, 4, 391.451.

Campa, J. M., and L. S. Goldberg (2005): “Exchange rate pass-through into import prices,” Review of Economics and Statistics, 87(4), 679.690.

Cantwell, M. (2001): "Properties and recommended conditions for long-term storage of fresh fruits and vegetables," Available online: http://postharvest.ucdavis.edu.

Chan, K.-S. (1993): "Consistency and limiting distribution of the least squares estimator of a threshold autoregressive model," The annals of statistics, pp. 520.533.

Cheikh, N. B., and W. Louhichi (2016): "Revisiting the role of inflation environment in exchange rate pass-through: A panel threshold approach,” Economic Modelling, 52, 233-238.

Choudhri, E. U., and D. S. Hakura (2006): "Exchange rate pass-through to domestic prices: does the inflationary environment matter?" Journal of International Money and Finance, 25(4), 614-639.

Devereux, M. B., P. R. Lane, and J. Xu (2006): "Exchange rates and monetary policy in emerging market economies," The Economic Journal, 116(511), 478-506.

Donayre, L., and I. Panovska (2016): "State-dependent exchange rate pass-through behavior," Journal of International Money and Finance, 64, 170-195.

Goldberg, P. K., \& Knetter, M.M. (1997). Goods prices and exchange rates: what have we learned? Journal of Economic Literature, 35, 1243-1272.

Gopinath, G. (2015): “The International Price System,” NBER Working Paper Series, p. No. 21646.

Gopinath, G., and O. Itskhoki (2010): "Frequency of price adjustment and pass- through," The Quarterly Journal of Economics, 125.

Gopinath, G., O. Itskhoki, and R. Rigobon (2010): "Currency choice and exchange rate passthrough," American Economic Review, 100(1), 304-336.

Hansen, B. E. (2000): “Sample splitting and threshold estimation," Econometrica, 68(3), 575-603. 
Kryvtsov, O., and V. Midrigan (2012): "Inventories, markups, and real rigidities in menu cost models," The Review of Economic Studies, p. rds028.

Lott, Z., \& Einav, L. (2013). Exchange Rate Pass-Through on EBay. Stanford University, mimeo.

Menon, J. (1995). Exchange rate pass-through. Journal of Economic Survey, 9(2), 197-231.

Nazlioglu, S., and U. Soytas (2011): "World oil prices and agricultural commodity prices: evidence from an emerging market," Energy Economics, 33(3), 488-496.

Richards, P. D., R. J. Myers, S. M. Swinton, and R. T. Walker (2012): "Exchange rates, soybean supply response, and deforestation in South America," Global environmental change, 22(2), 454-462.

Schaffnit-Chatterjee, C., S. Schneider, M. Peter, and T. Mayer (2010): "Risk management in agriculture," Deutsche Bank Research Working Paper, September.

Shintani, M., A. Terada-Hagiwara, and T. Yabu (2013): "Exchange rate pass-through and inflation: A nonlinear time series analysis," Journal of International Money and Finance, 32, 512527.

Vega, M., D. Winkelried, et al. (2005): "Inflation Targeting and Inflation Behavior: A Successful Story?," International Journal of Central Banking, 1(3).

Winkelried, D. (2014): "Exchange rate pass-through and inflation targeting in Peru," Empirical Economics, 46(4), 1181. 
VITA

AMIN SHOJA

2010

2013

2015

2016

$2013-2018$
B.Sc. Economics

University of Tehran

M.A. Development Economics

University of Tehran

M.A. Economics

Florida International University

Ph.D. Candidate

Florida International University

Graduate Teaching Assistant

Florida International University 